\title{
DESIGN OF A ROBUST SPEED AND POSITION SENSORLESS DECOUPLED P-Q CONTROLLED DOUBLY-FED INDUCTION GENERATOR FOR VARIABLE-SPEED WIND ENERGY APPLICATIONS
}

\author{
Kyriakos Gogas \\ B.Eng. Concordia University, Canada
}

\begin{abstract}
A thesis submitted to
The Faculty of Graduate Studies and Research

In partial fulfillment of the requirements for the degree of Master of Engineering

Department of Electrical and Computer Engineering

McGill University

Montreal, Quebec, Canada
\end{abstract}

February 2007

(C) Kyriakos Gogas, 2007 


$\begin{array}{ll}\begin{array}{l}\text { Library and } \\ \text { Archives Canada }\end{array} & \begin{array}{l}\text { Bibliothèque et } \\ \text { Archives Canada }\end{array} \\ \begin{array}{l}\text { Published Heritage } \\ \text { Branch }\end{array} & \begin{array}{l}\text { Direction du } \\ \text { Patrimoine de l'édition }\end{array} \\ \begin{array}{l}\text { 395 Wellington Street } \\ \text { Ottawa ON K1A 0N4 }\end{array} & \begin{array}{l}\text { 395, rue Wellington } \\ \text { Ottawa ON K1A ON4 } \\ \text { Canada }\end{array} \\ \end{array}$

Your file Votre référence ISBN: 978-0-494-32590-2 Our file Notre référence ISBN: 978-0-494-32590-2

NOTICE:

The author has granted a nonexclusive license allowing Library and Archives Canada to reproduce, publish, archive, preserve, conserve, communicate to the public by telecommunication or on the Internet, loan, distribute and sell theses worldwide, for commercial or noncommercial purposes, in microform, paper, electronic and/or any other formats.

The author retains copyright ownership and moral rights in this thesis. Neither the thesis nor substantial extracts from it may be printed or otherwise reproduced without the author's permission.
AVIS:

L'auteur a accordé une licence non exclusive permettant à la Bibliothèque et Archives Canada de reproduire, publier, archiver, sauvegarder, conserver, transmettre au public par télécommunication ou par l'Internet, prêter, distribuer et vendre des thèses partout dans le monde, à des fins commerciales ou autres, sur support microforme, papier, électronique et/ou autres formats.

L'auteur conserve la propriété du droit d'auteur et des droits moraux qui protège cette thèse. $\mathrm{Ni}$ la thèse ni des extraits substantiels de celle-ci ne doivent être imprimés ou autrement reproduits sans son autorisation.
In compliance with the Canadian

Privacy Act some supporting forms may have been removed from this thesis.

While these forms may be included in the document page count, their removal does not represent any loss of content from the thesis.
Conformément à la loi canadienne sur la protection de la vie privée, quelques formulaires secondaires ont été enlevés de cette thèse.

Bien que ces formulaires aient inclus dans la pagination, il n'y aura aucun contenu manquant. 


\begin{abstract}
Wind energy is a relatively young but rapidly expanding industry. In order for wind generation to be cost effective, it must produce energy at a minimum cost per dollar of investment. Performance characteristics such as power output versus wind speed must be optimized in order to compete with other energy sources. Also, if the utility uses wind power for a part of its generation, the output power of these turbines must have the same high quality and reliability when it enters the utility grid. The ability to vary operating speed is important in wind generation because it allows for an optimization of the transfer of power from the wind to the turbine shaft. Doubly-fed induction generators (DFIG) are an interesting solution for variable-speed systems with limited variable speed range, and are typically used in wind energy conversion systems.

The objectives of this thesis are to implement a decoupled P-Q control of a DFIG that does not rely on mechanical sensors and to design a speed and position sensorless algorithm that is robust to variations of the values of the machine parameters. The sensorless DFIG control algorithm presented in this thesis is based on a modified phasedlock loop with an improved positioning algorithm. With the measured stator voltages, stator and rotor currents, the speed and position of the DFIG are estimated. The speed is estimated independent of machine parameters, which results in a significant improvement in speed control robustness to parameter variations. In addition, the algorithm avoids using differentiation, which significantly improves its immunity to noise and does not require the measurement of the rotor voltages. Also, it is shown that the positioning algorithm has an improved operation in generator mode. Although the accuracy of the positioning algorithm is depended on machine parameters; it is shown with the designed controller that the P-Q decoupled control is robust to changes of machine parameters. Theoretical and simulation results are validated on an experimental setup.
\end{abstract}




\section{Résumé}

L'énergie éolienne est une industrie relativement jeune mais qui joue un rôle de plus en plus important. Pour qu'elle soit rentable, elle doit produire de l'énergie à un coût minimum par dollar d'investissement. Des caractéristiques, telles que le rendement en puissance en fonction de la viteșse de vent, doivent être optimisées afin de concurrencer d'autres sources d'énergie. En outre, si le gestionnaire du réseau compte sur l'énergie éolienne pour une partie de sa production, la puissance produite par ces turbines doit avoir la même haute qualité que celle des autres sources d'énergie. La possibilité de varier la vitesse de fonctionnement est importante dans la production d'énergie éolienne parce qu'elle tient compte d'une optimisation du transfert de la puissance du vent aux pales de la turbine. Les machines asynchrones à double alimentation (DFIG) sont une solution intéressante pour des systèmes de vitesse variable et sont typiquement employées dans des systèmes de conversion d'énergie éolienne.

Les objectifs de cette thèse sont de concevoir une commande DFIG sans sonde et d'éliminer la sensibilité de l'estimation de la vitesse et de la position due aux variations des paramètres de la machine. La commande DFIG sans sonde présentée dans cette thèse est basée sur une boucle à verrouillage modifiée avec un algorithme de positionnement amélioré. Avec les tensions du stator, et les courants du stator et de l'arbre, la vitesse et la position du DFIG sont estimées. L'estimation de la vitesse est indépendante des paramètres de machine, ce qui a comme conséquence une amélioration significative de la robustesse de la commande de vitesse aux variations des paramètres. De plus, il est montré que l'algorithme de positionnement a un meilleur fonctionnement en mode générateur. Bien que l'exactitude de l'algorithme de positionnement dépende des paramètres de machine, il est montré que la commande découplée $P-Q$ est robuste aux changements des paramètres de machine. L'analyse théorique et les simulations sont validées expérimentalement. 


\section{Acknowledgements}

I would like to express my gratitude to all those who gave me the possibility to complete this thesis. I am deeply indebted to my supervisor Prof. Dr. Geza Joos whose help, stimulating suggestions and encouragement helped me in all the time of research for and writing of this thesis. I am also deeply grateful to Prof. Dr. Boon-Teck Ooi for his important support throughout this work.

I wish to express my warm and sincere thanks to the graduate students in the power research group for their valuable advice and friendly help, especially Chad Abbey, John Chahwan and Jean Morneau. Their extensive discussions around my work have been very helpful for this study. I would like to also acknowledge the financial support from NSERC for the past two years, which allowed me to devote all my time and energy to my research. 


\section{Table of Contents}

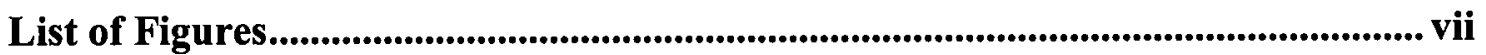

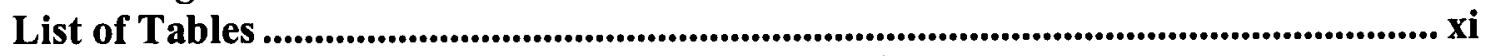

List of Main Symbols ..................................................................................................... xii

Chapter 1: Introduction ................................................................................................ 1

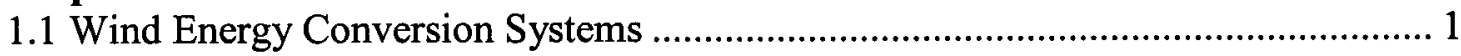

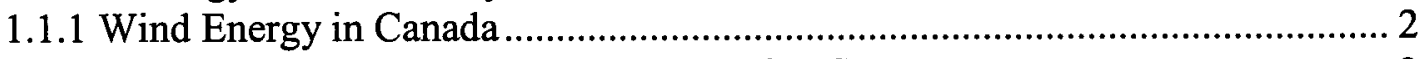

1.1.2 Components of a Wind Energy Conversion System..................................... 2

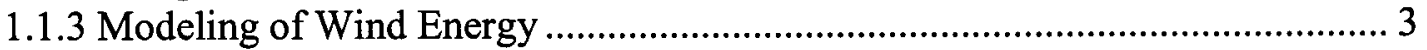

1.1.4 Variable-Speed Wind Turbines................................................................ 5

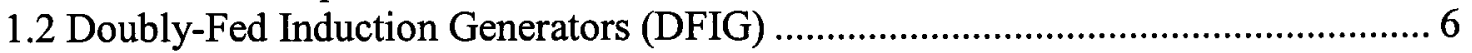

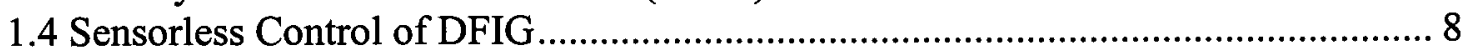

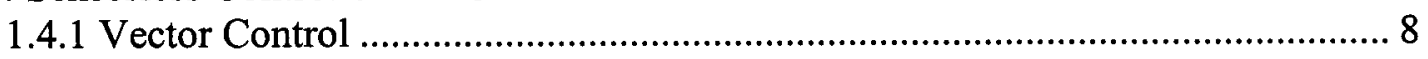

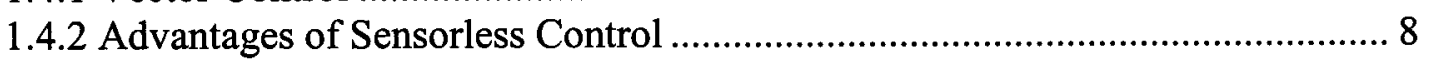

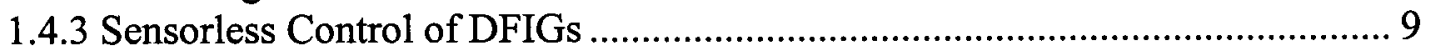

1.4.3 Sensorless Control Algorithms Based on Machine Equations ...................... 11

1.4 Objectives and Contributions of Thesis ............................................................ 12

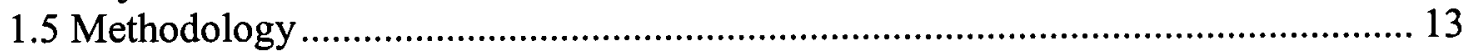

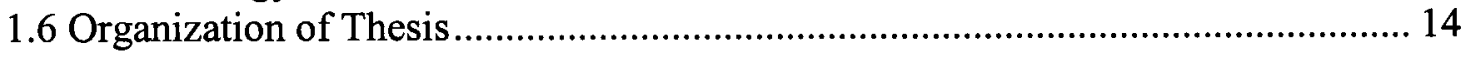

Chapter 2: Induction Machine Theory .................................................................. 16

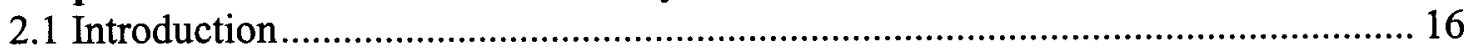

2.2 Electromechanical Energy Conversion Systems ............................................... 16

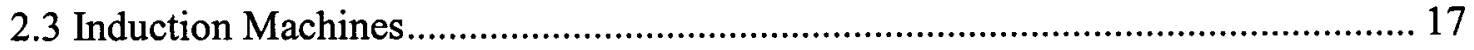

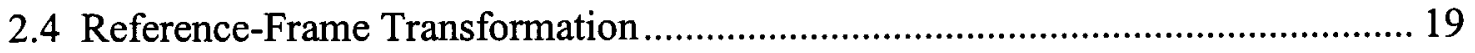

$2.5 \mathrm{Dq}$ Equivalent Model of Induction Machine .................................................... 21

2.6 Machine Model Parameter Measurement .......................................................... 23

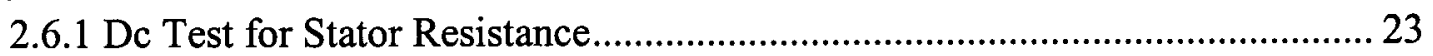

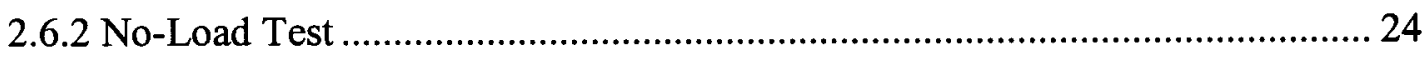

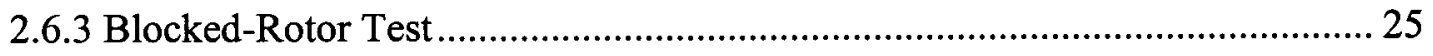

Chapter 3: Sensorless Measurement of Speed and Position ...................................... 28

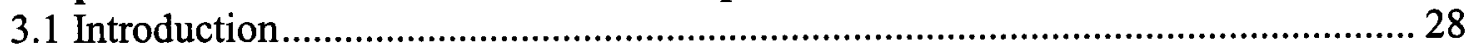

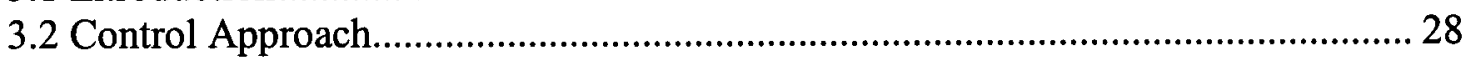

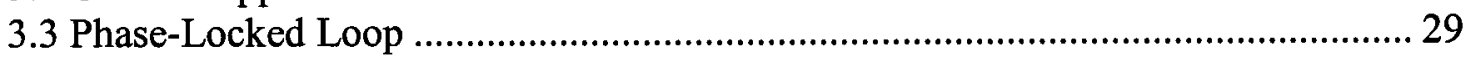

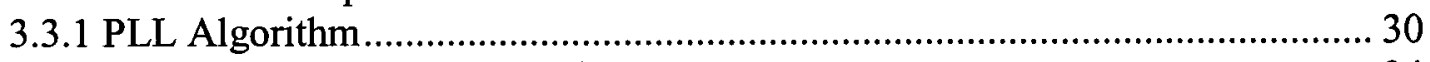

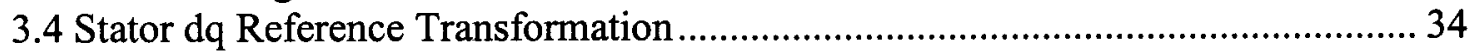

3.4.1 Real and Reactive Power Calculation....................................................... 35

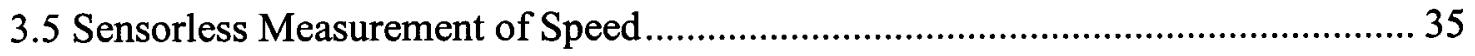

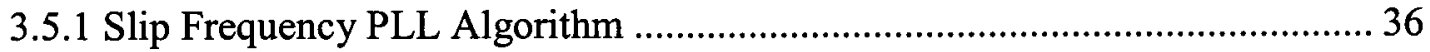

3.5.2 Simulation Results of Speed Sensorless Algorithm................................... 40

3.6 Sensorless Measurement of Position ............................................................... 43 
3.6.1 Transformation of Rotor Quantities to Stator dq Reference Frame................ 43

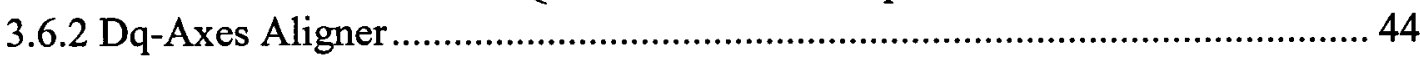

3.6.3 Simulation Results of Position Sensorless Measurement .............................. 45

Chapter 4: Comparison Between PLL and Machine-Equations Based Sensorless

Algorithms ..................................................................................................... 47

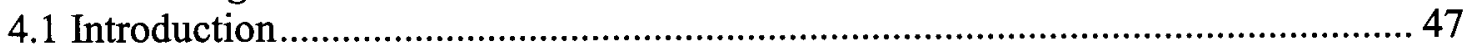

4.2 Sensorless Algorithm Based on Machine Equations .......................................... 47

4.3 Performance of Sensorless Algorithms - Immunity to Noise .............................. 48

4.4 Performance of Sensorless Algorithms - Robustness to Changes in Machine

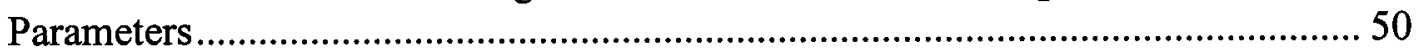

4.5 Performance of Sensorless Algorithm During Faults ....................................... 51

Chapter 5: Sensorless P-Q Control ....................................................................... 53

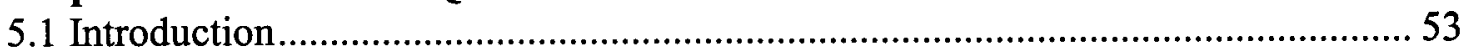

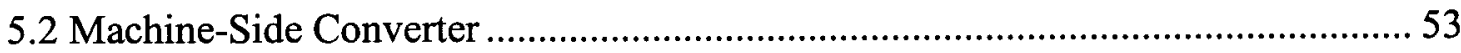

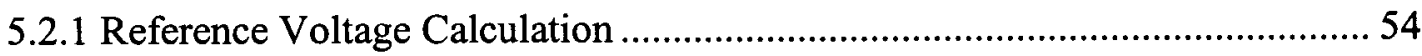

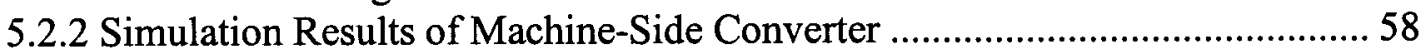

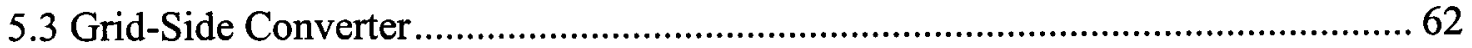

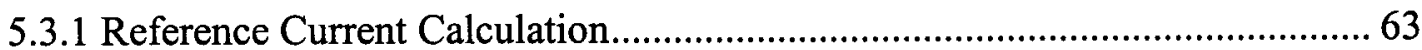

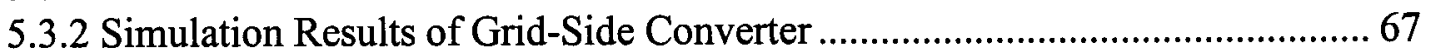

5.4 Complete DFIG System ............................................................................. 70

Chapter 6: Experimental Validation............................................................................. 75

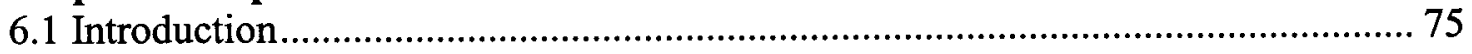

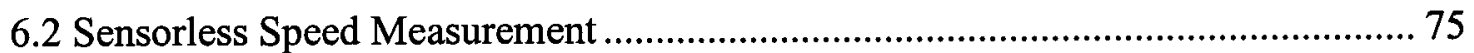

6.3 Machine-Side Converter Operation .................................................................. 77

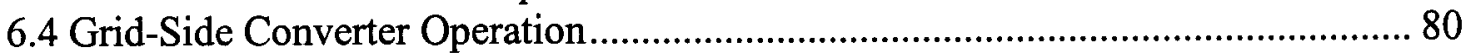

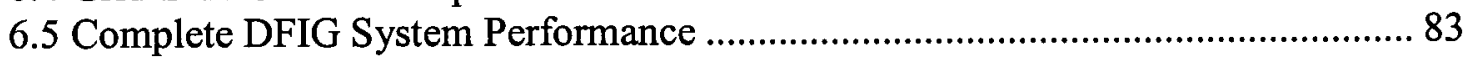

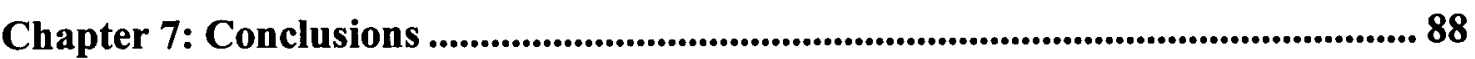

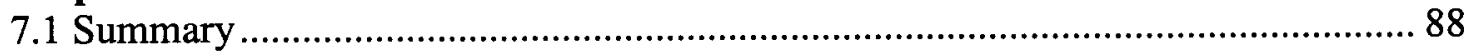

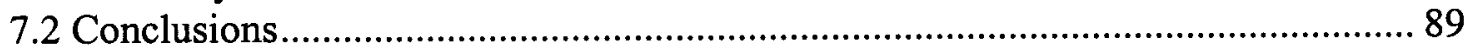

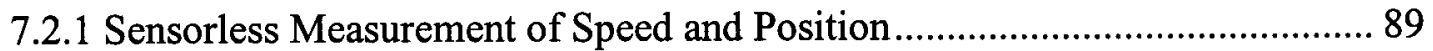

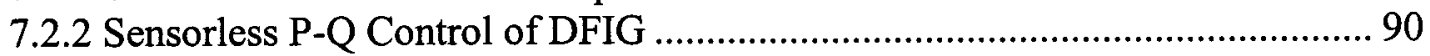

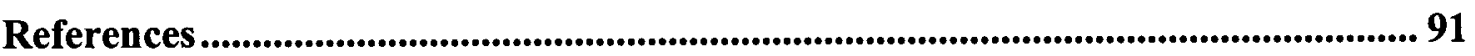

Appendix A: Experimental Equipment ........................................................................ 95

Appendix B: Experimental Setup........................................................................ 97 


\section{List of Figures}

Figure 1.1: Wind energy conversion system - basic configuration .................................................. 3

Figure 1.2: Example of wind energy fluctuation.............................................................................4

Figure 1.3: Power efficiency vs rotational speed of a $2 \mathrm{MW}$ variable speed wind turbine - power

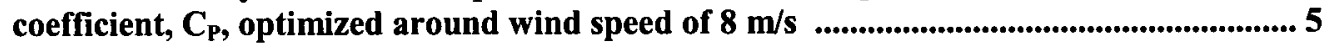

Figure 1.4: Doubly-fed induction generator (DFIG) - circuit diagram ................................................ 6

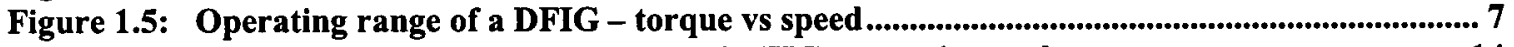

Figure 1.6: Sensorless decoupled P-Q control of DFIG - experimental setup .................................... 14

Figure 2.1: Simplified electromechanical system - block diagram ...................................................... 17

Figure 2.2: Two-pole, 3-phase, wye-connected symmetrical induction machine - winding arrangement ........................................................................................................................ 18

Figure 2.3: Reference transformations $a b c$ (stationary) to $d q$ (rotating $\omega$ ) ....................................... 21

Figure 2.4: Equivalent circuit of steady-state operation of a symmetrical induction machine.......... 22

Figure 2.5: De resistance test - circuit diagram.................................................................................... 24

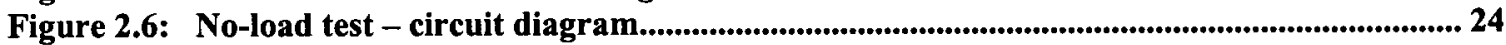

Figure 2.7: Blocked-rotor test - circuit diagram ........................................................................... 26

Figure 3.1: Sensorless measurement of speed and position of DFIG - overall block diagram .......... 29

Figure 3.2: Phase-locked loop - block diagram .................................................................................... 30

Figure 3.3: Stator phase-locked loop - detailed block diagram (Block A)........................................... 31

Figure 3.4: Linearised PLL system - bode diagram ............................................................................. 34

Figure 3.5: Slip-frequency PLL - detailed block diagram (Block C) ................................................. 37

Figure 3.6: Linearised slip PLL system for different rotor current magnitudes $I_{r}$ - bode diagram .. 39

Figure 3.7: Speed sensorless algorithm - circuit diagram of simulation setup ................................... 40

Figure 3.8: Speed tracking - sinusoidal input torque, shorted rotor, resistance added at rotor machine parameters of a $2 \mathrm{MW}$ induction machine - variables: estimated and actual speeds vs time

Figure 3.9: Speed tracking - step change in generator torque, shorted rotor, resistance added at rotor - machine parameters of a $2 \mathrm{MW}$ induction machine - variables: estimated and actual speeds vs time

Figure 3.10: Speed tracking - sinusoidal generator torque $(5 \mathrm{~Hz})$, shorted rotor, resistance added at rotor - machine parameters of a $2 \mathrm{MW}$ induction machine - variables: estimated and actual speeds vs time

Figure 3.11: Sensorless measurement of position - block diagram (Block D)...................................... 43

Figure 3.12: $\mathrm{D} q$ axes - rotor and stator - phase difference of $\Phi$ between stator and rotor axes ........ 44

Figure 3.13: Position tracking - comparison between dq-axes aligners $V_{d}=V$ and $V_{q}=0$ (presence of steady-state error for $V_{d}$ aligner in generator mode) - estimated and actual positions vs time (both motor and generator operation) ................................................................... 44

Figure 3.14: Dq-axes aligner - block diagram ...................................................................................45

Figure 3.15: Position tracking - variable input torque, shorted rotor, resistance added at rotor machine parameters of a $2 \mathrm{MW}$ induction machine - estimated and actual positions vs time

Figure 4.1: Position tracking - variable generator torque, shorted rotor, $R$ added to rotor - exact machine parameters used in the sensorless algorithms - noise added to signals variables: difference between actual position and estimated positions using both the PLL and machine-equations based algorithms

Figure 4.2: Position tracking - variable generator torque, shorted rotor, resistance added to rotor exact machine parameters used in the sensorless algorithms - noise added to signals variables: actual speed and estimated speeds using both the PLL and machine-equations based algorithms

Figure 4.3: Position tracking - variable generator torque, shorted rotor, resistance added to rotor modified machine parameters used in the sensorless algorithms- variables: difference between actual position and estimated positions using both the PLL and machineequations based algorithms 
Figure 4.4: Unsymmetrical fault - phase $C$ grounded between 2 and 2.5 seconds, constant generator torque, shorted rotor, resistance added to rotor - exact machine parameters used in the sensorless algorithm - variables: grid voltages, speeds and positions vs time ............... $51 \underline{2}$

Figure 4.5: Symmetrical fault - grid voltages grounded between 2 and 2.5 seconds, constant generator torque, shorted rotor, resistance added to rotor - exact machine parameters used in the sensorless algorithm - variables: grid voltages, speeds and positions vs time

Figure 5.1: Machine-side converter - system configuration................................................................... 54

Figure 5.2: Reference rotor voltage calculation of machine-side converter - block diagram............ 55

Figure 5.3: Reference power calculation with speed governor - block diagram (Block B-1) ............ 56

Figure 5.4: Reference power calculation without speed governor - block diagram (Block B-2) ....... 56

Figure 5.5: Reference stator current calculation - block diagram (Block C) ...................................56

Figure 5.6: Reference rotor voltage calculation - block diagram (Block E) ......................................5 57

Figure 5.7: $D q$ reference frame transformation for rotor voltage - block diagram ............................ 58

Figure 5.8: Machine-side converter - circuit diagram of simulation setup ........................................... 59

Figure 5.9: Machine-side converter, speed and $Q$ control- constant generator torque input (1 p.u.), - exact machine parameters used in the sensorless algorithm - variables: actual and reference speed and $Q$ s vs time.

Figure 5.10: Machine-side converter, speed and $Q$ control - constant generator torque ( 1 p.u.) variable speed reference, constant $Q s$ reference $(Q s=0$ p.u.) - modified machine parameters used in the sensorless algorithm - variables: actual and reference speeds and Qs...........................................................................................................................................62 62

Figure 5.11: Machine-side converter, speed and $Q$ control - constant generator torque (1 p.u.) variable speed reference, constant $Q s$ reference $(Q s=0$ p.u. $)$ - modified machine parameters used in the sensorless algorithm - no integrator in P-I controller - variables: actual and reference speeds and $Q s$ vs time

Figure 5.12: Grid-side converter - system configuration...............................................................63

Figure 5.13: Reference current calculation of grid-side converter - block diagram ............................. 63

Figure 5.14: Grid-side converter - small signal system diagram ............................................................65 65

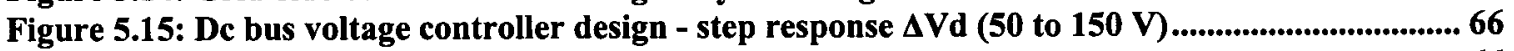

Figure 5.16: $D q$ reference frame transformation for reference current - block diagram .................... 66

Figure 5.17: Grid-side converter - circuit diagram of simulation setup ..........................................67

Figure 5.18: Grid-side converter, dc bus voltage controller - constant $Q g$ reference $(Q g=0$ p.u. $)$, step changes of dc bus voltage reference - variables: reference and actual Vdc vs time........ 67

Figure 5.19: Grid-side converter, performance power controller - step changes in power flow constant dc voltage reference $(V d c=1$ p.u. $)$, constant $Q g$ reference $(Q g=0$ p.u. $)-$ variables: dc bus voltage Vdc and current vs time.

Figure 5.20: Grid-side converter, performance power controller - step changes in power flow constant dc voltage reference $(V d c=1$ p.u. $)$, constant $Q g$ reference $(Q g=0$ p.u. $)-$ variables: grid converter voltage $\mathrm{Vg}$ and current $\mathrm{Ig}$ vs time.

Figure 5.21: Grid-side converter, performance reactive power controller - step changes in reactive power - constant de voltage reference ( $V d c=1$ p.u.), constant de bus load - variables: reference and actual $\mathrm{Vdc}$ and $\mathrm{Qg}$ vs time

Figure 5.22: Grid-side converter, performance reactive power controller - step changes in reactive power - constant de voltage reference (Vdc $=1$ p.u.), constant de bus load - variables: grid converter voltage $\mathrm{Vg}$ and current Ig vs time

Figure 5.23: Complete DFIG system performance, $P-Q$ control - constant generator torque (1 p.u.) variable $P$ s reference, constant $Q$ s reference $(Q s=0$ p.u.) - variables: reference and actual Ps and Qs vs time

Figure 5.24: Complete DFIG system performance, $P-Q$ control - constant generator torque (1 p.u.) variable $Q s$ reference, constant $P s$ reference $(P s=\mathbf{- 0 . 8 7 5}$ p.u.) - variables: reference and actual $P s$ and Qs vs time

Figure 5.25: Complete DFIG system performance, $P-Q$ control - variable generator torque-constant $Q s$ reference, constant Ps reference (Ps $=\mathbf{- 0 . 8 2 5}$ p.u.) - variables: torque, reference and actual Ps and Qs vs time 
Figure 5-26: Induction generator connected to the ac grid, no P-Q controller - variable generator torque - variables: reference and actual $P s$ and Qs vs time.

Figure 5.27: Complete DFIG system performance, $P-Q$ control -variable generator torque- variable Ps reference, constant $Q s$ reference $(Q s=0$ p.u.) - variables: torque, reference and actual $P s$ and Qs vs time

Figure 5.28: Complete DFIG system performance, $P-Q$ control -variable generator torque- variable Ps reference, constant $Q s$ reference (Qs $=0$ p.u.) - variables: speed, rotor currents and dc bus voltage vs time

Figure 5.29: Complete DFIG system performance, $P-Q$ control -variable generator torque- variable Ps reference, constant $Q$ s reference ( $Q s=0$ p.u.) - variables: grid converter voltage Vg and current Ig vs time.

Figure 6.1: Speed sensorless measurement - experimental setup

Figure 6.2: Sensorless speed measurement - variable input torque, shorted rotor - above and below synchronous speed (generator and motor operation) - variables: estimated speed and rotor currents vs time

Figure 6.3: Sensorless speed measurement - variable input torque, shorted rotor - above and below synchronous speed (generator and motor operation) - variables: estimated and actual speeds

Figure 6.4: Machine-side converter - experimental setup 78

Figure 6.5: Machine-side converter, speed and $Q$ control -unregulated generator torque - variable speed reference, constant $Q$ s reference $(Q s=0$ p.u.) - above and below synchronous speed (generator operation)

Figure 6.6: Machine-side converter, speed and $Q$ control -unregulated generator torque - operating speed: 1.07 rated speed, $200 \mathrm{rad} / \mathrm{s}$, constant $Q$ s reference $(Q s=0$ p.u.) - variables: stator voltage $V a$ and current Ia vs time. 79

Figure 6.7: Machine-side converter, speed and $Q$ control - unregulated generator torque - variable Qs reference, constant speed reference (speed $=1.2$ p.u.)...................................................8 80

Figure 6.8: Machine-side converter, speed and $Q$ control -unregulated generator torque - variable Qs reference, constant speed reference (speed = 1.2 p.u.) - variables: stator voltage Va and current Ia......................................................................................................................... 80

Figure 6.9: Grid-side converter - experimental setup.................................................................8 81

Figure 6.10: Grid-side converter, dc bus voltage controller - constant $Q g$ reference $(Q g=0$ p.u. $)$, step changes of dc bus voltage reference - variables: reference and actual Vdc vs time........ 81

Figure 6.11: Grid-side converter, performance reactive power controller - step changes in reactive power - constant de voltage reference $(\mathrm{Vdc}=350 \mathrm{~V})$, constant dc bus resistive load variables: reference and actual grid converter current Ig vs time

Figure 6.12: Grid-side converter, performance reactive power controller - step changes in reactive power - constant de voltage reference $(\mathrm{Vdc}=350 \mathrm{~V})$, constant dc bus resistive load variables: grid converter voltage $\mathrm{Vg}$ and current Ig vs time.

Figure 6.13: Grid-side converter, performance power controller - variable resistive load - constant dc voltage reference $(\mathrm{Vdc}=350 \mathrm{~V}$, constant $\mathrm{Qg}$ reference $(\mathrm{Qg}=\mathbf{0}$ p.u. $)$ - variables: grid converter voltage $\mathrm{Vg}$ and current $\mathrm{Ig}$ vs time

Figure 6.14: Complete DFIG system - experimental setup

Figure 6.15: Complete DFIG system performance, P-Q control - unregulated generator torque variable Ps reference, constant $P$ s reference $(Q s=0$ p.u.) - variables: reference and actual Ps and Qs and speed vs time

Figure 6.16: Complete DFIG system performance, $P-Q$ control - unregulated generator torque variable Qs reference, constant $P s$ reference $(P s=-0.7$ p.u.) - variables: reference and actual Ps and Qs vs time

Figure 6.17: Complete DFIG system performance, P-Q control - unregulated generator torque variable $Q s$ reference, constant Ps reference $(P s=\mathbf{- 0 . 7}$ p.u.) - variables: stator voltage Va and current Ia vs time.

Figure 6.18: Complete DFIG system performance, $P-Q$ control - variable generator torque-constant Qs and Ps reference ( $Q s=0$ p.u., $P s=\mathbf{- 0 . 7}$ p.u.) - variables: reference and actual Ps and Qs, speed and torque vs time. 
Figure 6.19: Complete DFIG system performance, $P-Q$ control - variable generator torque, above and below synchronous speed - constant $Q$ s reference $(Q s=0$ p.u. $)$, constant $P s$ reference ( $P s=\mathbf{- 0 . 6}$ p.u.) -variables: speed and rotor currents vs time

Figure 6.20: Complete DFIG system performance, $P-Q$ control - variable generator torque constant $Q$ s reference $(Q s=0$ p.u.), constant $P s$ reference $(P s=\mathbf{- 0 . 7}$ p.u. $)$ - variables: $d c$ bus voltage and grid converter voltage $\mathrm{Vg}$ and current $\mathrm{Ig}$ vs time. 


\section{List of Tables}

Table 2.1: Typical parameters of induction machines in p.u.

Table 2.2: Data for induction machine circuit model parameter identification tests $-0.2 \mathrm{~kW}$, 4-pole,

120 phase-ground volts, 3-phase, $60 \mathrm{~Hz}$ wound-rotor induction machine ............................ 23

Table 2.3: Rules of thumb for dividing rotor and stator reactances ..................................................... 27

Table 2.4: Machine model parameters of induction machine used for experimental setup.................. 27

Table 3.1: Machine parameters of a typical induction machine used in wind energy conversion systems (60 Hz, 2 MW, 4-pole) 


\section{List of Main Symbols}

$\omega$

S

$P_{W}$

$C_{p}$

$v$

$\theta_{s}$

$\omega_{s}, f_{s}$

$\theta_{r}$

$\omega_{r}, f_{r}$

$\theta_{m}$

$\omega_{m}$

$\Phi$

$i_{g a b c}$

$i_{\text {rabc }}$

$i_{\text {sabc }}$

$i_{g a \beta}$

$i_{\text {rap }}$

$i_{\text {sap }}$

$i_{\text {gdq }}$

$i_{r d q}$

$i_{s d q}$

$v_{\text {gabc }}$

$v_{\text {rabc }}$

$v_{s a b c}$

$v_{g a \beta}$

$v_{r a \beta}$

$v_{s a \beta}$

$v_{g d q}$

$v_{r d q}$

$v_{s d q}$

$V_{d c}$

$P$

$Q$

$p f$

$P_{s}$

$Q_{s}$

$P_{g}$

$Q_{g}$

$\Phi_{s}, \Phi_{r}$

$\lambda_{s}, \lambda_{r}$

$C_{d}$

$L_{m}$

$R_{s}, R_{r}$

$L_{s}, L_{r}$

$X_{s}, X_{r}$

ref

Angular velocity of generator

Slip

Mechanical power produced by wind turbine

Power coefficient of wind turbine

Wind speed

Stator side angle

Stator side frequency, synchronous speed

Rotor side angle

Rotor side frequency

Machine angle - output of slip frequency PLL

Machine speed - output of slip frequency PLL

Output angle of dq-axes aligner

Three-phase grid-side converter currents

Three-phase rotor currents

Three-phase stator currents

Components of grid-side converter currents in stator $\alpha \beta$ frame

Components of rotor currents in stator $\alpha \beta$ frame

Components of stator currents in stator $\alpha \beta$ frame

Components of grid-side converter currents in stator $\mathrm{dq}$ frame

Components of rotor currents in stator $\mathrm{dq}$ frame

Components of stator currents in stator dq frame

Three-phase grid-side converter voltages

Three-phase rotor currents voltages

Three-phase stator currents voltages

Components of grid-side converter voltages in stator $\alpha \beta$ frame

Components of rotor voltages in stator $\alpha \beta$ frame

Components of stator voltages in stator $\alpha \beta$ frame

Components of grid-side converter voltages in stator dq frame

Components of rotor voltages in stator dq frame

Components of stator voltages in stator dq frame

Dc bus voltage

Real power

Reactive power

Power factor

Stator-side real power

Stator-side reactive power

Grid-side converter real power

Grid-side converter reactive power

Stator and rotor fluxes

Stator and rotor flux linkages

Dc bus capacitor

Magnetizing inductance

Stator and rotor resistances

Stator and rotor leakage inductances

Stator and rotor leakage reactances

Reference

Subscript denoting reference values of corresponding variables 


\section{Chapter 1: Introduction}

\subsection{Wind Energy Conversion Systems}

From sailboats to windmills to wind turbines, wind power has always provided human beings with a viable source of renewable energy. In recent years, wind power has become the fastest growing energy source in the world. Installed capacity has, over the last 5 years, grown at an annual rate of nearly $30 \%$. By the beginning of 2004, global wind power installations reached a level of 40,000 MW, of which 8,300 MW were added during 2003 [26].

Wind energy facilities are common in areas with consistent and predictable high average wind. They tend to be located in coastal areas, at high elevations, or in valleys or plains near mountainous areas. Even though wind power facilities are not readily dispatchable, their output is often predictable based on daily wind patterns. In order for wind generation to be cost effective, it needs to extract the maximum amount of energy from wind at any given time in order to produce energy at a minimum cost per dollar of investment. Performance characteristics such as power output versus wind speed must be optimized in order to compete with other energy sources. Also, if the utility uses wind power for a part of its generation, the output power of these turbines must have the same high quality when it enters the utility grid. 


\subsubsection{Wind Energy in Canada}

In June 2006, Canada became the 12 th country to surpass $1,000 \mathrm{MW}$ of installed wind energy capacity. Wind energy produces enough electricity to meet the needs of more than 315,000 Canadian homes. According to Robert Hornung, President of the Canadian Wind Energy Association, “Canada's provincial governments are now targeting to have a minimum of $9,000 \mathrm{MW}$ of wind energy production in place by 2015 and many are currently examining the possibilities of going further"[33].

Existing wind energy farms in Quebec include the Le Nordais project in Matane, with 57 wind turbines rated $750 \mathrm{~kW}$ each, the Le Nordais project in Cap Chat, with 76 wind turbines rated $750 \mathrm{~kW}$ each and the Mont Miller Project, with 30 wind turbines rated 1.8MW each [35]. In April 2006, a Cree band on James Bay and a Toronto-based company set in motion plans to build a \$3-billion wind energy project that would be Canada's largest wind park. The Chisasibi band's project would generate 1,650 megawatts of wind power with 1,100 windmills [32].

\subsubsection{Components of a Wind Energy Conversion System}

The major components of a typical wind energy conversion system include a wind turbine, a generator, an interconnection apparatus and a control system. Wind turbines convert the kinetic energy from the wind into electricity, which can be fed to the grid for distribution. As shown in the Figure 1.1, the power originates from the mass flow of moving air. Aero-dynamical forces rotate the blade to transform the wind energy to mechanical energy. Then, the wind turbine shaft transports the energy to the generator, which is connected to the grid. To improve the quality of electrical power supplied to the grid, speed and control mechanisms are employed. 


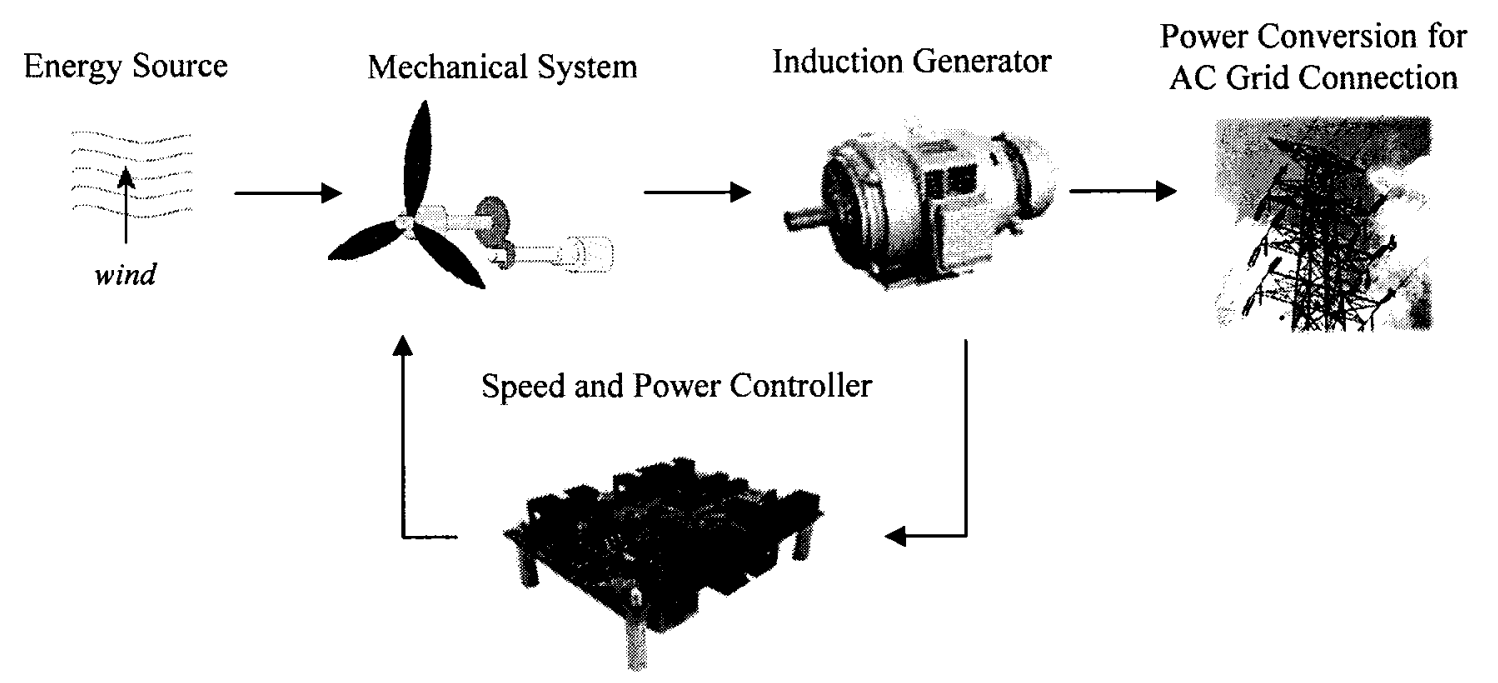

Figure 1.1: Wind energy conversion system - basic configuration

\subsubsection{Modeling of Wind Energy}

A wind turbine obtains its power input by converting the force of the wind into torque acting on the rotor blades. The amount of energy which the wind transfers to the rotor depends on the density of the air, the rotor area, and the wind speed. The energy content of the wind varies with the cube of the average wind speed. The power of the wind passing perpendicularly through a circular area is given as:

$$
\begin{gathered}
P_{W}=\frac{1}{2} \rho v^{3} \pi r^{2} \\
\text { where } P_{W}=\text { the power of the wind }(W) \\
\rho=\text { the density of dry air }\left(1.225 \mathrm{~kg} / \mathrm{m}^{3}\right) \\
v=\text { the velocity of the wind }(\mathrm{m} / \mathrm{s}) \\
r=\text { the radius of the turbine }(\mathrm{m})
\end{gathered}
$$

The wind speed is always fluctuating, and thus the energy content of the wind is always changing. An example of wind energy fluctuation is shown in Figure 1.2. Energy output from a wind turbine will vary as the wind varies, although the most rapid variations will to some extent be compensated for by the inertia of the wind turbine rotor. 
Turbulence decreases the possibility of using the energy in the wind. It also imposes more wear and tear on the wind turbine. Towers are usually made tall enough to avoid turbulence from the wind close to ground level.

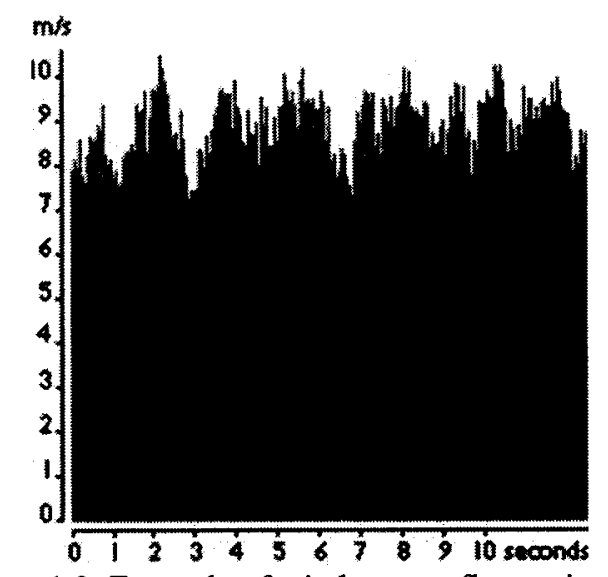

Figure 1.2: Example of wind energy fluctuation [38]

Betz' law states that you can only convert less than $16 / 27$ (or 59\%) of the kinetic energy in the wind to mechanical energy using a wind turbine. The actual amount of power capable of being produced by a wind turbine is given by:

$$
P_{W}=\frac{1}{2} \rho v^{3} \pi r^{2} \cdot C_{p}(\lambda)
$$

where $C_{p}(\lambda)$ is the power coefficient of the wind turbine

$C_{p}$ is dependent on the ratio between the tangential velocity of the blade tip and the wind velocity. This ratio, known as the tip-speed ratio, is defined as:

$$
\begin{aligned}
\lambda=\frac{\omega \cdot r}{v} & \text { gear_ratio } \\
\text { where } \lambda & =\text { tip-speed ratio } \\
\omega & =\text { the angular velocity of the generator }(\mathrm{rad} / \mathrm{s})
\end{aligned}
$$

The power coefficient of a wind turbine (both for fixed and variable pitch), $C_{p}$, is optimized for the most probable local wind speed; for instance around $8 \mathrm{~m} / \mathrm{s}$ over land in Denmark, as shown in Figure 1.3. This is a deliberate choice by the engineers who 
designed the turbine. At low wind speeds efficiency is not so important, because there is not much energy to harvest. At high wind speeds the turbine must waste any excess energy above what the generator was designed for. Efficiency therefore matters most in the region of wind speeds where most of the energy is to be found.

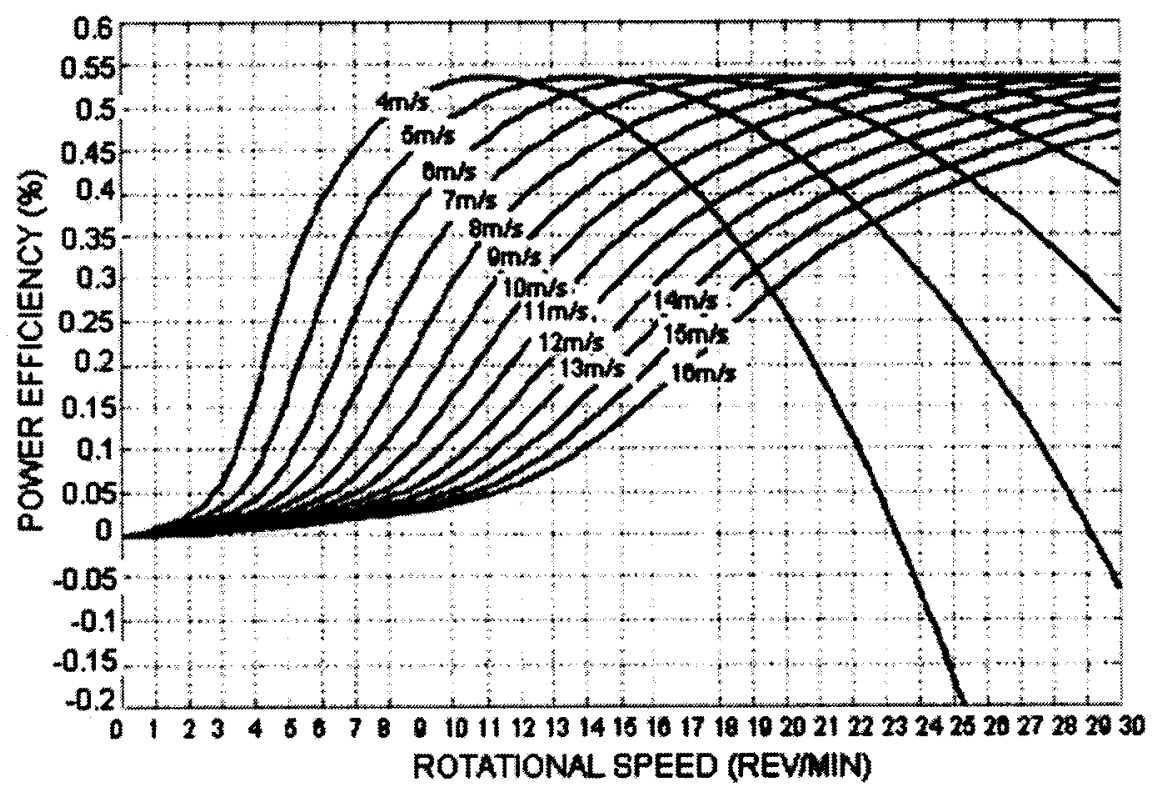

Figure 1.3: Power efficiency vs rotational speed of a $2 \mathrm{MW}$ variable speed wind turbine - power coefficient, $C_{P}$, optimized around wind speed of $8 \mathrm{~m} / \mathrm{s}$ [13]

\subsubsection{Variable-Speed Wind Turbines}

Wind turbine generators are a bit unusual, compared to other generating units you ordinarily find attached to the electrical grid. One reason is that the generator has to work with a power source which supplies very fluctuating mechanical power. During the past decade, variable-speed wind turbines have become the dominant type among the installed wind turbines. They are designed to achieve maximum aerodynamic efficiency over a wide range of wind speeds. With variable speed operation, it has become possible to continuously adapt the rotational speed $\omega$ to the wind speed $v$. Contrary to a fixed-speed wind turbine, a variable-speed system keeps the generator torque fairly constant and the variations in wind are absorbed by changes in generator speed. The variable-speed 
operation also makes it possible to increase annual power production by approximately $5 \%$ [31]. Hence, the advantages of variable speed wind turbines are an increased energy capture, improved power quality and reduced mechanical stress on the wind turbine. On the other hand, the disadvantages are losses in power electronics, the use of more components and the increase cost of equipment.

\subsection{Doubly-Fed Induction Generators (DFIG)}

DFIGs are an interesting solution for variable-speed systems with limited variable speed range, that is $\pm 30 \%$ of the synchronous speed. Power electronic converters only need to handle a fraction of the total real power (around 30\%). In addition to the cost of the converter becoming lower, there is also less losses compared to a system where the converter has to handle the total power. As shown in Figure 1.4, the stator circuit of the DFIG is connected to the grid, whereas the rotor circuit is connected to the converter via slip rings. DFIGs have the ability of reactive power control and decoupling of real and reactive power control by independent control of torque and rotor excitation currents [24].

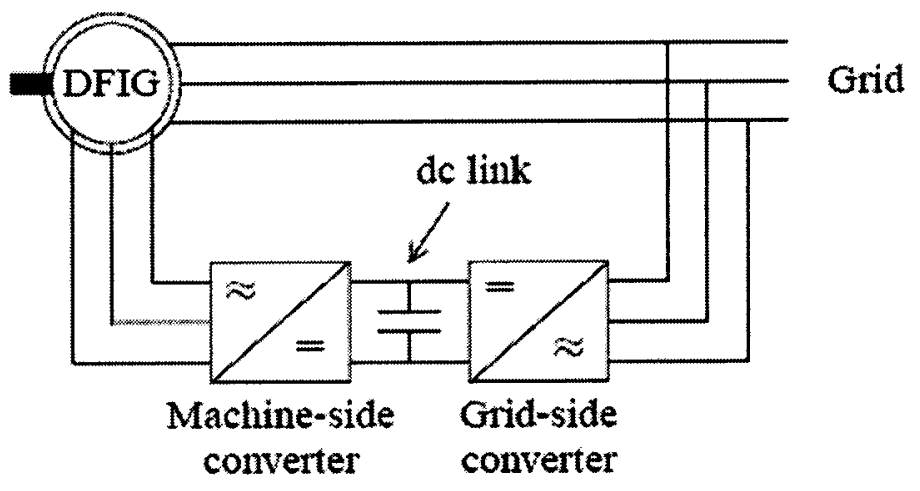

Figure 1.4: Doubly-fed induction generator (DFIG) - circuit diagram 
The back-to-back converter consists of a machine-side and grid-side converters. It allows for four-quadrant operation, meaning that the active power can flow in any direction. Between the two converters an energy storage device is placed in order to keep the voltage variations in the dc-voltage small. With the machine-side converter, it is possible to control the torque or speed of the DFIG and also the power factor at the stator terminals. With the grid-side converter, it is possible to maintain the dc voltage constant. Also, similar to a STATCOM, the grid-side converter can provide or absorb reactive power from the grid, it can enhance voltage stability and smooth the voltage profile. It allows bidirectional power flow, unlike a diode bridge rectifier, which would require a power sink. The speed-torque characteristic can be seen in the Figure 1.5. The DFIG can operate both in the motor and generator operation with a speed-range of $\Delta \omega^{\max }$ around the synchronous speed [24].

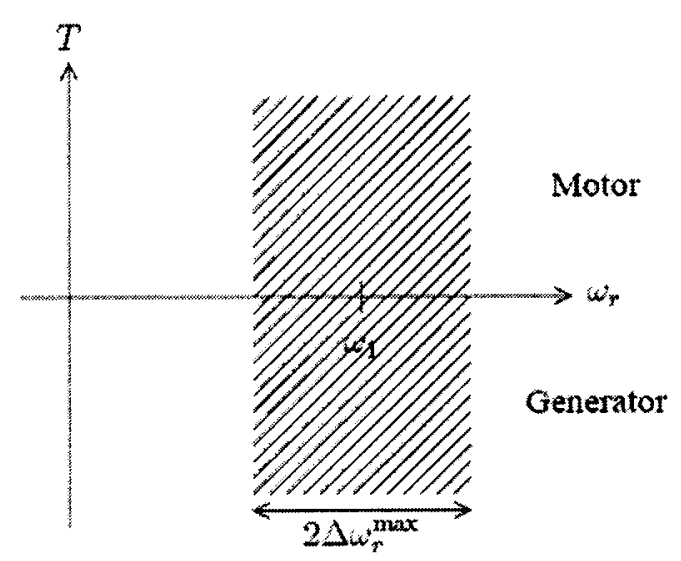

Figure 1.5: Operating range of a DFIG - torque vs speed

Other examples of applications that DFIGs are used are flywheel energy storage systems [13], stand-alone diesel systems [15] and rotating converters feeding a railway grid from a constant frequency public grid. 


\subsection{Sensorless Control of DFIG}

\subsubsection{Vector Control}

Precise and accurate control of the speed or torque of induction machines can only be accomplished by vector control, as established by Blashke in the 1960s [15]. In special reference frames, the expression for the electromagnetic torque of an induction machine is similar to the expression for the torque of the separately excited DC machine. The stator currents of the induction machine are separated into flux and torque producing components by utilizing transformation to the $d q$ coordinate system. The implementation of vector control requires accurate information on the slip angle (rotor position with reference to the stator) in order to maintain the direct axis $(d)$ of the stator current aligned with the rotor flux space vector. Given that the rotor position of the induction machine can be measured by a mechanical shaft, vector control becomes an easy task.

\subsubsection{Advantages of Sensorless Control}

For several years, there has been a significant interest in sensorless control, which implies control without a mechanical shaft sensor. While electrical measurements are acceptable since the sensors can be placed anywhere, usually inside the converter cabinet, a mechanical sensor is often considered a nuisance because of space restriction and also due to the added cost and complexity, especially for smaller machines. The driving motivations behind the development in sensorless control can be summarized as [22]:

- Lower cost: For low and medium power drives, the cost of a shaft sensor can be comparable to the cost of the induction machine (IM) itself 
- Reliability: Shaft sensors are prone to eventually fail, just like any other component of an IM drive. The removal of the shaft sensor results in one less critical component of an IM drive, thus improving the reliability of the IM drive

- Operating environment: Shaft sensors are delicate mechanical devices that cannot always be mounted in certain hostile environments, such as chemical plants.

There are presently several commercial sensorless drives for squirrel cage induction machines in the market such as the DTC family of ABB [30] and NFO Sinus [36]. The various designs of controlled AC drives without any mechanical sensor have in common that only terminal quantities, i.e. stator voltage and currents, are measured from which information of the flux and the speed are derived. These are based on the nominal parameters of the induction machine.

\subsubsection{Sensorless Control of DFIGs}

For several years, there has been a significant interest in research of sensorless drives for DFIGs specifically for wind energy conversion systems. Unlike squirrel-cage induction machines, the rotor currents and voltages are accessible and thus, sensorless schemes are based on the measurement of both the stator and rotor quantities to estimate the position and speed of the DFIG. In literature, there are numerous methods involving sensorless control of doubly-fed induction generators [1] [2] [6] [8] [10]. L. Morel, H. Godfroid, A. Miraian and J.M. Kauffmann [9] were the earliest pioneers to propose rotor position sensing in the DFIG. The rotor speed is then obtained by differentiating the rotor position. The disadvantage with this method, similar to many other existing sensorless schemes, is that differentiation can lead to significant inaccuracy due to the noise inherent in measured signals. 
Another important issue regarding the different sensorless schemes is their robustness to variations in machine parameters. For instance, saturation and nonlinearity of the inductance of the iron core, as well as temperature dependence of resistors, may cause variations of inductances and resistances in the induction machine. Disagreement between actual machine parameters and those that have been used to derive control constants can result in imperfect decoupling control. In addition, as shown in [2], an observer with incorrect parameters can lead to a significant ripple in the estimated speed which can produce oscillations and even instability. Also, an estimated speed with a stead-state error may give rise to the following issues:

- Reduced power capture: Because of steady-state speed error, the control strategy will not be able to drive the wind energy conversion system to maximum power capture (the variation of the power coefficient in respect to the tip-speed ratio).

- Incorrect pitch control operation: The pitch angle is controlled using the rotational speed signal. When the rotational speed is above $\varpi_{r \max }$, the pitch angle of the blade is controlled to reduce the power capture. Because the power capture is a function of the cube of the wind velocity, incorrect switching between control strategies may produce overloading or reduced power capture. In [21], a hysteresis band of only $2 \%$ of the nominal speed is used to switch between operations (with and without pitch control).

- Incorrect operation for other control systems: There are other control schemes which require an accurate rotational speed signal. For instance, the speed can be used to estimate the wind velocity. Therefore, an accurate estimation of the rotational speed is necessary in wind energy conversion systems. 


\subsubsection{Sensorless Control Algorithms Based on Machine Equations}

There are two main methods to perform sensorless measurement [25]. In the first method, the rotor currents are measured in one reference frame, and then the rotor currents are estimated in another reference frame to estimate the rotor position. The estimation of the rotor currents can be estimated either in the stator coordinates [4] or the rotating synchronous coordinate frame [5] [6]. The stator flux $\Phi_{s}$ in rotating synchronous coordinates is given by:

$$
\Phi_{s}=L_{m}\left(i_{s}+i_{r}\right)
$$

where $L_{m}$ is the magnetizing inductance, $i_{s}$ and $i_{r}$ are the stator and rotor currents. Given that the stator flux is defined as $\Phi_{s}=v_{s} / \omega_{s}$, the rotor current can be estimated as:

$$
\hat{i}_{r}=\frac{v_{s}}{\omega_{s} L_{m}}-i_{s}
$$

where $v_{s}$ is the stator voltage, $\omega_{s}$ the synchronous speed and $\hat{i}_{r}$ the estimated rotor current. The rotor position $\hat{\theta}_{m}$ can then be estimated as:

$$
\hat{\theta}_{m}=\angle i_{r}-\angle \hat{i}_{r}
$$

where $i_{r}$ is the measured rotor current. The rotor angle is differentiated to obtain the rotor speed. The disadvantage with this method is that since the rotor position is differentiated, the rotor speed signal is noisy.

The second method is based on determining the rotor speed from the rotor circuit equations. As shown [7], the rotor voltage equation is given by:

$$
v_{r}=R_{r} i_{r}+\frac{d \Phi_{r}}{d t}+j \omega_{m} \Phi_{r}
$$


where $v_{r}$ is the rotor voltage, $\omega_{m}$ is the rotor speed, $R_{r}$ is the rotor resistance and $\Phi_{r}$ the rotor flux. Neglecting the derivative term, the rotor speed can be estimated as:

$$
\hat{\omega}_{m}=\frac{v_{r}-R_{r} i_{r}}{\Phi_{r}}
$$

Hence, the rotor position can be found by integrating the rotor frequency:

$$
\hat{\theta}_{m}=\int \hat{\omega}_{m} d t
$$

The disadvantage with this method is that it requires the value of the rotor voltages which is not required in the decoupled control of the DFIG. Similarly, the speed estimation is based on the machine equations, which can lead to significant steady-state errors for variations in machine parameters.

\subsection{Objectives and Contributions of Thesis}

The objectives of this thesis are to implement a decoupled P-Q control of a DFIG that does not rely on mechanical sensors and to design a speed and position sensorless algorithm that is robust to variations of the values of the machine parameters. The sensorless DFIG control algorithm presented in this thesis is based on a modified phasedlock loop [11] [12] with an improved positioning algorithm. With the measured stator voltages, stator and rotor currents, the speed and position of the DFIG are estimated. The speed is estimated independent of machine parameters, which results in a significant improvement in speed control robustness to parameter variations. In addition, the algorithm avoids using differentiation, which significantly improves its immunity to noise and does not require the measurement of the rotor voltages. Also, it is shown that the positioning algorithm has an improved operation in generator mode. Although the accuracy of the positioning algorithm is depended on machine parameters; it is shown 
with the designed controller that the P-Q decoupled control is robust to changes of machine parameters (inductance and resistance). Theoretical and simulation results are validated on an experimental setup.

The main contributions of this thesis are the development and implementation of an improved positioning algorithm and experimental validation of the sensorless $\mathrm{P}-\mathrm{Q}$ control algorithm. In the process, the following have been done:

A. Simulation results showing the robustness of the decoupled P-Q control of the DFIG for any changes of machine parameters.

B. A comparison between the sensorless scheme presented in this thesis and one based on the machine equations typically found in literature. The proposed algorithm is shown to have an improved performance in the estimation of the speed in terms of robustness to machine parameters and noise reduction.

C. Experimental implementation and testing of the sensorless DFIG validating the sensorless decoupled P-Q control algorithm

\subsection{Methodology}

The sensorless decoupled P-Q control of the DFIG model was evaluated using both digital simulations and an experimental setup. The simulation software used is Matlab/Simulink. The SimPowerSystem toolbox of Matlab/Simulink has many features for incorporating power electronic controller and includes a software model of woundrotor induction machine which is conveniently used to represent the DFIG. Once the algorithm was simulated and its behavior and performance was verified, a set of experiments were carried out to validate the theoretical analysis. 
The experimental setup is shown in Figure 1.6. A variable torque drive is used to emulate the wind energy. A wound-rotor induction machine is used as a wind turbine generator, for which identification tests were done to determine its machine parameter values. Two power converters are used, one for the grid-side converter and the other for the machine-side converter. The algorithm was translated into a Real-Time Interface using a powerful digital controller based on INTEL Core 2 Duo processors. The controller interface takes as inputs the voltage and current values of the DFIG stator and rotor windings and outputs the gating signals of the converters.

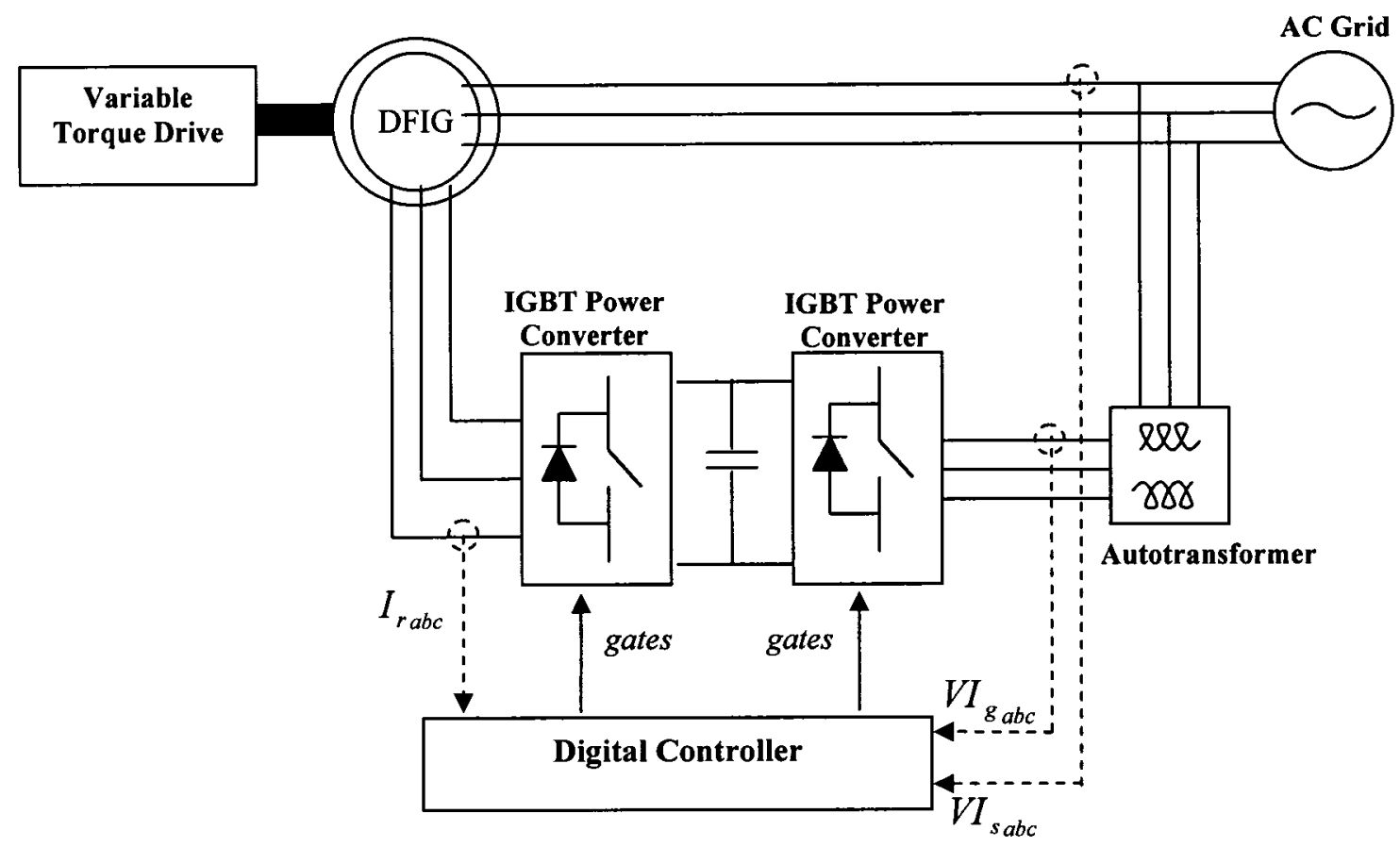

Figure 1.6: Sensorless decoupled P-Q control of DFIG - experimental setup

\subsection{Organization of Thesis}

This thesis can be summarized as follows:

Chapter 1 introduces the development of DFIG in wind energy applications and a literature review of sensorless schemes. It also presents the scope of the thesis. 
Chapter 2 provides theory on induction machines and reference frame transformations. In addition, it provides a detailed explanation of the measurement of the machine parameters for the wound-rotor induction machine used in the experimental setup.

Chapter 3 presents the speed and position sensorless algorithms and simulation results to validate the theory.

Chapter 4 evaluates the immunity to noise and the robustness to changes in machine parameters of the speed and position measurement algorithms. A comparison is made with a sensorless scheme based on the machine equations typically found in literature.

Chapter 5 presents the algorithm of the sensorless P-Q control for both the gridside and machine-side converters and simulation results to validate the theory

Chapter 6 evaluates the sensorless P-Q control experimentally. First the accuracy of the sensorless speed algorithm is evaluated. Then, the grid-side and machine-side converters are tested separately. Finally, the performance of the entire sensorless decoupled P-Q control algorithm is evaluated.

Chapter 7 presents a summary of the thesis and the conclusions of the study. 


\section{Chapter 2: Induction Machine Theory}

\section{$2.1 \quad$ Introduction}

A strong understanding of induction machine theory is essential for the implementation of the sensorless P-Q control of the DFIG algorithm. First, the induction machine model is derived based on the interaction of the rotor and stator flux linkages. Then, the $d q$ reference frame is explained which is essential for vector control. From the reference frame transformation, we obtain the $d q$ model of the induction machine which is used in the implementation of the different algorithms presented in the following chapters. In addition, a detailed explanation of the measurement of the machine parameters for the wound-rotor induction machine used in the experimental setup is given.

\subsection{Electromechanical Energy Conversion Systems}

Magnetically coupled electric circuits are central to the operation of electrical machines. Circuits in relative motion are magnetically coupled in order to transfer energy between mechanical and electrical systems. An important concept is flux linkage, where an electromotive force is induced (by the process of electromagnetic induction) in one of the circuits by a change of current in another circuit. When the magnetic system is linear, the flux linkages are generally expressed in terms of inductances and currents. Two types of inductances are defined: self-inductance and mutual inductance. Self-inductance of a winding is the ratio of the flux linked by that winding to the current flowing in the 
winding with all winding currents to zero. Mutual inductance is the ratio of the flux linked by one winding due to current flowing in a second winding with all the other currents set to zero (including itself).

Electromechanical systems are comprised of electrical systems, mechanical systems and a means where the electrical and mechanical systems interact. A diagram of a simplified system is shown in Figure 2.1. We must also consider losses, which occur in all the components of the electromechanical system. For instance heat loss occurs in the mechanical system due to friction and heat dissipation occurs in the electrical system due to the resistance of the conductor. Similarly, eddy current and hysteresis losses occur in all the ferromagnetic material.

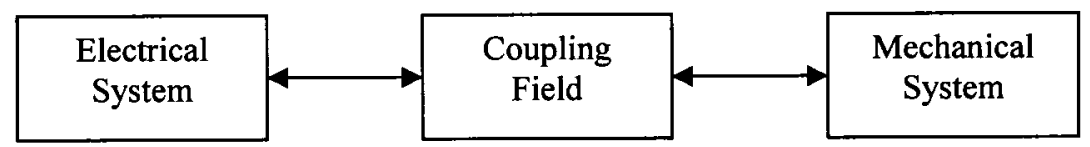

Figure 2.1: Simplified electromechanical system - block diagram

\subsection{Induction Machines}

The winding arrangement and flux distribution of a 2-pole, 3-phase, wyeconnected symmetrical induction machine is shown in Figure 2.2. With balanced 3-phase currents flowing in the stator windings, a rotating air-gap magnetomotive force (MMF) is established which rotates at a speed determined by the stator frequency and the number of poles. If the rotor speed is different from the speed of the stator MMF, 3-phase currents will be induced in the short-circuit rotor windings. The frequency of the rotor currents corresponds to the difference in the speed of the rotating stator MMF and the speed of the rotor. In the case of the wound-rotor induction machine, we can directly apply a voltage 
source to the rotor, and hence influence the amplitude, frequency and phase of the rotor currents.

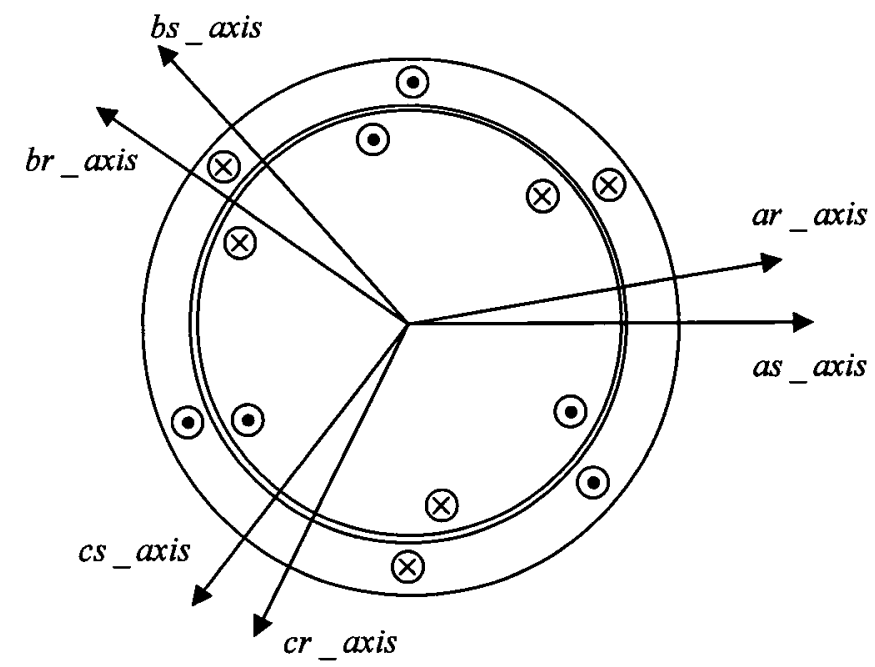

Figure 2.2: Two-pole, 3-phase, wye-connected symmetrical induction machine - winding arrangement

The rotor currents will in turn produce an air-gap MMF that rotates at a speed corresponding to the frequency of the rotor currents. The speed of the rotor MMF superimposed to the rotor speed is the same as the speed of the stator MMF. Hence, the two MMF rotate synchronously and torque is produced due to an interaction of both MMFs.

The voltage equations in machine variables may be expressed as:

$$
\begin{aligned}
& v_{s a b c}=r_{s} i_{s a b c}+\frac{d \lambda_{s a b c}}{d t} \\
& v_{r a b c}=r_{r} i_{r a b c}+\frac{d \lambda_{r a b c}}{d t}
\end{aligned}
$$

where $r_{r}$ and $r_{s}$ are the stator and rotor resistances and the flux linkages may be expressed as:

$$
\left[\begin{array}{l}
\lambda_{s a b c} \\
\lambda_{r a b c}
\end{array}\right]=\left[\begin{array}{cc}
L_{s} & L_{s r} \\
\left(L_{s r}\right)^{T} & L_{r}
\end{array}\right]\left[\begin{array}{l}
i_{s a b c} \\
i_{r a b c}
\end{array}\right]
$$


The self and mutual inductances are defined as:

$$
\begin{aligned}
& L_{s}=\left[\begin{array}{ccc}
L_{l s}+L_{m s} & -\frac{1}{2} L_{m s} & -\frac{1}{2} L_{m s} \\
-\frac{1}{2} L_{m s} & L_{l s}+L_{m s} & -\frac{1}{2} L_{m s} \\
-\frac{1}{2} L_{m s} & -\frac{1}{2} L_{m s} & L_{l s}+L_{m s}
\end{array}\right] \\
& L_{r}=\left[\begin{array}{ccc}
L_{l r}+L_{m r} & -\frac{1}{2} L_{m r} & -\frac{1}{2} L_{m r} \\
-\frac{1}{2} L_{m r} & L_{l r}+L_{m r} & -\frac{1}{2} L_{m r} \\
-\frac{1}{2} L_{m r} & -\frac{1}{2} L_{m r} & L_{l r}+L_{m r}
\end{array}\right] \\
& L_{s r}=L_{r s}=\left[\begin{array}{ccc}
\cos \theta_{r} & \cos \left(\theta_{r}+\frac{2 \pi}{3}\right) & \cos \left(\theta_{r}-\frac{2 \pi}{3}\right) \\
\cos \left(\theta_{r}-\frac{2 \pi}{3}\right) & \cos \theta_{r} & \cos \left(\theta_{r}+\frac{2 \pi}{3}\right) \\
\cos \left(\theta_{r}+\frac{2 \pi}{3}\right) & \cos \left(\theta_{r}-\frac{2 \pi}{3}\right) & \cos \theta_{r}
\end{array}\right]
\end{aligned}
$$

$L_{l s}$ and $L_{m s}$ are the leakage and magnetizing inductances of the stator windings, $L_{l r}$ and $L_{m r}$ are the leakage and magnetizing inductances of the rotor windings, and $L_{s r}$ is the amplitude of the mutual inductances between stator and rotor windings.

The torque equation may be expressed as:

$$
T_{e}=\frac{P}{2}\left(i_{s a b c}\right)^{T}\left(\frac{\partial L_{s r}}{\partial \theta_{r}}\right) i_{r a b c}
$$

where $P$ is the number of poles

\subsection{Reference-Frame Transformation}

We find that some of the machine inductances are functions of the rotor speed and that the coefficients of the voltage equations that describe the behavior of an induction machine are time-varying. A change of variable is often used to reduce the complexity of 
these equations. The transformation refers machine variables to a frame of reference that rotates at an arbitrary angular velocity.

A change of variables that formulates a transformation of the 3-phase variables of stationary circuit elements to the arbitrary may be expressed as:

$$
f_{\text {sqd } 0}=K_{s} f_{\text {sabc }}
$$

Where,

$$
\begin{aligned}
& f_{s q d 0}{ }^{T}=\left[\begin{array}{lll}
f_{s q} & f_{s d} & f_{s 0}
\end{array}\right] \\
& f_{s a b c s}{ }^{T}=\left[\begin{array}{lll}
f_{s a} & f_{s b} & f_{s c}
\end{array}\right] \\
& K_{s}=\frac{2}{3}\left[\begin{array}{ccc}
\cos \theta & \cos \left(\theta-\frac{2 \pi}{3}\right) & \cos \left(\theta+\frac{2 \pi}{3}\right) \\
\sin \theta & \sin \left(\theta-\frac{2 \pi}{3}\right) & \sin \left(\theta+\frac{2 \pi}{3}\right) \\
\frac{1}{2} & \frac{1}{2} & \frac{1}{2}
\end{array}\right] \\
& \omega=\frac{d \theta}{d t}
\end{aligned}
$$

where $\omega$ is the angular velocity and $\theta$ the angular displacement.

The inverse transformation (i.e. $K_{s} \cdot K_{s}^{-1}=I$ ) is:

$$
K_{s}^{-1}=\left[\begin{array}{ccc}
\cos \theta & \sin (\theta) & 1 \\
\cos \left(\theta-\frac{2 \pi}{3}\right) & \sin \left(\theta-\frac{2 \pi}{3}\right) & 1 \\
\cos \left(\theta+\frac{2 \pi}{3}\right) & \sin \left(\theta+\frac{2 \pi}{3}\right) & 1
\end{array}\right]
$$

In the above equations, $f_{s}$ can represent voltage, current, flux linkage or electric charge. The angular displacement must be continuous, however the angular velocity associated with the change of variables is unspecified. The frame of reference may rotate at any constant or varying angular velocity or it may remain stationary.

The equations of transformation may be thought of as if $f_{s q}$ and $f_{s d}$ variables are directed along paths orthogonal to each other and rotating at an angular velocity of $\omega$, 
whereas $f_{s a}, f_{s b}$, and $f_{s c}$ may be considered as variables directed along stationary paths, each displaced by $120^{\circ}$. This is shown in Figure 2.3. Note that $f_{s 0}$ variables are not associated with the arbitrary reference frame. Instead the zero variables are related arithmetically to the $a b c$ variables, independent of theta.

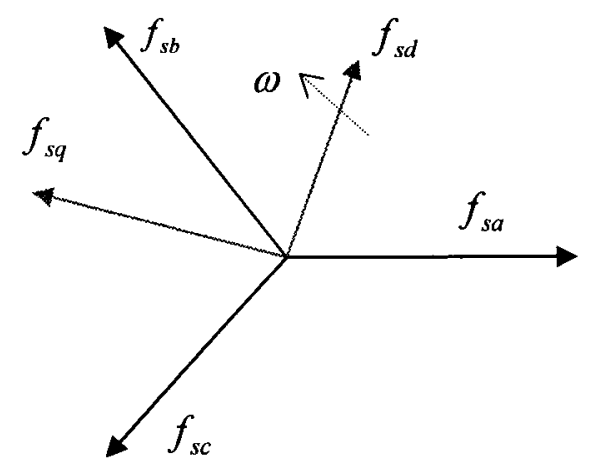

Figure 2.3: Reference transformations $a b c$ (stationary) to $d q$ (rotating $\omega$ )

It is particularly convenient when applying it to ac machines where the direction of $f_{s a}, f_{s b}$, and $f_{s c}$ may also be thought of as the direction of the magnetic axes of the stator windings. The direction of $f_{s q}$ and $f_{s d}$ can be considered as the direction of the magnetic axes of the new windings created by the change of variables. For flux-based rotating frames, changes in the $d$ component will lead to reactive power changes; changes in the $q$ component of current will vary active power exchanges. In voltage-based rotating frames (and thus $90 \mathrm{deg}$. ahead of flux based frames) the effect is the opposite.

\subsection{Dq Equivalent Model of Induction Machine}

With the $d q$ transformation, the induction machine voltage equations become: 


$$
\left[\begin{array}{c}
v_{s d} \\
v_{s q} \\
v_{r d} \\
v_{r q}
\end{array}\right]=\left[\begin{array}{cccc}
R_{s}+\frac{d L_{s s}}{d t} & -\omega_{s} L_{s s} & \frac{d L_{m}}{d t} & -\omega_{s} L_{m} \\
\omega_{s} L_{s s} & R_{s}+\frac{d L_{s s}}{d t} & \omega_{s} L_{m} & \frac{d L_{m}}{d t} \\
\frac{d L_{m}}{d t} & -\left(\omega_{s}-\omega_{m}\right) L_{m} & R_{r}+\frac{d L_{r r}}{d t} & -\left(\omega_{s}-\omega_{m}\right) L_{r r} \\
\left(\omega_{s}-\omega_{m}\right) L_{m} & \frac{d L_{m}}{d t} & \left(\omega_{s}-\omega_{m}\right) L_{r r} & R_{r}+\frac{d L_{r r}}{d t}
\end{array}\right]\left[\begin{array}{c}
i_{s d} \\
i_{s q} \\
i_{r d} \\
i_{r q}
\end{array}\right]
$$

where, $L_{s s}=L_{l s}+L_{m}$

$$
L_{r r}=L_{l r}+L_{m}
$$

The torque can be expressed as:

$$
T_{e}=\frac{3}{2} \frac{P}{2} L_{m}\left(i_{s q} i_{r d}-i_{d s} i_{r q}\right)
$$

The 1-phase equivalent circuit of the induction machine is shown in Figure 2.4.

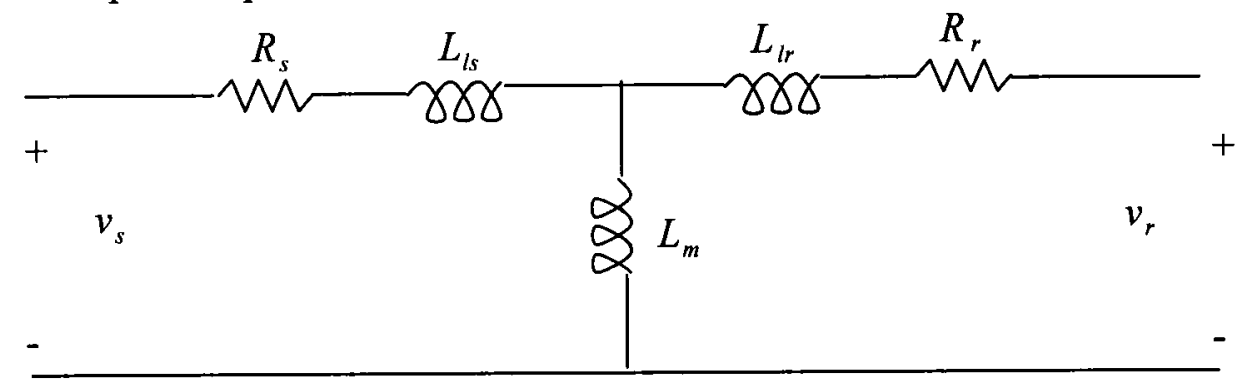

Figure 2.4: Equivalent circuit of steady-state operation of a symmetrical induction machine

Table 2.1 shows the values of some typical parameters of inductance machines in per unit.

Table 2.1: Typical parameters of induction machines in p.u. [28]

\begin{tabular}{|c|c|c|c|c|c|c|}
\hline & \multicolumn{2}{|c|}{ Small Machines } & \multicolumn{2}{c|}{ Medium Machines } & \multicolumn{2}{c|}{ Large Machines } \\
\hline Power (kW) & 4 & 15 & 100 & 200 & 745 & 1676 \\
\hline $\begin{array}{c}\text { Stator and } \\
\text { Rotor } \\
\text { Resistances }\end{array}$ & 0.045 & 0.025 & 0.014 & 0.009 & 0.012 & 0.007 \\
\hline $\begin{array}{c}\text { Leakage } \\
\text { Inductance }\end{array}$ & 0.092 & 0.1 & 3.5 & 3.8 & 0.09 & 0.077 \\
\hline $\begin{array}{c}\text { Mutual } \\
\text { Inductance }\end{array}$ & 1.7 & 2.2 & 0.15 & 0.12 & 8.1 & 4.5 \\
\hline
\end{tabular}




\subsection{Machine Model Parameter Measurement}

The parameters of the equivalent circuit shown in Figure 2.4 can be determined from tests analogous to the short-circuit and the open-circuit test of a transformer. The tests must be performed under precisely controlled conditions, since the resistances vary with temperature and the rotor resistance varies with rotor frequency. The exact details of how each induction motor test must be performed in order to achieve accurate results are described in IEEE Standard 112 [39].

The tests generally performed are a dc test, a no-load test and a blocked-rotor test . The data obtained for a $0.2 \mathrm{~kW}, 4$-pole, 120 phase-ground volts, 3-phase, $60 \mathrm{~Hz}$ woundrotor induction machine are shown in Table 2.2 .

Table 2.2: Data for induction machine circuit model parameter identification tests - $0.2 \mathrm{~kW}, 4$-pole, 120 phase-ground volts, 3-phase, $60 \mathrm{~Hz}$ wound-rotor induction machine

\begin{tabular}{|l|l|l|}
\hline DC Test & Locked-Rotor Test & No Load Test \\
\hline$V_{d c}=38.75 \mathrm{~V}$ & $V_{L R}=50.33 \mathrm{~V}$ & $V_{N L}=119.89 \mathrm{~V}$ \\
$I_{d c}=1.5 \mathrm{~A}$ & $I_{L R}=1.537 \mathrm{~A}$ & $I_{N L}=0.876 \mathrm{~A}$ \\
& $S_{L R}=227.1 \mathrm{VA}$ & $P_{N L}=47.10 \mathrm{~W}$ \\
& $p f_{L R}=0.82$ & $p f_{N L}=0.151$ \\
\hline
\end{tabular}

\subsubsection{Dc Test for Stator Resistance}

During the dc test, a dc voltage is applied across two terminals while the machine is standstill. Because the current is dc, there is no induced voltage in the rotor circuit and no resulting rotor current flow. Also, the reactance of the motor is zero at direct current. Therefore, the only quantity limiting current flow is the stator resistance. The basic circuit for the de test is shown in Figure 2.5. The current in the stator windings is adjusted to the rated value in an attempt to heat the windings to the same temperature they would have in normal operation. The current flows through two of the windings, therefore: 


$$
R_{s}=\frac{V_{d c}}{2 \times I_{d c}}=\frac{38.75}{2 \times 1.5}=12.92 \Omega
$$

However, the resistance to alternating current may differ from the resistance to direct current for many reasons, including skin effect. According to IEEE Standard 118 [40], skin effect is explained as follows: Magnetic fields produced by the current within the conductor force the current to concentrate near the outside surface or skin. The effective cross-sectional area of the conductor is therefore reduced. This effect increases with frequency and is a function of the relative permeability. However, since skin effect is most noticeable in conductors of large cross-section, and we are using a small machine, there is no need to add compensation.

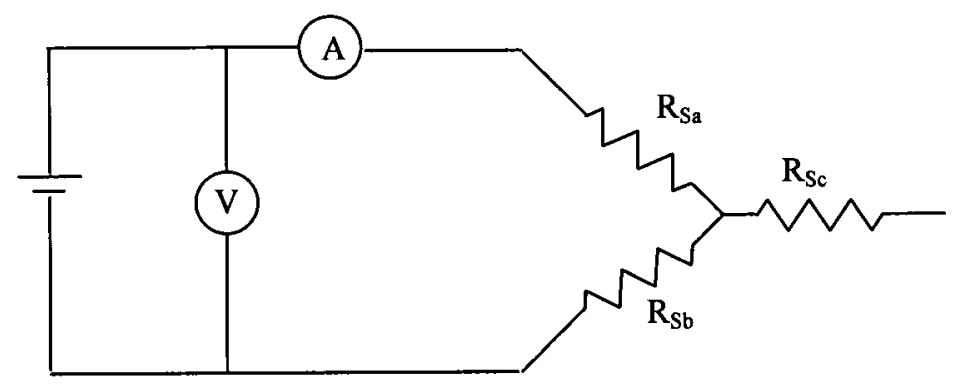

Figure 2.5: Dc resistance test - circuit diagram

\subsubsection{No-Load Test}

The no-load test, which is analogous to the transformer open-circuit test, is preformed with balanced three-phase, $60 \mathrm{~Hz}$ voltages applied to the stator winding without mechanical load on the machine. The test circuit is shown in Figure 2.6.

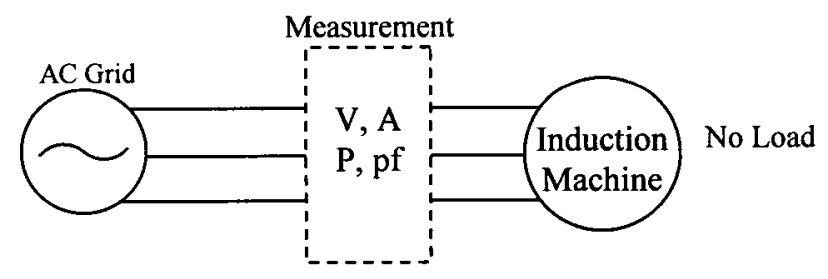

Figure 2.6: No-load test - circuit diagram 
The input power during this test must equal the losses in the machine, which is the sum of the stator copper losses, the core losses due to hysteresis and eddy current losses and rotational losses due to friction and windage. Thus,

$$
P_{I N}=P_{S C L}+P_{C O R E}+P_{F W}=P_{S C L}+P_{R O T}=47.10 \mathrm{~W}
$$

The stator copper losses are:

$$
P_{S C L}=3 I_{N L}^{2} R_{S}=3 \times 0.876^{2} \times 12.92=29.74 \mathrm{~W}
$$

Therefore the power losses due to friction, windage and core losses are:

$$
P_{\text {ROT }}=17.36 \mathrm{~W}
$$

In the equivalent circuit, this loss is neglected. It is generally small, and in most cases, little error is introduced by neglecting it. It can be taken into account by placing a resistor in shunt with the magnetizing reactance $X_{m}$ or by applying a small mechanical load to the shaft of the machine.

It is noted from the no-load test data that the power factor is very small. The noload test is highly inductive and its magnitude is the sum of the stator leakage and the magnetizing reactance because the rotor speed is essentially synchronous, thus $R_{r} / \mathrm{s}$ is much larger than $X_{m}$. The equivalent input impedance is thus approximately:

$$
\left|Z_{e q}\right|=\frac{V_{N L}}{I_{N L}}=\frac{119.89}{0.876}=136.86 \Omega \approx X_{s}+X_{m}
$$

\subsubsection{Blocked-Rotor Test}

During the blocked-rotor test, which is analogous to the transformer short-circuit test, the rotor is locked by some external means and balanced 3-phase stator voltages are applied. The resulting current, voltage and power are measured. The connections for the 
blocked-rotor test are show in Figure 2.7. The current flow is adjusted to be approximately full-load value.

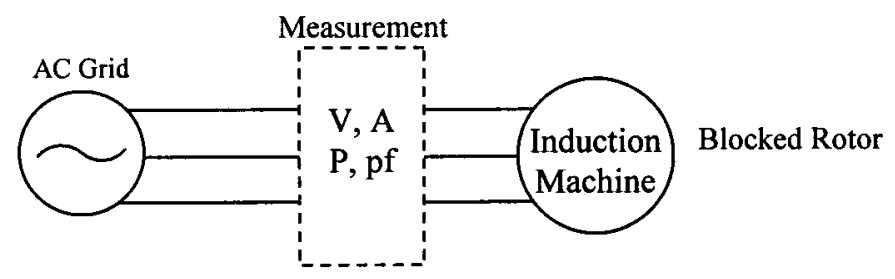

Figure 2.7: Blocked-rotor test - circuit diagram

Since the rotor is not moving, the slip $s=1$ and hence the rotor resistance $R_{r} / s$ is equal to $R_{r}$ (a small value). Given that $R_{r}$ and $X_{r}$ are small, almost all the input current will flow through them, instead of the much larger magnetizing reactance $X_{m}$. Therefore, the circuit under these conditions looks like a series combination of $X_{s}, R_{s}, X_{r}$ and $R_{r}$.

The problem with this test is that under normal operation conditions, the stator frequency is the line frequency of the power system, whereas, at normal operation, the rotor frequency is in the range of 1 to $3 \mathrm{~Hz}$. This creates a problem in that the line frequency does not represent the normal operating condition of the rotor. A typical compromise is to use a frequency of $25 \%$ or less of the rated frequency.

The input power to the motor is given by

$$
P_{S C L}=3 \cdot V_{L R} \cdot I_{L R} \cdot p f_{L R}=3 \times 50.33 \times 1.537 \times 0.82=190.30 \mathrm{~W}
$$

where the locked-rotor power factor was found to be 0.82 and $\theta=\cos ^{-1}\left(p f_{L R}\right)=35^{\circ}$. The magnitude of the total impedance of this motor is

$$
\left|Z_{L R}\right|=\frac{V_{L R}}{I_{L R}}=\frac{50.33}{1.537}=32.75 \Omega
$$

The locked-rotor resistance $R_{L R}=\left|Z_{L R}\right| \cdot \cos \theta=26.86 \Omega=R_{s}+R_{r}$, where $R_{s}$ was found in the de test. Hence, $R_{r}=13.9 \Omega$. 
The total rotor reactance referred to the stator can also be found. Since the reactance is directly proportional to the frequency, the total equivalent reactance at the normal operating frequency can be found as:

$$
X_{L R}=\frac{f_{\text {rated }}}{f_{\text {test }}}\left|Z_{L R}\right| \cdot \sin \theta=18.78 \Omega=X_{s}+X_{r}
$$

Unfortunately, there is no simple way to separate the contributions of the stator and rotor reactances from each other. Over the years, experience has shown that motors of certain design types have certain proportions between the rotor and stator reactances.

Table 2.3 summarizes this experience. Hence, for the wound-rotor,

$$
X_{s}=X_{r}=\frac{X_{L R}}{2}=9.39 \Omega
$$

From the no-load test, $X_{m}=X_{N L}-X_{s}=127.47 \Omega$

Table 2.3: Rules of thumb for dividing rotor and stator reactances [41]

\begin{tabular}{|l|c|c|}
\hline \multirow{2}{*}{ Rotor Design } & $X_{s}$ and $X_{r}$ as functions of $X_{L R}$ \\
\cline { 2 - 3 } & $X_{s}$ & $X_{r}$ \\
\hline Wound rotor & $0.5 X_{L R}$ & $0.5 X_{L R}$ \\
\hline Design A & $0.5 X_{L R}$ & $0.5 X_{L R}$ \\
\hline Design B & $0.4 X_{L R}$ & $0.6 X_{L R}$ \\
\hline Design C & $0.3 X_{L R}$ & $0.7 X_{L R}$ \\
\hline Design D & $0.5 X_{L R}$ & $0.5 X_{L R}$ \\
\hline
\end{tabular}

The compiled results of the parameter of wound-rotor induction machine are shown in Table 2.4 .

Table 2.4: Machine model parameters of induction machine used for experimental setup

\begin{tabular}{|c|c|c|}
\hline Parameter & Value (ohms) & Value (p.u.) \\
\hline$X_{s}$ & 9.39 & 0.12 \\
\hline$R_{s}$ & 12.92 & 0.17 \\
\hline$X_{r}$ & 9.39 & 0.12 \\
\hline$R_{r}$ & 13.9 & 0.18 \\
\hline$X_{m}$ & 127.47 & 1.65 \\
\hline
\end{tabular}




\section{Chapter 3: Sensorless Measurement of Speed and Position}

\subsection{Introduction}

With the induction machine model presented in the previous chapter, a sensorless mean of obtaining the speed and position of the DFIG can be found. The speed and position are estimated using a modified PLL and a dq-axes aligner respectively. This chapter provides a detailed theoretical analysis, modeling and simulation of the sensorless algorithms.

\subsection{Control Approach}

Figure 3.1 shows the block diagram of the entire algorithm for the sensorless measurement of the speed and position of the DFIG. Because both machine and grid converters handle ac quantities, vector control techniques are used. The aim of vector control is to implement control schemes which produce high-dynamic performance similar to those used to control DC machines. With a suitable choice of reference frame, the ac currents appear as dc quantities in the steady-state.

The input signals are the $a b c$ stator currents and voltages and the $a b c$ rotor currents. The outputs are the $d q$ stator voltage and current, the $d q$ rotor current and the position and speed of the DFIG. The first step involves the extraction of the voltage angle $\theta_{s}$ using a phase-locked loop. Then, the stator currents and voltages are converted from ac quantities to dc quantities using the $d q$ reference frame. Next, using the slip frequency PLL, the speed of the DFIG is found. Finally, the dq-axes aligner allows us to obtain both 
the $d q$ rotor currents and the position of the DFIG. All the blocks shown in Figure 3.1 will be presented in the following subsections.

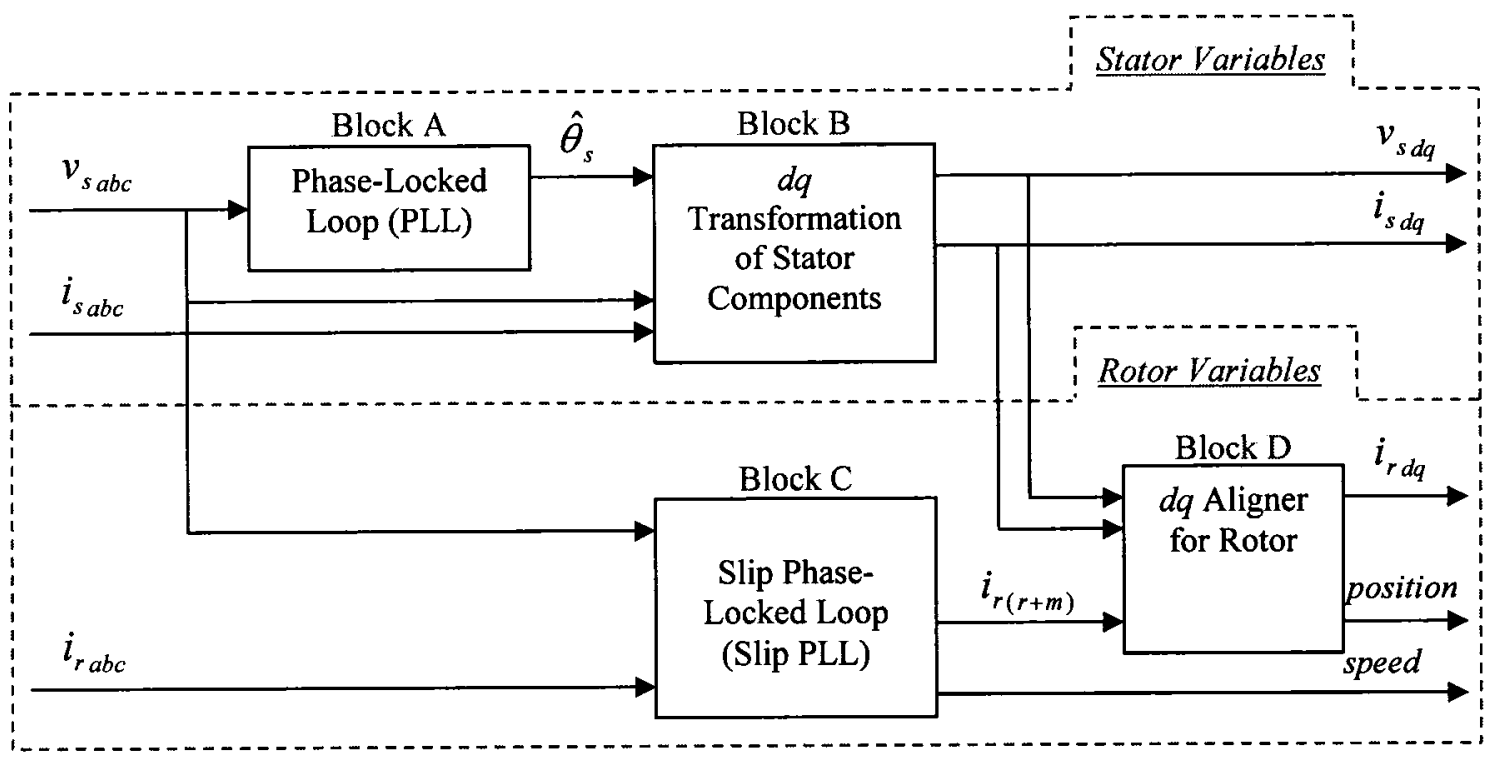

Figure 3.1: Sensorless measurement of speed and position of DFIG - overall block diagram

\subsection{Phase-Locked Loop}

A phase-locked loop (PLL) is a closed-loop feedback control system that generates and outputs a signal in relation to the frequency and phase of an input signal. A phase-locked loop circuit locks to the frequency and the phase of the input signals, automatically raising or lowering the frequency of a controlled oscillator until it is matched to the reference in both frequency and phase. It is often used in telecommunication, where the PLL ensures that a communication signal is locked on a specific frequency that can be used to generate, modulate and demodulate a signal. It is also used in power systems, where it is necessary to extract the frequency and phase of either the voltage or current. 


\subsubsection{PLL Algorithm}

The configuration of the PLL is shown in Figure 3.2, where $\theta$ is the real angle of the signal and $\hat{\theta}, \hat{\omega}$ are the estimated angle and frequency of the signal. It consists of a phase detector, a P-I controller and a voltage controlled oscillator (VCO). It is based on the PLL reported in [16], which was shown to have excellent phase tracking performance with broad frequency acquisition and good immunity against high frequency noise.

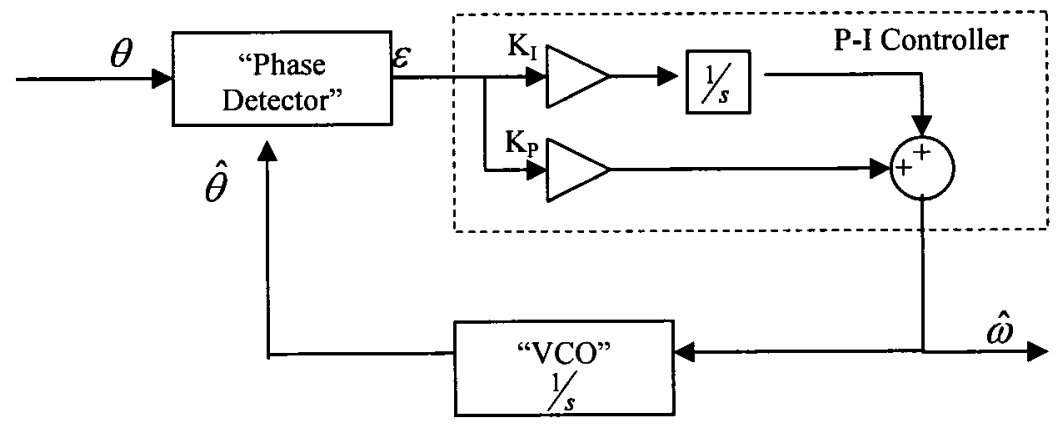

Figure 3.2: Phase-locked loop - block diagram

In the analysis of the algorithm, we assume balanced and symmetrical 3-phase $a b c$ signals. They are given as follows:

$$
\left[\begin{array}{l}
v_{a} \\
v_{b} \\
v_{c}
\end{array}\right]=\left[\begin{array}{c}
V \sin \left(\omega_{s} t+\varphi_{s}\right) \\
V \sin \left(\omega_{s} t+\varphi_{s}-\frac{2 \pi}{3}\right) \\
V \sin \left(\omega_{s} t+\varphi_{s}+\frac{2 \pi}{3}\right)
\end{array}\right]=\left[\begin{array}{c}
V \sin \left(\theta_{s}\right) \\
V \sin \left(\theta_{s}-\frac{2 \pi}{3}\right) \\
V \sin \left(\theta_{s}+\frac{2 \pi}{3}\right)
\end{array}\right]
$$

where $V$ is the peak magnitude of the signal (in this case the stator voltage), $\omega_{s}$ and $\varphi_{s}$ are the frequency $(\mathrm{rad} / \mathrm{s})$ and phase $(\mathrm{rad})$ of the sinusoidal signals, and $\theta_{s}(\mathrm{rad})$ is the angle of the signals. A detailed block diagram of the PLL is shown in Figure 3.3. 


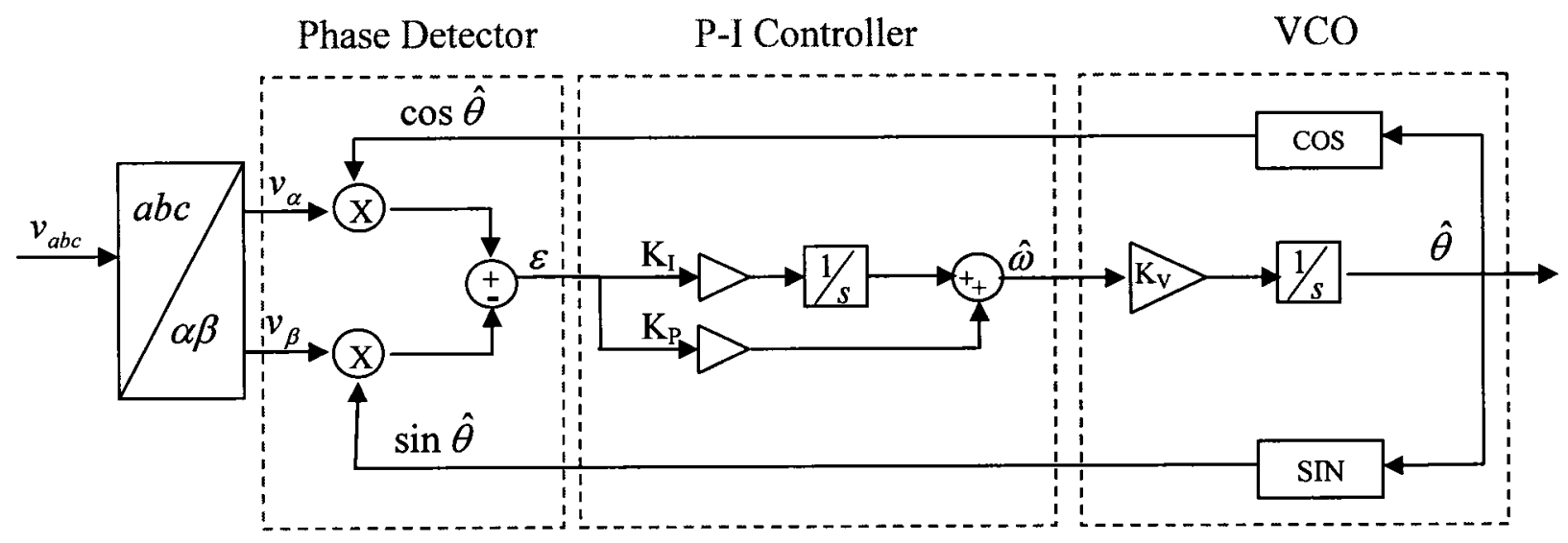

Figure 3.3: Stator phase-locked loop - detailed block diagram (Block A)

\subsubsection{Alpha-Beta Transformation}

The first step in the algorithm is to convert from the $a b c$ reference frame to the $\alpha \beta$ reference frame using the transformation below.

$$
\begin{aligned}
& {\left[\begin{array}{l}
v_{\alpha} \\
v_{\beta} \\
v_{0}
\end{array}\right]=K_{a b c T O \alpha \beta} \times\left[\begin{array}{l}
v_{a} \\
v_{b} \\
v_{c}
\end{array}\right]} \\
& K_{a b c \text { TO } \alpha \beta}=\frac{2}{3} \times\left[\begin{array}{ccc}
1 & -0.5 & -0.5 \\
0 & \frac{\sqrt{3}}{2} & -\frac{\sqrt{3}}{2} \\
0.5 & 0.5 & 0.5
\end{array}\right]
\end{aligned}
$$

With the $\alpha \beta$ transformation, we are able to extract the sine and cosine of the angle as shown below.

$$
\begin{aligned}
& {\left[\begin{array}{l}
v_{\alpha} \\
v_{\beta} \\
v_{0}
\end{array}\right]=\frac{2}{3} \times\left[\begin{array}{ccc}
1 & -0.5 & -0.5 \\
0 & -\frac{\sqrt{3}}{2} & \frac{\sqrt{3}}{2} \\
0.5 & 0.5 & 0.5
\end{array}\right] \times\left[\begin{array}{c}
V \sin \left(\theta_{s}\right) \\
V \sin \left(\theta_{s}-\frac{2 \pi}{3}\right) \\
V \sin \left(\theta_{s}+\frac{2 \pi}{3}\right)
\end{array}\right]} \\
& =\frac{2}{3} \times\left[\begin{array}{c}
V \sin \left(\theta_{s}\right)-0.5 V \sin \left(\theta_{s}-\frac{2 \pi}{3}\right)-0.5 V \sin \left(\theta_{s}+\frac{2 \pi}{3}\right) \\
-\frac{\sqrt{3}}{2} V \sin \left(\theta_{s}-\frac{2 \pi}{3}\right)+\frac{\sqrt{3}}{2} V \sin \left(\theta_{s}+\frac{2 \pi}{3}\right) \\
0.5 V \sin \left(\theta_{s}\right)+0.5 V \sin \left(\theta_{s}-\frac{2 \pi}{3}\right)+0.5 V \sin \left(\theta_{s}+\frac{2 \pi}{3}\right)
\end{array}\right]
\end{aligned}
$$




$$
\left[\begin{array}{l}
v_{\alpha} \\
v_{\beta} \\
v_{0}
\end{array}\right]=\left[\begin{array}{c}
V \sin \left(\theta_{s}\right) \\
V \cos \left(\theta_{s}\right) \\
0
\end{array}\right]
$$

\subsubsection{Phase Detector}

For the phase detector, we use the following trigonometric properties:

$$
\begin{aligned}
& \sin (A+B)=\sin A \cos B+\cos A \sin B \\
& \sin (A-B) \approx A-B \text { for } A \approx B
\end{aligned}
$$

By using the simple algorithm of the phase detector shown in the block diagram of Figure 3.3, we get the following result:

$$
\begin{aligned}
\varepsilon & =v_{\alpha} \cos \hat{\theta}-v_{\beta} \sin \hat{\theta} \\
& =V \sin \theta \cos \hat{\theta}-V \cos \theta \sin \hat{\theta} \\
& =V \sin (\theta-\hat{\theta})
\end{aligned}
$$

Hence, once PLL is phase-locked, i.e. $\theta \approx \hat{\theta}$, the above equation can be linearised, such that:

$$
\varepsilon \approx V(\theta-\hat{\theta})
$$

\subsubsection{Voltage Controlled Oscillator}

As shown in Figure 3.3, the block diagram of the voltage controlled oscillator includes a gain $K_{v}$, an integrator and sine and cosine generator. The input of the VCO is the estimated frequency $\hat{\omega}$ and the outputs are estimated angle $\hat{\theta}, \cos \hat{\theta}$ and $\sin \hat{\theta}$. Hence, the relation between the output and input is given as:

$$
\frac{\hat{\theta}}{\hat{\omega}}=K_{v} \frac{1}{s}
$$




\subsubsection{Design P-I Controller}

The P-I controller must be designed for quick phase tracking performance (the overall transfer function must have a magnitude of 1 and no phase delay below $10 \mathrm{~Hz}$ ) and good immunity against high frequency noise (the overall transfer function must have a magnitude close to 0 for above $1 \mathrm{kH}$ ). The transfer function relation of the P-I controller as shown in Figure 3.3 is:

$$
\frac{\hat{\omega}}{\varepsilon}=K_{P}+K_{I} \frac{1}{s}
$$

Using the above equations (3.7), (3.8) and (3.9), we can find the linearised overall system equation, which is given below.

$$
\begin{aligned}
& \frac{\hat{\omega}}{\varepsilon} \times \frac{\hat{\theta}}{\hat{\omega}}=\frac{\hat{\theta}}{\varepsilon}=K_{V} \frac{1}{s} \times\left(K_{P}+K_{I} \frac{1}{s}\right) \\
& \text { and } \varepsilon=V(\theta-\hat{\theta})=\frac{\hat{\theta}}{K_{V} \frac{1}{s} \times\left(K_{P}+K_{I} \frac{1}{s}\right)} \text { and if we make } K_{V}=1 \\
& \frac{\hat{\theta}}{\theta}=\frac{V \cdot\left(s K_{p}+K_{I}\right)}{s^{2}+s S K_{P}+S K_{I}}
\end{aligned}
$$

In our experimental setup, the value of the voltage $(V)$ is $170 \mathrm{~V}$ and the $K_{P}$ and the $K_{I}$ values are set to 10 and 40 respectively. The transfer function of the system becomes:

$$
\frac{\hat{\theta}}{\theta}=\frac{1700 s+6800}{s^{2}+1700 s+6800}
$$

The Bode plot is shown in Figure 3.4. We see from the Bode diagram of the entire system of the PLL, that it acts like a low-pass filter, eliminating high frequency noise (amplitude $-10 \mathrm{db}$ at $4 \mathrm{kH}$ ), without introducing a time delay at low frequencies (nearly 0 
deg. phase delay below $10 \mathrm{~Hz}$ ). Hence, the PLL can reduce the effect of any harmonic distortion and any unbalances in the measured signals. Simulations results of the performance of the PLL are shown section 3.5 (slip-PLL).

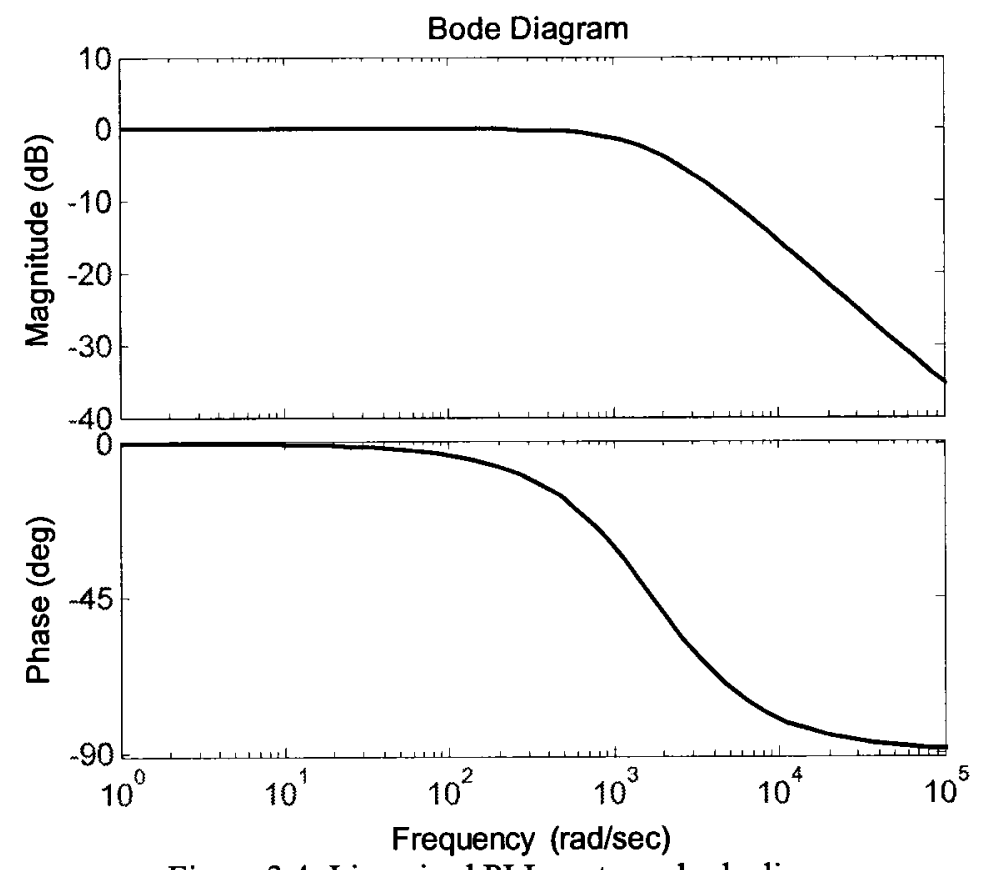

Figure 3.4: Linearised PLL system - bode diagram

\subsection{Stator dq Reference Transformation}

The next step in the algorithm involves transforming the stator voltage and currents into $d q$ components. The transformation from $\alpha \beta$ to $d q$ is shown below.

$$
\begin{aligned}
& {\left[\begin{array}{l}
S_{d} \\
S_{q}
\end{array}\right]=K_{\alpha \beta T O d q} \times\left[\begin{array}{l}
S_{\beta} \\
S_{\alpha}
\end{array}\right]} \\
& K_{\alpha \beta T O d q}=\left[\begin{array}{ll}
\cos \theta_{s} & \sin \theta_{s} \\
\sin \theta_{s} & -\cos \theta_{s}
\end{array}\right]
\end{aligned}
$$

where $S$ is the stator voltage or current. As was mentioned in section 2.4, we are using voltage-based rotating frames, where changes in the direct $(d)$ component will lead to active power changes; changes in the quadrature $(q)$ component will lead to reactive power changes. A note regarding the stator $d q$ transformation is that if we look at the 
$d q$ voltages, where $\hat{\theta}_{s}$ is the estimated angle of the stator voltage, we get the following results:

$$
\begin{aligned}
{\left[\begin{array}{l}
v_{d} \\
v_{q}
\end{array}\right] } & =\left[\begin{array}{ll}
\cos \hat{\theta}_{s} & \sin \hat{\theta}_{s} \\
\sin \hat{\theta}_{s}-\cos \hat{\theta}_{s}
\end{array}\right] \times\left[\begin{array}{l}
v_{\beta} \\
v_{\alpha}
\end{array}\right]=\left[\begin{array}{l}
v_{\beta} \cos \hat{\theta}_{s}+v_{\alpha} \sin \hat{\theta}_{s} \\
v_{\beta} \sin \hat{\theta}_{s}-v_{\alpha} \cos \hat{\theta}_{s}
\end{array}\right] \\
& =\left[\begin{array}{l}
V \cos \theta \cos \hat{\theta}_{s}+V \sin \theta \sin \hat{\theta}_{s} \\
V \cos \theta \sin \hat{\theta}_{s}-V \sin \theta \cos \hat{\theta}_{s}
\end{array}\right]=\left[\begin{array}{l}
V \\
0
\end{array}\right]
\end{aligned}
$$

That is, from the $d q$ transformation of the stator voltage, the $q$ component will be zero, whereas the $d$ component is equal to the peak value of the stator voltage.

\subsubsection{Real and Reactive Power Calculation}

In $d q$ reference frame, the real and reactive power at the stator can be measured as [19]:

$$
\begin{aligned}
& P_{s}=\frac{3}{2}\left(v_{s d} i_{s d}+v_{s q} i_{s q}\right) \\
& Q_{s}=\frac{3}{2}\left(v_{s q} i_{s d}-v_{s d} i_{s q}\right)
\end{aligned}
$$

Given that $v_{q s}=0$, we get :

$$
\begin{aligned}
& P_{s}=\frac{3}{2} v_{s d} i_{s d} \\
& Q_{s}=-\frac{3}{2} v_{s d} i_{s q}
\end{aligned}
$$

Hence, we see that the real and reactive powers are decoupled and can be independently controlled by the direct and quadrature components of the stator current.

\subsection{Sensorless Measurement of Speed}

In order to measure the speed of the doubly-fed induction machine, we use an extension of the traditional PLL. As presented in [11], by extracting the angle of the stator voltage and the angle of the rotor current, we are able to extract the speed of the 
induction machine. The algorithm is similar to the block diagram of Figure 3.2, the major difference being in the phase detector.

\subsubsection{Slip Frequency PLL Algorithm}

From theory, we know that induction machine works by inducing voltages and currents in the rotor. If the rotor is locked, the rotor will have the same frequency as the stator. At synchronous speed, the rotor current frequency will be zero. For any speed in between, the rotor frequency is directly proportional to the difference between the speed of the magnetic field and the speed of the rotor. The slip is defined as:

$$
s=\frac{n_{s y n}-n_{m}}{n_{s y n c}}
$$

The rotor frequency can be defined as:

$$
f_{r}=s f_{s}
$$

where $f_{r}$ is the rotor frequency, $f_{s}$ is the stator frequency and $n_{s y n}$ and $n_{m}$ are

the synchronous and machine speeds respectively in revolutions per minute (rpm). The synchronous speed is defined as:

$$
n_{s y n}=\frac{120}{P} f_{s}
$$

where $P$ is the number of poles.

From the above equations, we find that the frequencies in steady-state are related as:

$$
f_{s}=f_{r}+f_{m}
$$

Hence, given $f_{s}$, which can be extracted from the stator voltages and $f_{r}$, which can be extracted from the rotor currents, we can obtain the frequency $f_{m}$, which is the mechanical speed of the rotor. The detailed block diagram is shown in Figure 3.5. The steps of the algorithm are explained in the following subsections. 


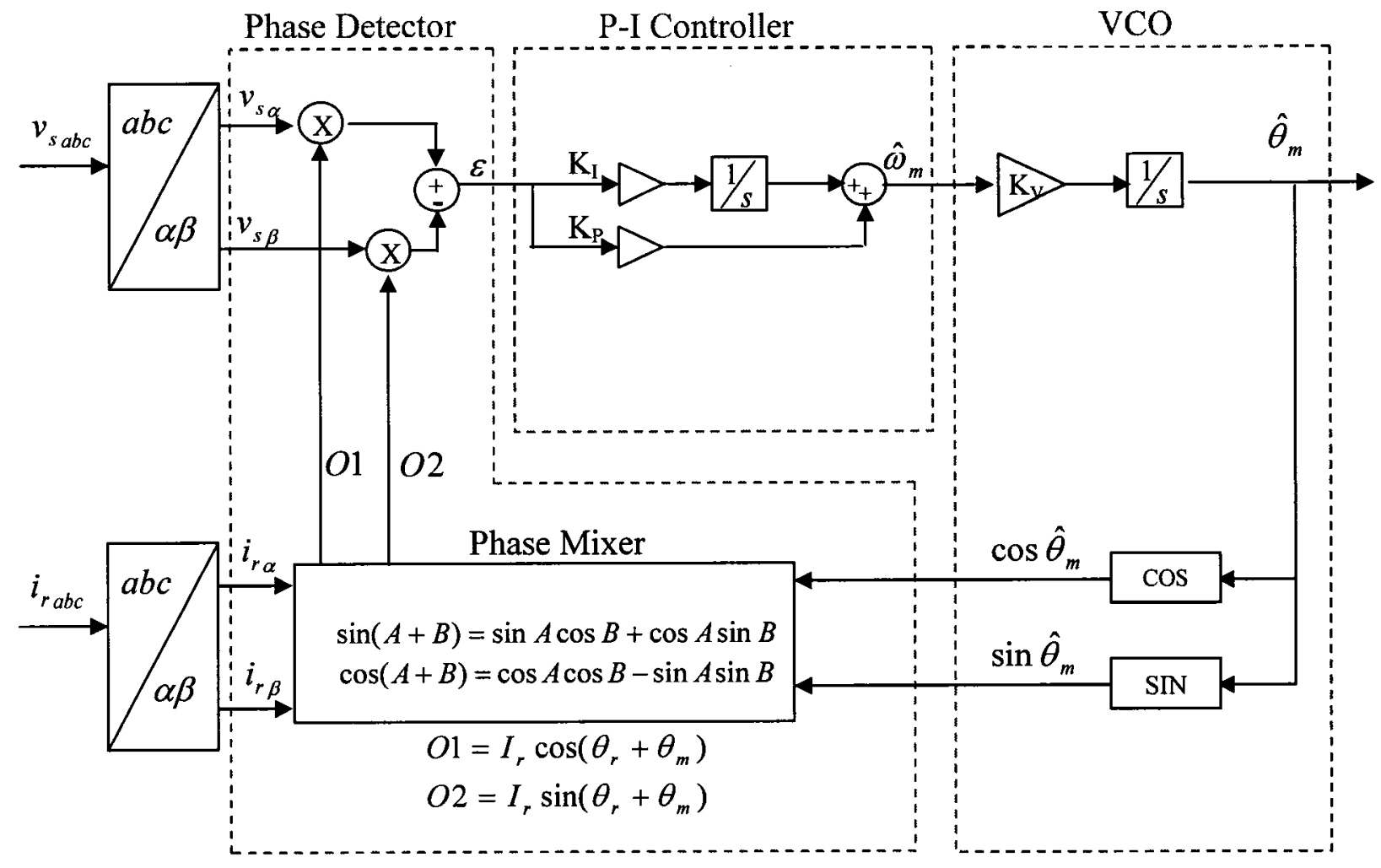

Figure 3.5: Slip-frequency PLL - detailed block diagram (Block C)

\subsubsection{Alpha-Beta Transformation}

The first step is to convert both the rotor currents and the stator voltages to a $\alpha \beta$ reference frame. The $\alpha \beta$ rotor currents and stator voltages become:

$$
\begin{aligned}
& {\left[\begin{array}{l}
v_{s \alpha} \\
v_{s \beta}
\end{array}\right]=\left[\begin{array}{l}
V_{s} \sin \theta_{s} \\
V_{s} \cos \theta_{s}
\end{array}\right]} \\
& {\left[\begin{array}{l}
i_{r \alpha} \\
i_{r \beta}
\end{array}\right]=\left[\begin{array}{l}
I_{r} \sin \left(\theta_{r}\right) \\
I_{r} \cos \left(\theta_{r}\right)
\end{array}\right]}
\end{aligned}
$$

where $V_{s}$ and $I_{r}$ are the peak amplitude of the stator voltage and rotor current respectively and $\theta_{s}$ and $\theta_{r}$ are the stator and rotor angles respectively .

\subsubsection{Phase detector}

For the phase detector, we use the same trigonometric properties (3.5) and (3.6).

By using the simple algorithm shown in Figure 3.5, we get the following result:

$$
\varepsilon=v_{\alpha} I_{r} \cos \left(\theta_{r}+\theta_{m}\right)-v_{\beta} I_{r} \sin \left(\theta_{r}+\theta_{m}\right)
$$




$$
\begin{aligned}
& =V_{s} I_{r} \sin \theta_{s} \cos \left(\theta_{r}+\theta_{m}\right)-V_{s} I_{r} \cos \theta_{s} \sin \left(\theta_{r}+\theta_{m}\right) \\
& =V_{s} I_{r} \sin \left(\theta_{s}-\left(\theta_{r}+\theta_{m}\right)\right)
\end{aligned}
$$

where $\theta_{m}$ is the machine position. Hence, once the PLL is phase-locked, i.e. $\theta_{s} \approx\left(\theta_{r}+\theta_{m}\right)$, the above equation can be linearized, such that:

$$
\varepsilon \approx V_{s} I_{r}\left(\theta_{s}-\left(\theta_{r}+\theta_{m}\right)\right)
$$

In order to obtain the signals $I_{r} \cos \left(\theta_{r}+\theta_{m}\right)$ and $I_{r} \sin \left(\theta_{r}+\theta_{m}\right)$, we use a phase mixer as shown in Figure 3.5. The phase mixer is based on the trigonometric properties shown below. In our case, $A=\theta_{r}$ and $B=\theta_{m}$.

$$
\begin{aligned}
& \sin (A+B)=\sin A \cos B+\cos A \sin B \\
& \cos (A+B)=\cos A \cos B-\sin A \sin B
\end{aligned}
$$

\subsubsection{Voltage Controlled Oscillator}

Figure 3.5 shows the block diagram of the voltage controlled oscillator used for the slip frequency PLL. It is identical to the traditional PLL. Hence, the relation between the output and input is given as:

$$
\frac{\theta_{m}}{\omega_{m}}=K_{v} \frac{1}{s}
$$

\subsubsection{Design P-I Controller}

The P-I controller shown in Figure 3.5 is similar to the traditional PLL. The P-I controller must be designed for quick phase tracking performance (the overall transfer function must have a magnitude of 1 and no phase delay below $10 \mathrm{~Hz}$ ) and good immunity against high frequency noise (the overall transfer function must have a magnitude close to 0 above $1 \mathrm{kH}$ ). The transfer function relation of the P-I controller is:

$$
\frac{\hat{\omega}_{m}}{\varepsilon}=K_{P}+K_{I} \frac{1}{s}
$$


Similar to the traditional PLL, the transfer function of the system is:

$$
\frac{\hat{\omega}_{m}}{\omega_{m}}=\frac{V_{s} I_{r}\left(s K_{p}+K_{I}\right)}{s^{2}+s V_{s} I_{r} K_{P}+V_{s} I_{r} K_{I}}
$$

In our experimental setup, the value of the voltage is $170 \mathrm{~V}$ and the rotor current varies between 1 and $3 \mathrm{~A}$, the $K_{P}$ and the $K_{I}$ values are set to 10 and 40 respectively. The transfer function of the system hence becomes:

$$
\frac{\hat{\omega}_{m}}{\omega_{m}}=\frac{I_{r}(1700 s+6800)}{s^{2}+1700 I_{r} s+6800 I_{r}}
$$

The Bode plot is shown in Figure 3.6 for different amplitudes of rotor current. We see from the Bode diagram of the entire system of the slip PLL, that it acts like a lowpass filter, eliminating high frequency noise (amplitude $-10 \mathrm{db}$ at $4 \mathrm{kH}$ ), without introducing a time delay at low frequencies (close to 0 phase delay below $10 \mathrm{~Hz}$; maximum phase delay of $3 \mathrm{deg}$. at $100 \mathrm{~Hz}$ )

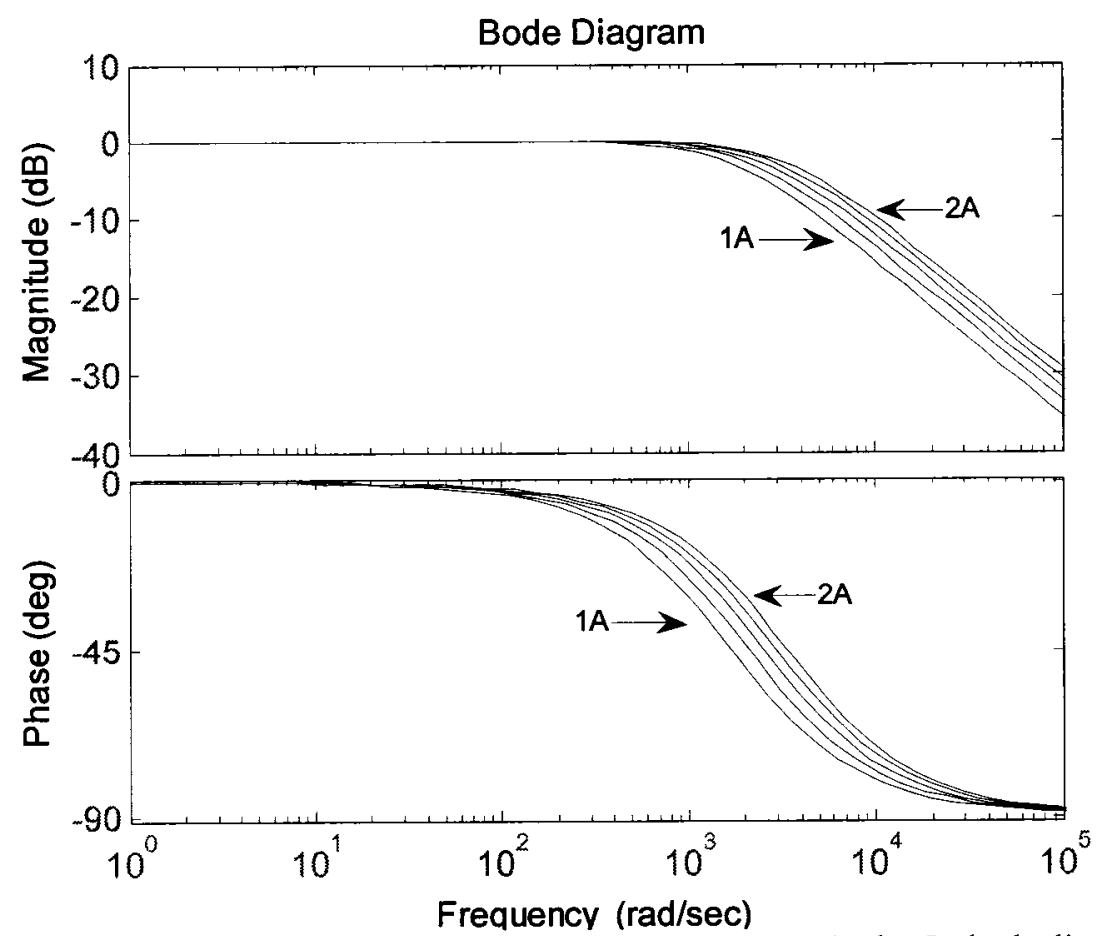

Figure 3.6: Linearised slip PLL system for different rotor current magnitudes $I_{r}$ - bode diagram 


\subsubsection{Simulation Results of Speed Sensorless Algorithm}

In order to test the accuracy of the speed sensorless algorithm, simulations were run using Matlab/Simulink. The tests were intended to find how accurately the slip frequency PLL estimates the speed in dynamic situations. The DFIG is represented by the software model of a wound-rotor induction machine (WRIM). The WRIM is excited by a three-phase voltage source at the stator and the rotor is shorted, as shown in Figure 3.7. In order to allow a larger range of rotor speed, resistance is added to the rotor. The input torque of the machine is varied both positive (motor) and negative (generator) values. The parameter values used are shown in Table 3.1, which are typically the values of a $60 \mathrm{~Hz}, 2 \mathrm{MW}$ wind turbine. As shown in Figure 3.8, the estimated speed is compared with the real speed. From the results, we see that the sensorless measurement of the speed is able to track the real speed with no steady state error. There is a discontinuity around the synchronous speed due to the fact that at that frequency, the rotor current is zero. However, when the rotor is fed a voltage, as will be shown in chapter 5 , there is no discontinuity around the synchronous speed.

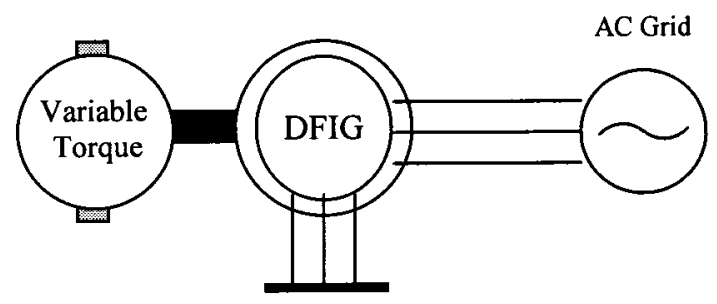

Figure 3.7: Speed sensorless algorithm - circuit diagram of simulation setup

Table 3.1: Machine parameters of a typical induction machine used in wind energy conversion systems

\begin{tabular}{|c|c|}
\multicolumn{2}{|c|}{$(60 \mathrm{~Hz}, 2 \mathrm{MW}$ 4-pole) [27] } \\
\hline Machine Parameter & Value (p.u.) \\
\hline $\mathrm{X}_{\mathrm{m}}$ & 3.0 \\
\hline $\mathrm{X}_{\mathrm{s}}$ & 0.10 \\
\hline $\mathrm{R}_{\mathrm{s}}$ & 0.01 \\
\hline $\mathrm{X}_{\mathrm{r}}$ & 0.08 \\
\hline $\mathrm{R}_{\mathrm{r}}$ & 0.01 \\
\hline
\end{tabular}




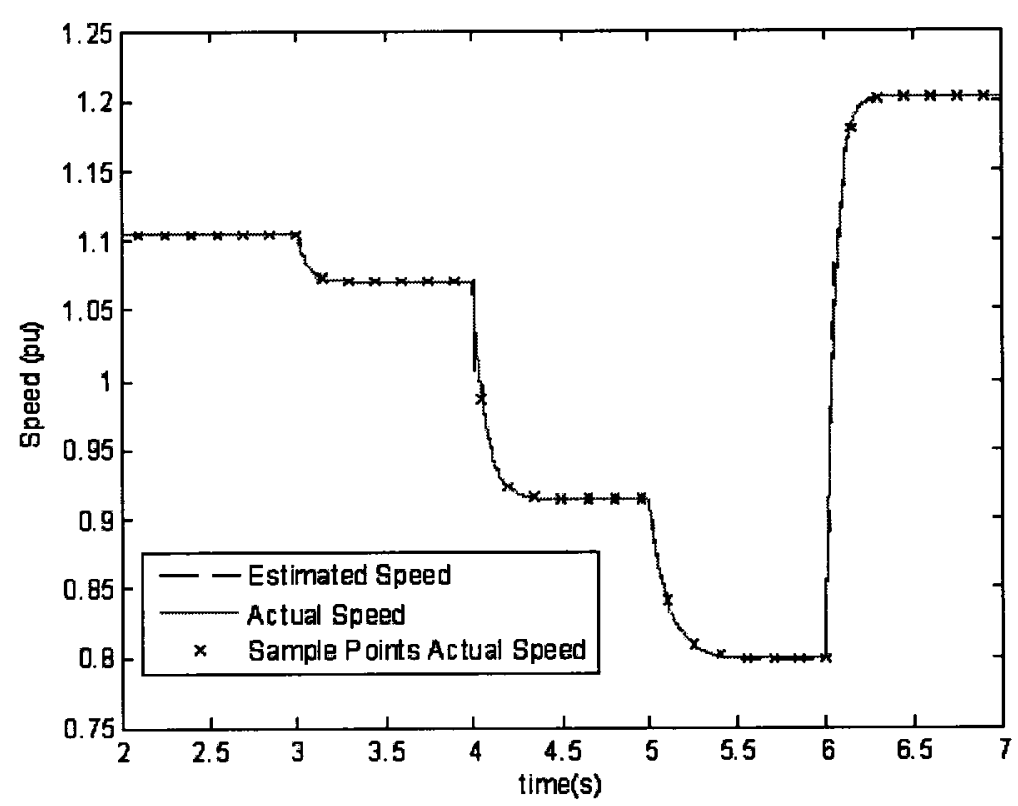

a)

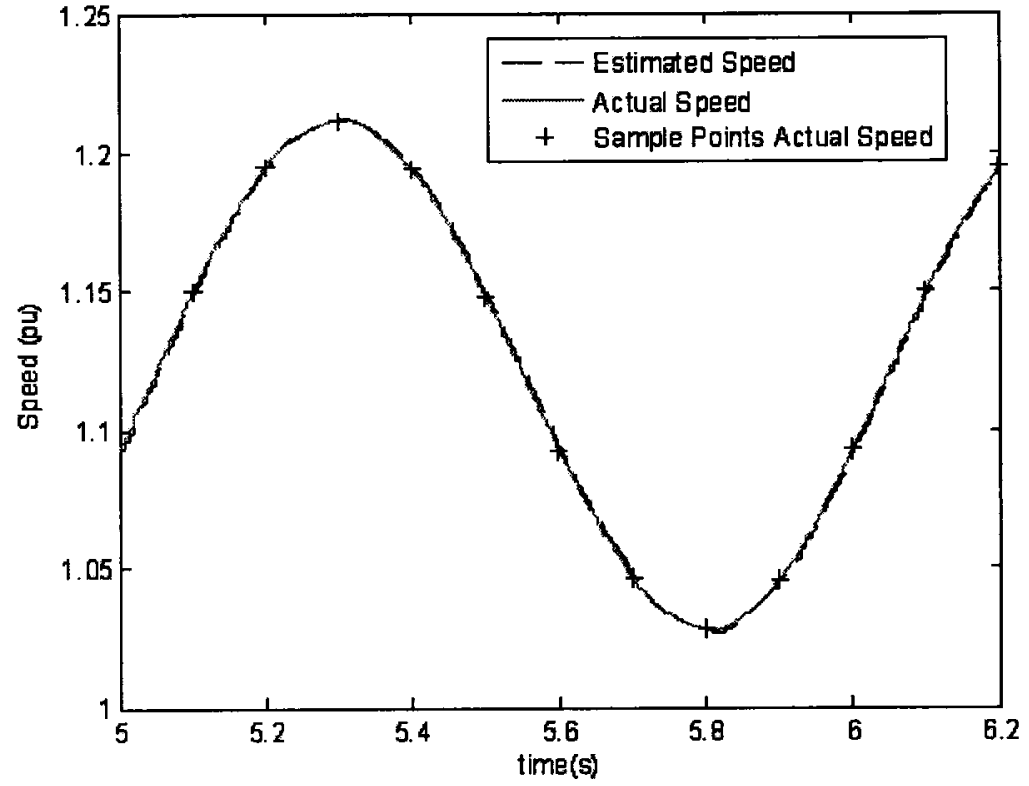

b)

Figure 3.8: Speed tracking - sinusoidal input torque, shorted rotor, resistance added at rotor - machine parameters of a $2 \mathrm{MW}$ induction machine - variables: estimated and actual speeds vs time

a) above and below synchronous speed b) above synchronous speed, setpoint 1.125 of rated speed

Although the PLL has the ability to significantly reduce high frequency noise, the drawback is that it has a slower response for quick transient changes. As shown in Figure 3.9, for a step change in the input torque, the PLL needs $0.1 \mathrm{~s}$ to track the real speed. Similarly, for a sinusoidal input torque of $5 \mathrm{~Hz}$, there is a small delay as shown in Figure 
3.10, which is expected from the Bode diagram of Figure 3.6 where at higher frequencies there is a phase delay. Although the design would slow the response for high speed applications, this is not an issue in wind energy application, since wind variations (input torque) and variation of the power sent to the grid (load) are typically much slower than those typically found in other motor drive applications, and thus variations in speed are much slower. For a grid with a large low frequency harmonic content, it would also be required to further decrease the bandwidth of the PLL to reduce the generated noise of the estimated signal, making the response slower for quick transient changes.

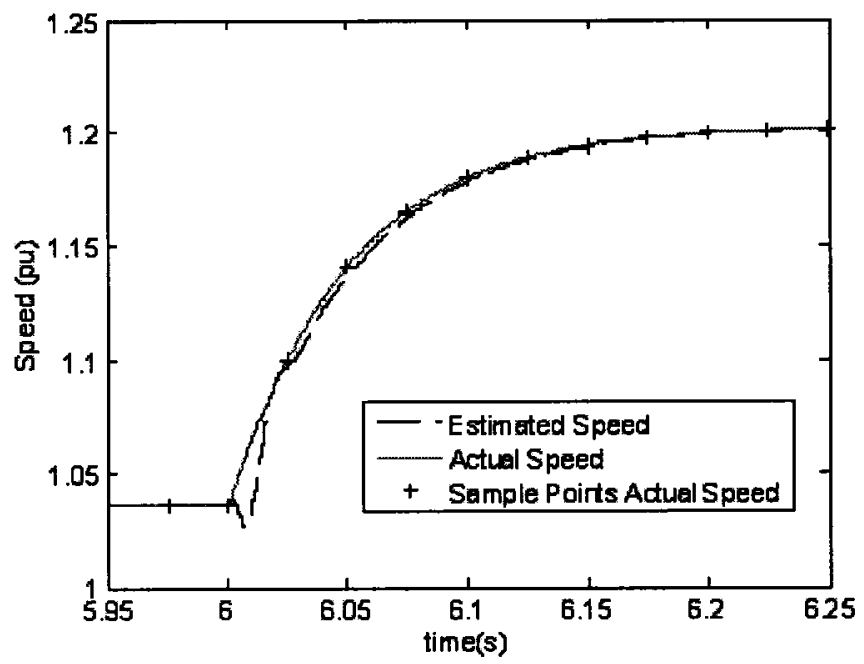

Figure 3.9: Speed tracking - step change in generator torque, shorted rotor, resistance added at rotor machine parameters of a $2 \mathrm{MW}$ induction machine - variables: estimated and actual speeds vs time

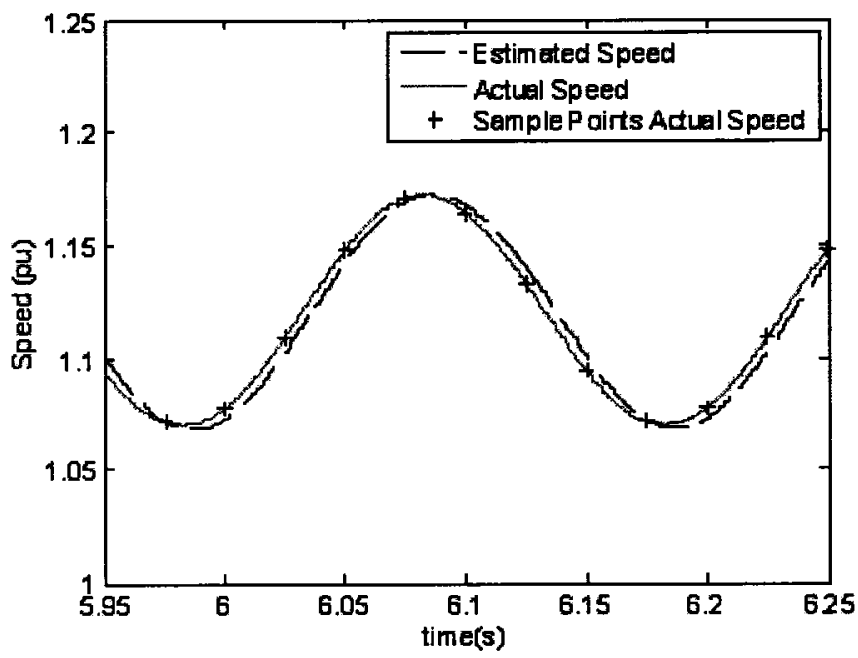

Figure 3.10: Speed tracking - sinusoidal generator torque $(5 \mathrm{~Hz})$, shorted rotor, resistance added at rotor machine parameters of a $2 \mathrm{MW}$ induction machine - variables: estimated and actual speeds vs time 


\subsection{Sensorless Measurement of Position}

The block diagram of the sensorless measurement of the position is shown in Figure 3.11. The position of the DFIG, often called the slip angle, is the integral of the rotor speed. First, the rotor parameters are converted to the $d q$ reference frame. Then, the dq-axes aligner aligns the rotor and stator axes. The outputs of the $d q$ aligner are the position of the DFIG and the correctly aligned $d q$ rotor currents. The different blocks of Figure 3.11 will be explained in the following subsections.

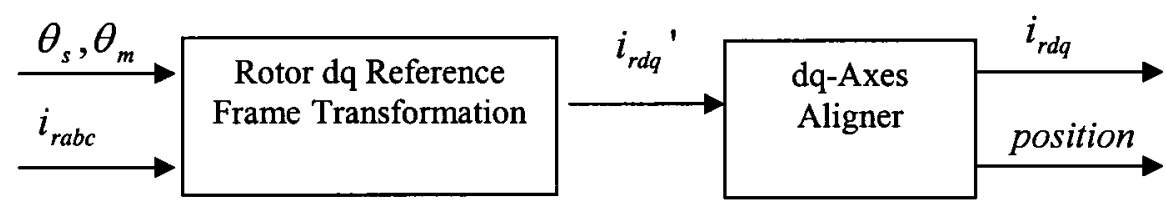

Figure 3.11: Sensorless measurement of position - block diagram (Block D)

\subsubsection{Transformation of Rotor Quantities to Stator dq Reference Frame}

From Figure 3.5, the output of the phase mixer are:

$$
\begin{aligned}
& I_{r} \cos \left(\theta_{r}+\theta_{m}\right) \\
& I_{r} \sin \left(\theta_{r}+\theta_{m}\right)
\end{aligned}
$$

Similar to the stator $d q$ reference frame, we use the stator $d q$ transformation (3.12) and given that $\omega_{r}+\omega_{m}-\omega_{s}=0$, we get :

$$
\begin{aligned}
{\left[\begin{array}{c}
i_{r d^{\prime}} \\
i_{r q}{ }^{\prime}
\end{array}\right] } & =\left[\begin{array}{cc}
\cos \hat{\theta}_{s} & \sin \hat{\theta}_{s} \\
\sin \hat{\theta}_{s}-\cos \hat{\theta}_{s}
\end{array}\right] \times\left[\begin{array}{c}
I_{r} \cos \left(\theta_{r}+\theta_{m}\right) \\
I_{r}\left(\sin \theta_{r}+\theta_{m}\right)
\end{array}\right]=\left[\begin{array}{l}
I_{r} \cos \left(\theta_{r}+\theta_{m}-\theta_{s}\right) \\
I_{r} \sin \left(\theta_{r}+\theta_{m}-\theta_{s}\right)
\end{array}\right] \\
& =\left[\begin{array}{c}
I_{r} \cos \left(\omega_{r} t+\omega_{m} t-\omega_{s} t+\varphi_{r}+\varphi_{m}-\varphi_{s}\right) \\
I_{r} \sin \left(\omega_{r} t+\omega_{m} t-\omega_{s} t+\varphi_{r}+\varphi_{m}-\varphi_{s}\right)
\end{array}\right]=\left[\begin{array}{c}
I_{r} \cos \left(\varphi_{r}+\varphi_{m}-\varphi_{s}\right) \\
I_{r} \sin \left(\varphi_{r}+\varphi_{m}-\varphi_{s}\right)
\end{array}\right]
\end{aligned}
$$

Although the rotor currents are rotating synchronously with the stator rotating frame, the frame is not aligned to the stator voltage $d q$ axes. There is a phase difference 
$\Phi$ between the stator and rotor rotating frames as shown in Figure 3.12, and hence, a dqaxes aligner is required.

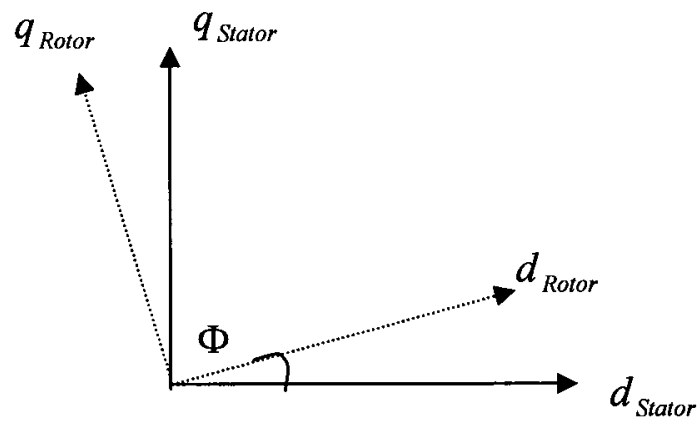

Figure 3.12: $\mathrm{D} q$ axes - rotor and stator - phase difference of $\Phi$ between stator and rotor axes

\subsubsection{Dq-Axes Aligner}

As reported in [11], the method of aligning the stator and rotor $d q$ axes consists of making $v_{s d}=V_{s}$, or equivalently, to make $v_{s q}=0$. However by making $v_{s d}=V_{s}$, it was found that there was a steady-state error in generator operation. Simulation results for a change from motor to generator operation of the estimated speed for both axes aligners is shown in Figure 3.13.

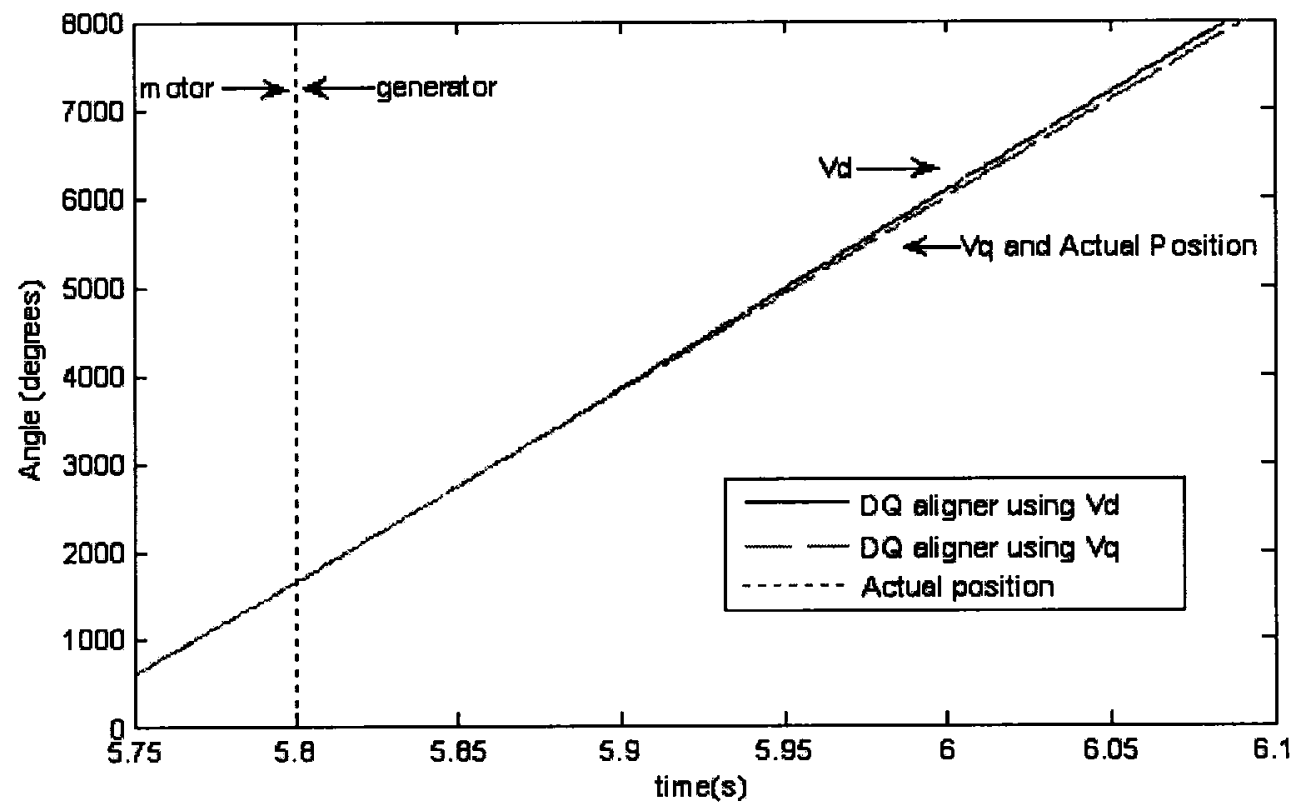

Figure 3.13: Position tracking - comparison between dq-axes aligners $V_{d}=V$ and $V_{q}=0$ (presence of steadystate error for $\mathrm{V}_{\mathrm{d}}$ aligner in generator mode) - estimated and actual positions vs time (both motor and generator operation) 
From the induction machine equations in section 2.5 , we find that:

$$
v_{s q}=R_{s} i_{s q}+\omega_{s}\left(L_{m} i_{r d}+L_{s} i_{s d}\right)
$$

where $L_{s s}=L_{m}+L_{s}$. Thus, using the algorithm of the block diagram of Figure 3.14, we can obtain the phase difference $\Phi$ between the rotor and stator axes. The calculated value of $v_{s q}$ is compared to the value of $V_{s q}$, and the error signal passes through a P-I controller to become the angle $\Phi$. The phase mixer rotates the phase of $i_{r d}{ }^{\prime}$ and $i_{r q}{ }^{\prime}$ by $\Phi$, giving the $d q$ components the rotor currents $i_{r d}$ and $i_{r q}$. Hence, once the rotor and stator axes are aligned, the angular position of the DFIG is given by:

$$
\text { Position }=\omega_{m} t+\phi_{m}+\Phi=\theta_{m}+\Phi
$$

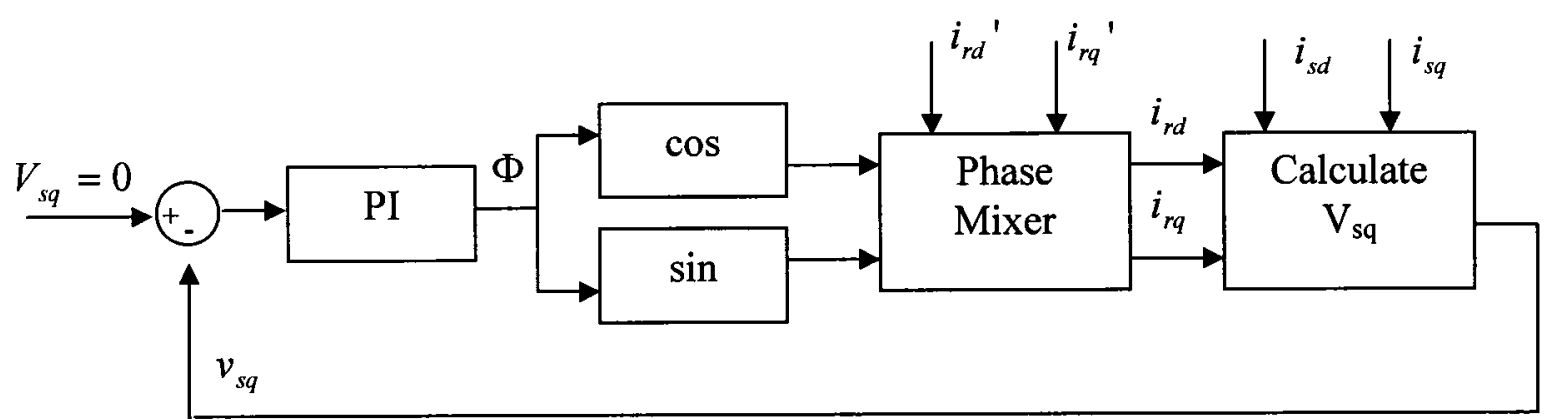

Figure 3.14: Dq-axes aligner - block diagram

\subsubsection{Simulation Results of Position Sensorless Measurement}

Using the exact same setup and input torque as section 3.5 .2 , we obtain the simulation results shown in Figure 3.15. We see that the estimated position tracks the real position even during transient changes in input torque. 


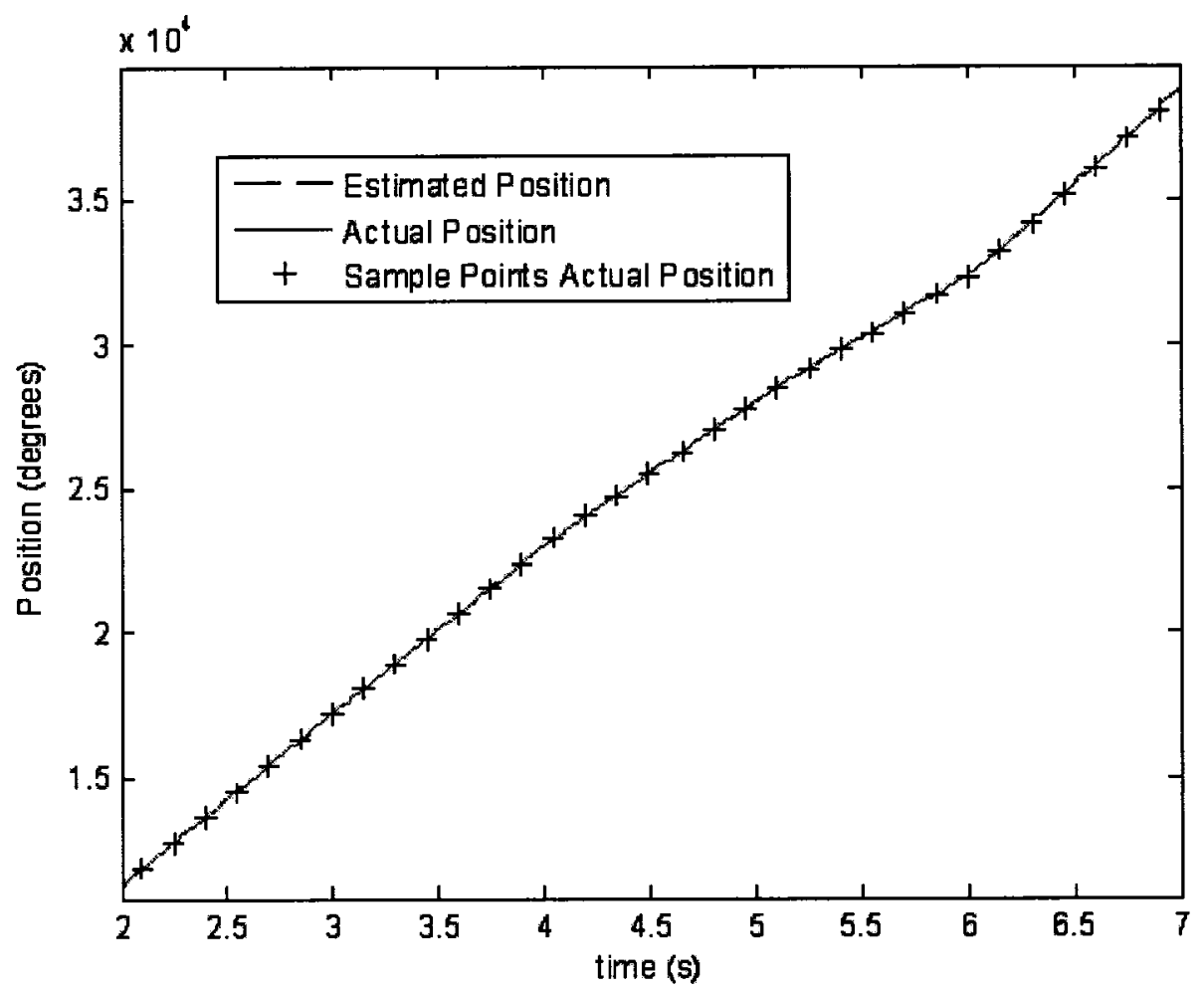

a)

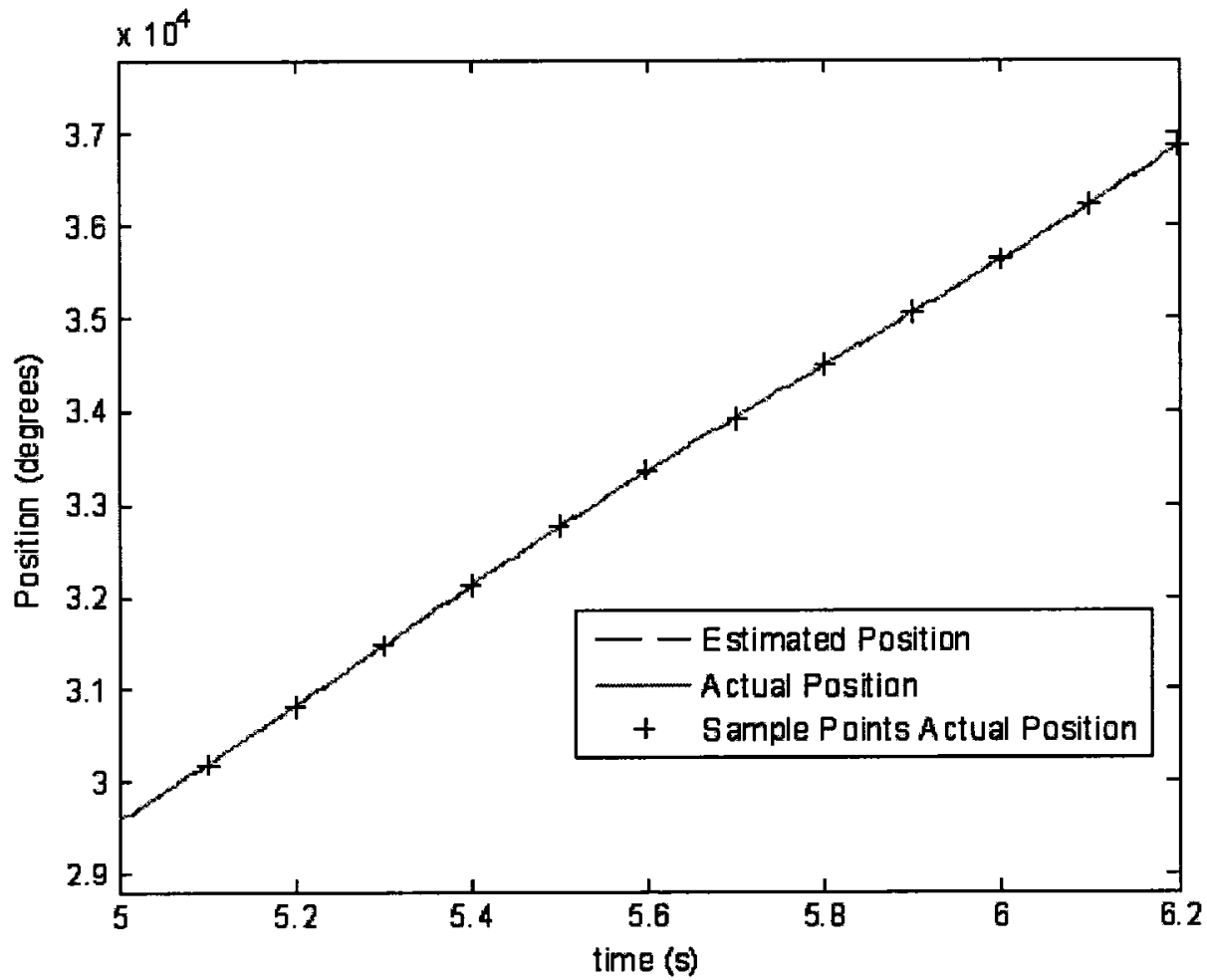

b)

Figure 3.15: Position tracking - variable input torque, shorted rotor, resistance added at rotor - machine parameters of a $2 \mathrm{MW}$ induction machine - estimated and actual positions vs time

a) speed varied above and below synchronous speed b) speed varied above synchronous speed only, setpoint 1.125 of rated speed 


\section{Chapter 4: Comparison Between PLL and Machine-Equations Based Sensorless Algorithms}

\subsection{Introduction}

As mentioned earlier, most algorithms measure the rotor currents in one reference frame, and estimate rotor currents in another reference frame (using the machine equations of Chapter 2) and compare them to estimate the rotor position. In order to obtain the speed of the machine, the angle is then differentiated. An example of the this type of implementation is based on the L. Morel, H. Godfroid, A. Miraian and J.M. Kauffmann algorithm [9] succinctly shown in the following subsection. Two important issues regarding sensorless algorithms are its effect due to noise and its robustness to changes in machine parameters which will be investigated in this chapter. Also, the performance of the sensorless algorithm during a fault is evaluated.

\subsection{Sensorless Algorithm Based on Machine Equations}

From the alpha-beta transformation, we can obtain the cosine and sine of the rotor and stator quantities:

$$
\begin{array}{ll}
\cos \theta_{s}=\frac{V_{s \beta}}{\sqrt{V_{s \alpha}{ }^{2}+V_{s \beta}^{2}}} & \cos \theta_{r}=\frac{I_{r \beta}}{\sqrt{I_{r \alpha}{ }^{2}+I_{r \beta}{ }^{2}}} \\
\sin \theta_{s}=\frac{V_{s \alpha}}{\sqrt{V_{s \alpha}{ }^{2}+V_{s \beta}^{2}}} & \sin \theta_{r}=\frac{I_{r \alpha}}{\sqrt{I_{r \alpha}{ }^{2}+I_{r \beta}{ }^{2}}}
\end{array}
$$


From the machine equations, we obtain (note that variables can also be obtained from the flux equations) the estimated $d q$ rotor currents:

$$
\begin{array}{ll}
i_{r d}=\frac{-\omega_{s} L_{s s} i_{s d}-R_{s} i_{s q}+v_{s q}}{\omega_{s} L_{m}} & \cos \theta=\frac{i_{r d}}{\sqrt{i_{r d}{ }^{2}+i_{r q}{ }^{2}}} \\
i_{r q}=\frac{R_{s} i_{s d}-\omega_{s} L_{s s} i_{s q}-v_{s d}}{\omega_{s} L_{m}} & \sin \theta=\frac{i_{r q}}{\sqrt{i_{r d}{ }^{2}+i_{r q}{ }^{2}}}
\end{array}
$$

where $L_{s s}=L_{m}+L_{s}$. The angle of the $d q$ rotor currents is given as $\theta=\theta_{m}+\theta_{r}-\theta_{s}$, where $\theta_{s}$ and $\theta_{r}$ are the stator and rotor angles and $\theta_{m}$ is the position. Using the phase mixers, we obtain:

$$
\cos \theta_{m} ; \sin \theta_{m} \rightarrow \theta_{m}=a \tan \theta_{m}
$$

Hence, in order to obtain the speed, the position is differentiated:

$$
\omega_{m}=\frac{d \theta_{m}}{d t}
$$

\subsection{Performance of Sensorless Algorithms - Immunity to Noise}

Given that $\frac{d(a \tan )}{d t}$ contributes to significant noise, a low pass filter is added in the output to eliminate the discontinuities. A comparison is made between the machine equation based algorithm and the slip frequency algorithm. The simulation setup is identical to Figure 3.7. In order to emulate the conditions found in an experimental setup, high frequency noise is added both to the rotor and stator quantities. Also, the ac grid voltage is unbalanced ( $V_{a}=1.0$ p.u., $V_{b}=0.95$ p.u. and $V_{c}=1.05$ p.u.). The exact machine parameters are used in the algorithm. The input torque is varied between 0.5 and 1.5 p.u. to obtain a variation of speed between 1 and 1.15 p.u. of the synchronous speed. From the simulation results of Figures 4.1 and 4.2, we see that both algorithms have a 
very small difference in error in position. However, we see a significant difference in the performance of the speed estimation, where the machine equation based algorithm has significant noise in the estimated speed signal.

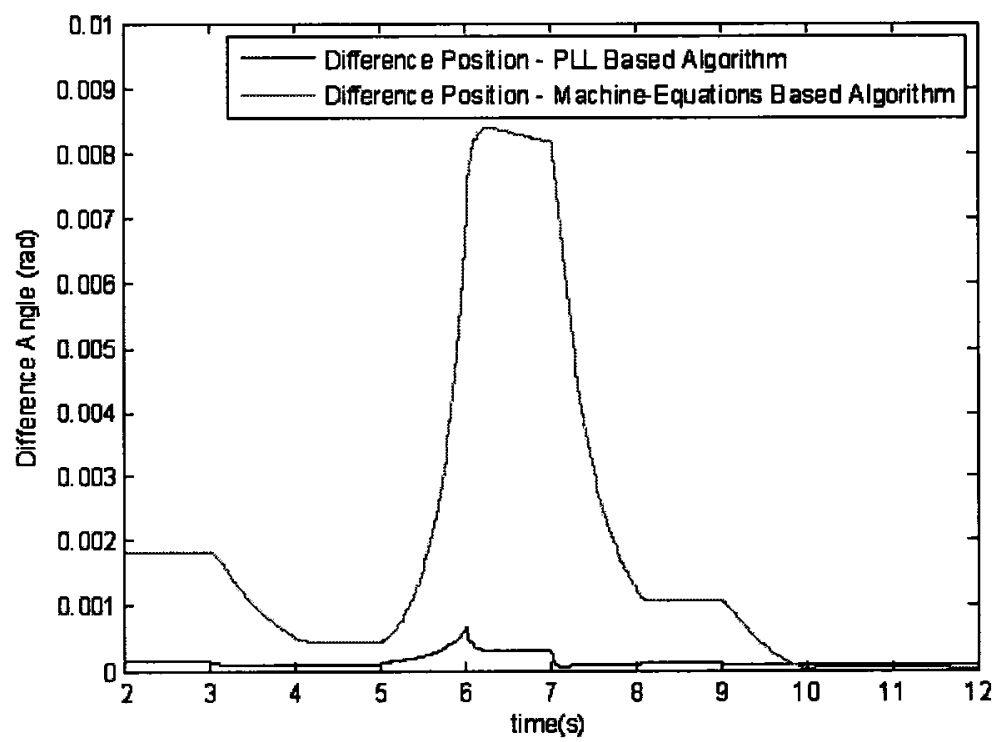

Figure 4.1: Position tracking - variable generator torque, shorted rotor, $\mathrm{R}$ added to rotor - exact machine parameters used in the sensorless algorithms - noise added to signals - variables: difference between actual position and estimated positions using both the PLL and machine-equations based algorithms
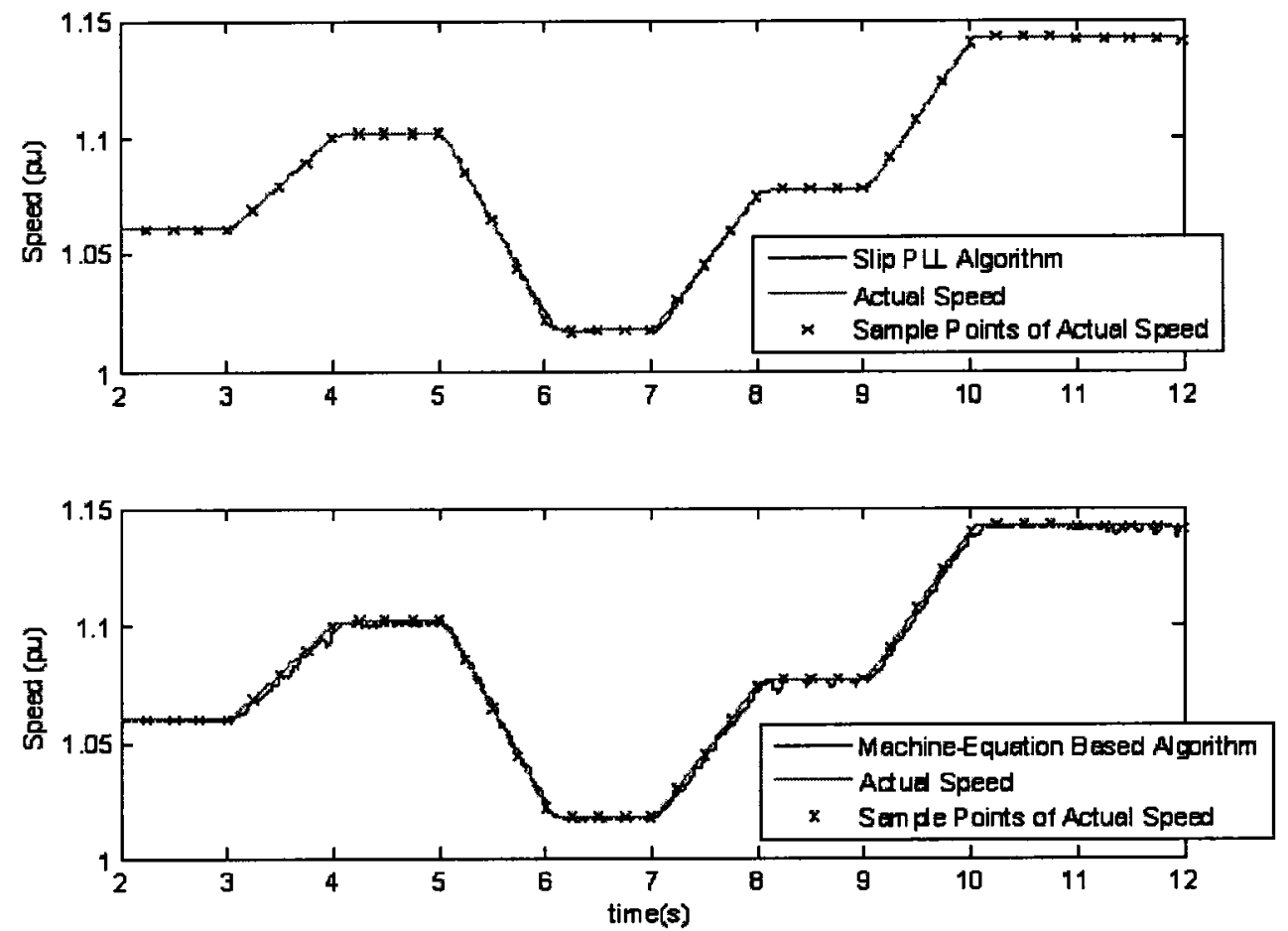

Figure 4.2: Position tracking - variable generator torque, shorted rotor, resistance added to rotor - exact machine parameters used in the sensorless algorithms - noise added to signals - variables: actual speed and estimated speeds using both the PLL and machine-equations based algorithms 


\subsection{Performance of Sensorless Algorithms - Robustness to Changes in Machine Parameters}

In order to test the robustness of both algorithms, the next test involves testing for changes in machine parameters. For instance, saturation and nonlinearity of the inductance of the iron core, as well as temperature dependence of resistors, may cause variations of inductances and resistances in the induction machine. The simulation results are shown in Figure 4.3 for the estimated positions. In the case of the speed, we get identical results, and hence are not shown. We see from the different parameters from equations (3.30) and (4.2), that $L_{m}$ has the largest effect since $L_{m}$ is much bigger than $L_{s}$ and $R_{s}$. This is also seen in the results in Figure 4.3, where a change in $L_{m}$ causes the largest steady-state error.

Both algorithms have similar steady-state errors in the estimation of position. This issue will be addressed in the design of the decoupled P-Q control algorithm in the next chapter. However, as mentioned earlier, the advantage of the PLL based algorithm is that the speed is robust for all changes of machine parameters and is better immune to noise.

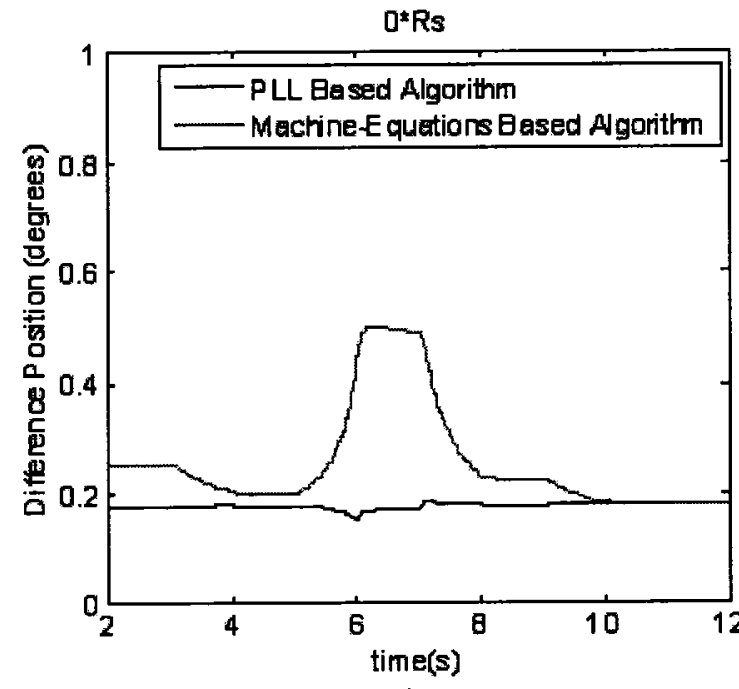

a)

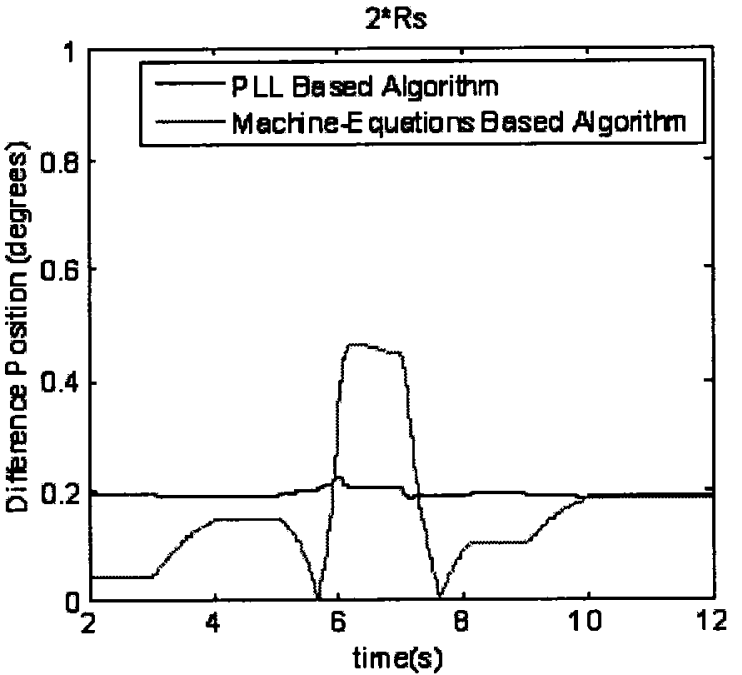

b) 


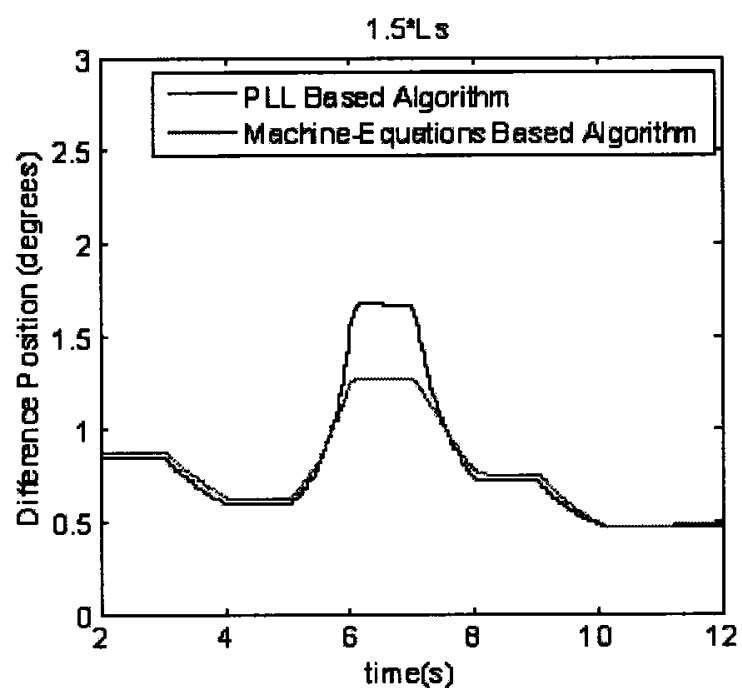

c)

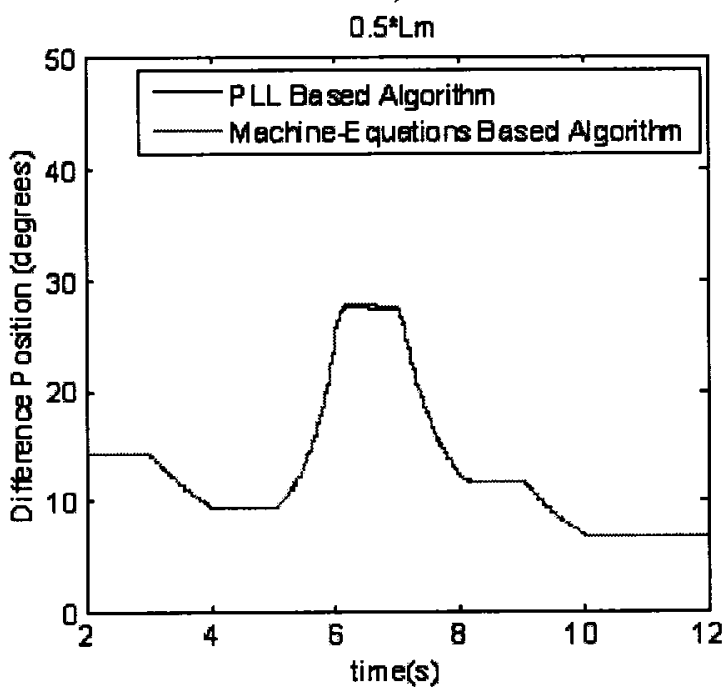

e)

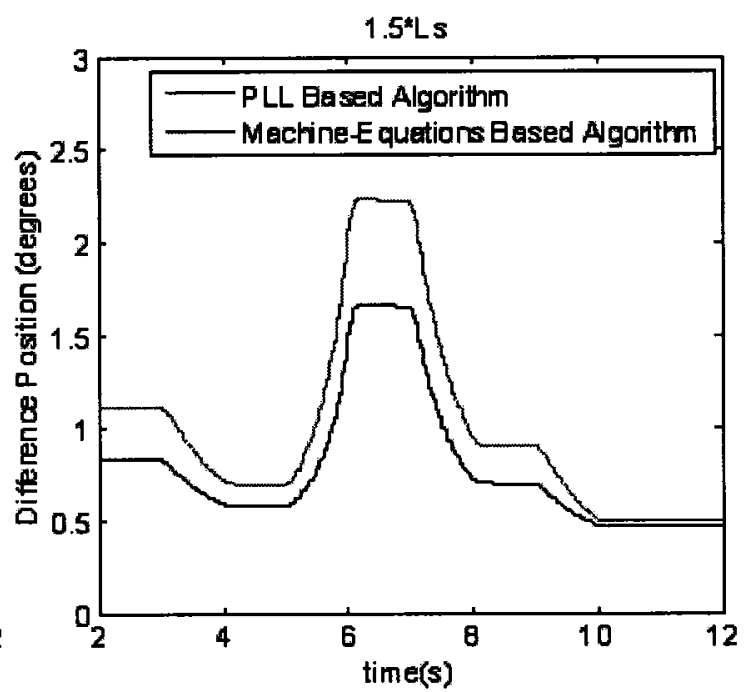

d)

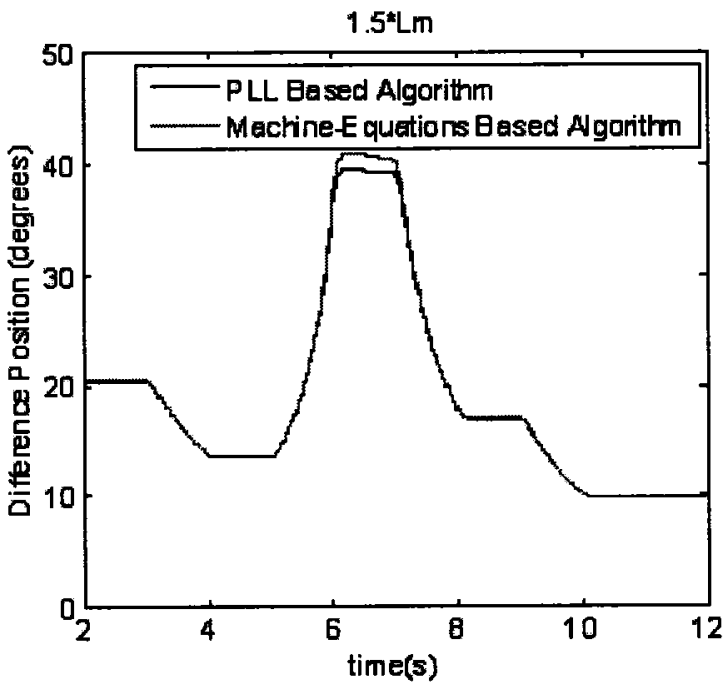

Figure 4.3: Position tracking - variable generator torque, shorted rotor, resistance added to rotor - modified machine parameters used in the sensorless algorithms- variables: difference between actual position and estimated positions using both the PLL and machine-equations based algorithms
a) $R_{s}=0$ b) $R_{s}=2^{*} R_{s}$ c) $L_{s}=0.5^{*} L_{s}$ d) $L_{s}=1.5^{*} L_{s}$ e) $L_{m}=0.5^{*} L_{m}$ f) $L_{m}=1.5^{*} L_{m}$

\subsection{Performance of Sensorless Algorithm During Faults}

The performance of the sensorless algorithm during an unsymmetrical fault is shown in Figure 4.4. The grid has a line-to ground fault and recovers after 0.5 seconds. Although, the algorithm is unable to estimate the speed during the grounded fault, the

algorithm resynchronizes with the real speed within 0.2 seconds after the system 
recovers. Typically, during the fault, a protection algorithm is engaged to protect the converter (i.e. crowbar), thus the ineffectiveness of the algorithm to track the speed will not harm the equipment (for instance, a system which has a speed controller). Figure 4.4 also shows the position, which isn't affected as much as the speed. Figure 4.5 shows the performance of the algorithm for a symmetrical fault (grid has a three-phase fault). The algorithm is able to resynchronize with the real speed within 0.1 seconds.

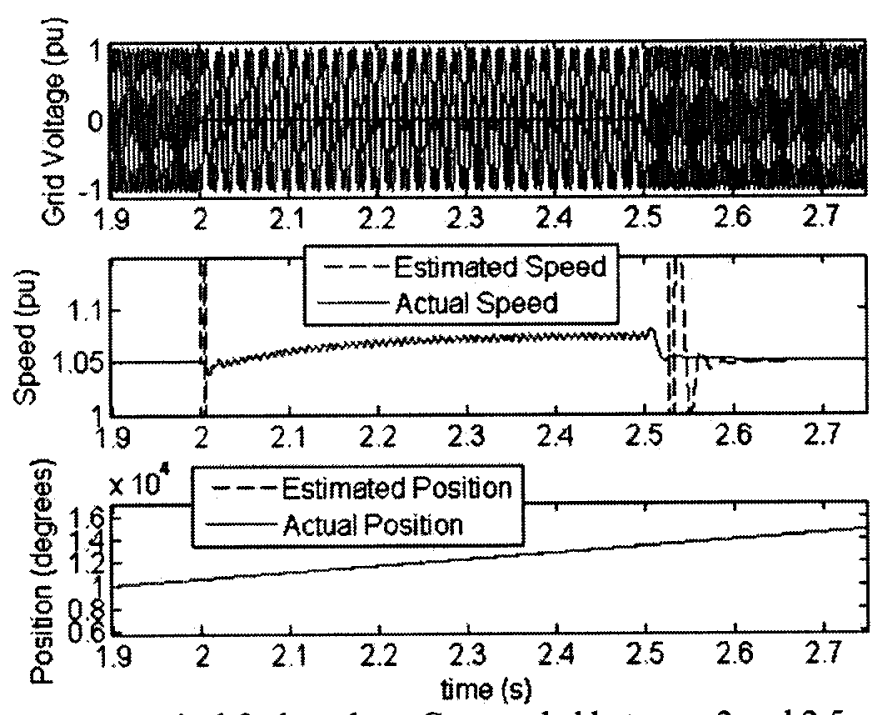

Figure 4.4: Unsymmetrical fault - phase $C$ grounded between 2 and 2.5 seconds, constant generator torque, shorted rotor, resistance added to rotor - exact machine parameters used in the sensorless algorithm - variables: grid voltages, speeds and positions vs time

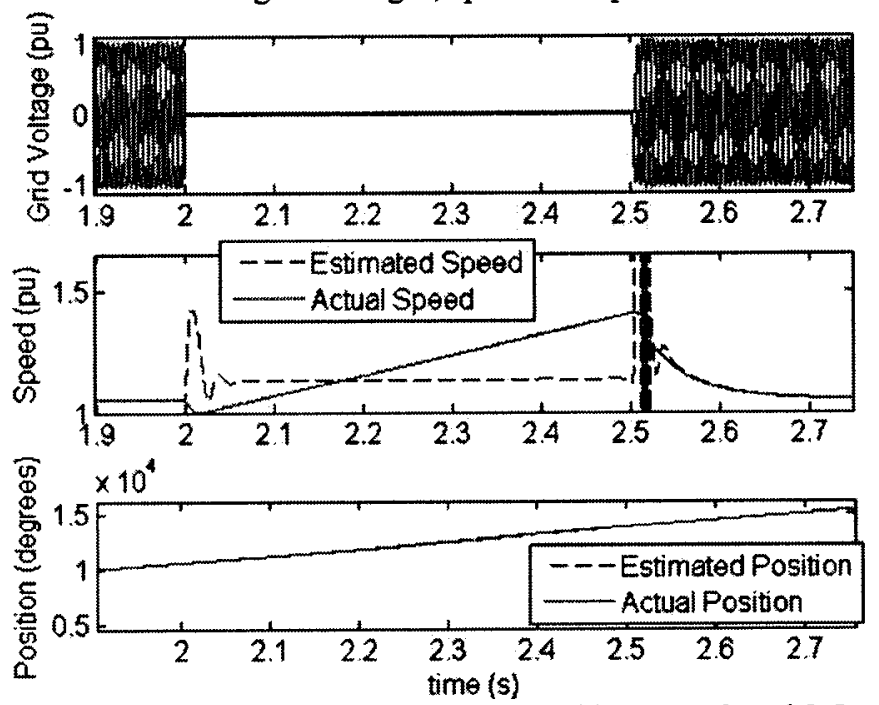

Figure 4.5: Symmetrical fault - grid voltages grounded between 2 and 2.5 seconds, constant generator torque, shorted rotor, resistance added to rotor - exact machine parameters used in the sensorless algorithm - variables: grid voltages, speeds and positions vs time 


\section{Chapter 5: Sensorless P-Q Control}

\subsection{Introduction}

The back-to-back converter consists of a machine-side and grid-side converters. This chapter deals with the design of the algorithms of the converters to control the dc bus voltage, line power (P-Q) and machine speed. With the machine-side converter, it is possible to control the torque or speed of the DFIG and also the power factor at the stator terminals by using the estimated speed and position algorithms of the previous chapters. With the grid-side converter, it is possible to control the dc bus voltage and the reactive power fed from the grid to the rotor.

\subsection{Machine-Side Converter}

With the machine-side converter, it is possible to control the torque or speed of the DFIG and also the power factor at the stator terminals. As mentioned earlier, DFIGs have the ability of reactive power control and decoupling of active and reactive powers. Given that DFIGs can be magnetized by the converter of the rotor circuit and not necessarily from the power grid, there are two possibilities of reactive power exchange. When it is connected to a strong power system with the voltage at, or near to, 1 p.u, the DFIG will be magnetized from the rotor circuit and there is no exchange of reactive power with the power system. The DFIG will produce active power only. When it is connected to a weak power system where the voltage may fluctuate, the DFIG may be ordered to produce or absorb an amount of reactive power. The DFIG will produce active 
power and exchange some reactive power with the grid, that is, it has the voltage control ability [31]. The entire system is shown in Figure 5.1. The PWM three-phase inverter is able to shape and control the three-phase output voltages in magnitude and frequency using sinusoidal pulse-width modulation (SPWM), depending on the reference voltages, whose calculation will be explained in the following subsections.

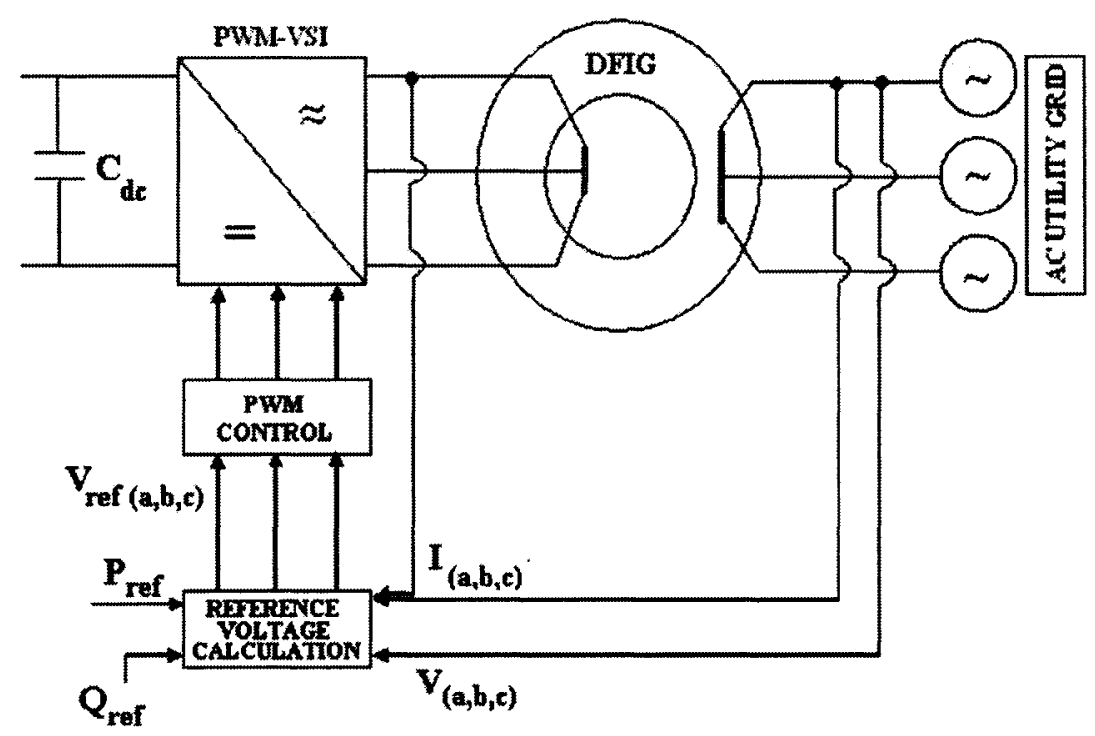

Figure 5.1: Machine-side converter - system configuration

\subsubsection{Reference Voltage Calculation}

From the previous chapters, we obtain the following variables from the position and speed sensorless measurement algorithms, which are used in the machine-side converter:

$v_{s q}, v_{s d}: d q$ components of stator voltages

$i_{s q}, i_{s d}: d q$ components of stator currents

$i_{r q}, i_{r d}: d q$ components of rotor currents $\theta_{s}:$ angle of stator voltage

$\theta_{m}, \omega_{m}:$ position and speed

$\Phi$ : angle from dq-axes aligner

The complete algorithm for machine-side converter is shown in Figure 5.2. The stator $d q$ voltage and current components are used to measure the real and reactive powers, whereas the DFIG speed and wind velocity $v$ are used to calculate the reference 
real and reactive powers. Comparison between the real and reference powers allows us to calculate the reference stator currents and with the stator voltages, the reference rotor currents. Finally by comparing the real and reference rotor currents, the reference rotor voltages are calculated. The different blocks will be explained in the following subsections.

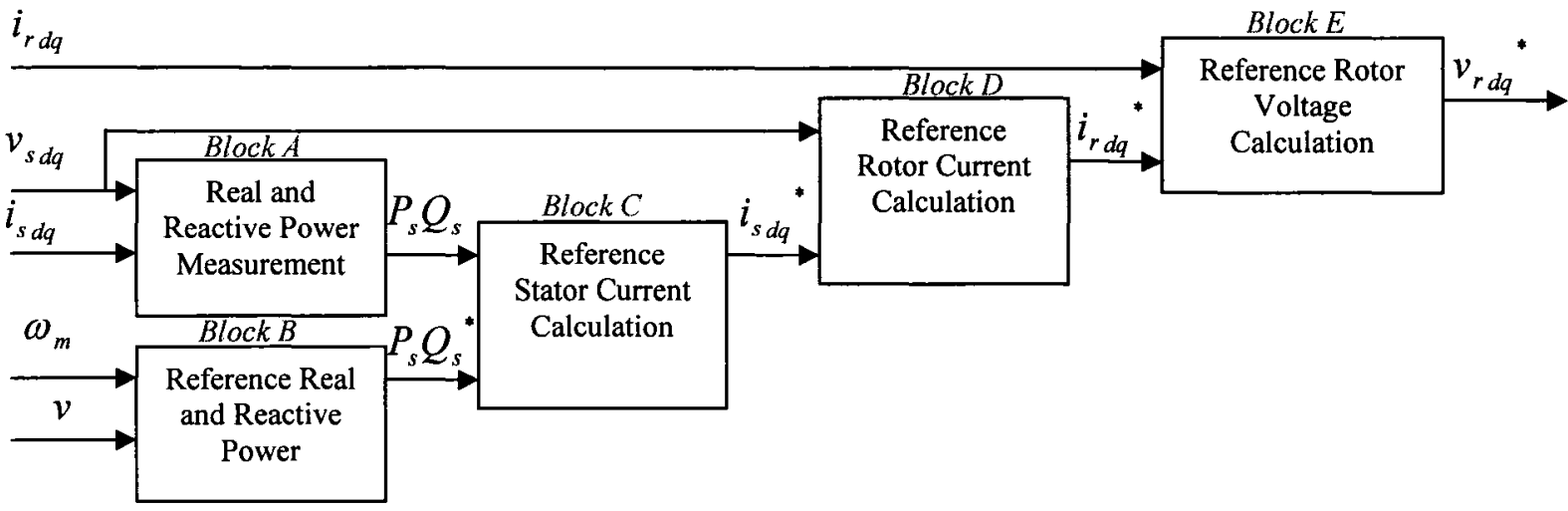

Figure 5.2: Reference rotor voltage calculation of machine-side converter - block diagram

\subsubsection{Real and Reactive Power Measurement}

As mentioned earlier, the stators-side real and reactive powers are:

$$
\begin{aligned}
& P_{s}=\frac{3}{2} v_{s d} i_{s d} \\
& Q_{s}=-\frac{3}{2} v_{s d} i_{s q}
\end{aligned}
$$

Thus the direct $(d)$ component of the stator current is related to the real power at the stator, and the quadrature $(q)$ component of the stator current is related to the reactive power at the stator.

\subsubsection{Reference Real and Reactive Calculation}

There are multiple ways to set the values of the reference real and reactive power. One method, in order to optimize the output power of the wind turbine, the generator speed is changed depending on the wind speed $v$ as shown in Figure 5.3. Another method 
is to set the power reference directly, as shown in Figure 5.4. The reference speeds or reference powers are set according to the power coefficient curves of the wind turbine similar to Figure 1.3.

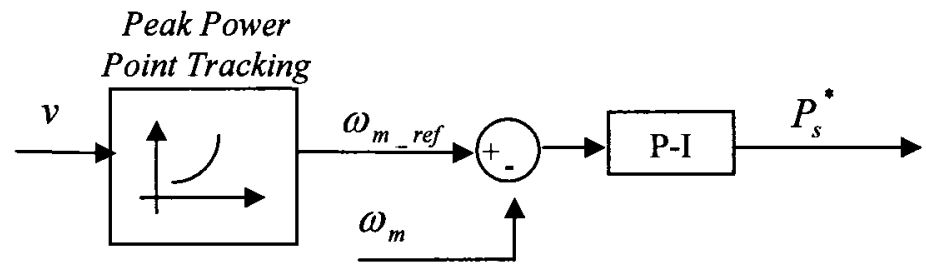

Figure 5.3: Reference power calculation with speed governor - block diagram (Block B-1)

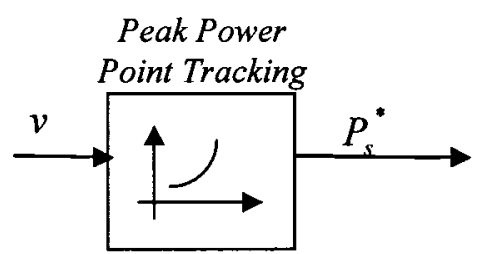

Figure 5.4: Reference power calculation without speed governor - block diagram (Block B-2)

The reactive power is set to zero, but can be changed to any value, either positive or negative. As mentioned earlier, it depends whether the power system is strong or weak.

\subsubsection{Reference Stator Current Calculation}

Given that the P-Q control is decoupled, the real and reference powers are compared to obtain the $d q$ reference components of the stator currents as shown in Figure

\section{5 .}

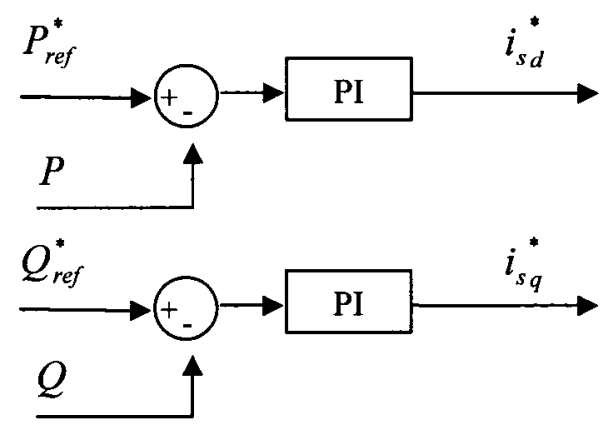

Figure 5.5: Reference stator current calculation - block diagram (Block C) 


\subsubsection{Reference Rotor Current Calculation}

From the $d q$ components of the stator voltages and reference currents, we are able to determine the reference rotor currents from the steady-state induction machine equations (the $d / d t$ components are not included, since they have a small effect in the calculation of the reference values, which will be shown in the simulation results). The equations of the reference rotor $d q$ currents are shown below:

$$
\begin{aligned}
& i_{r d}^{*}=\frac{-\omega_{s} L_{s s} i_{s d}^{*}-R_{s} i_{s q}^{*}+v_{s q}}{\omega_{s} L_{m}} \\
& i_{q r}^{*}=\frac{R_{s} i_{s d}^{*}-\omega_{s} L_{s s} i_{s q}^{*}-v_{s d}}{\omega_{s} L_{m}}
\end{aligned}
$$

\subsubsection{Reference Rotor Voltage Calculation}

The real and reference $d q$ rotor voltages are compared to obtain the reference rotor voltages as shown in Figure 5.6. The P-I controllers were fine-tuned for stable steady-state operation, fast tracking of the reference values, no steady-error and reduction of the generated noise in the feedback system due to the harmonic content and noise of the signals. The performance of the controller is shown in the following section. The controller is able to decouple the P-Q powers and hence does not require feedforward control.

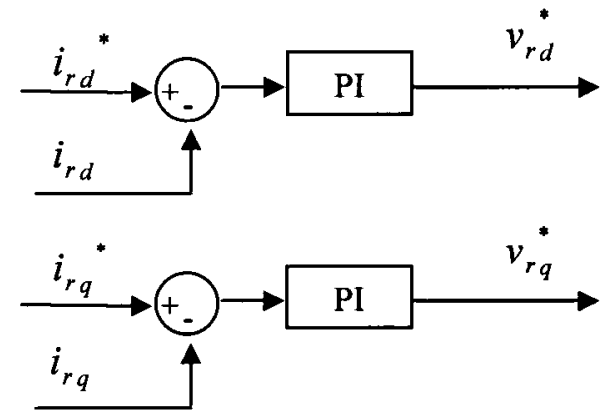

Figure 5.6: Reference rotor voltage calculation - block diagram (Block E) 


\subsubsection{6 dq to abc Transformation of Rotor Voltages}

Once the $d q$ reference currents are obtained, the next step involves the conversion from $d q$ to $a b c$. The block diagram for this conversion is shown in Figure 5.7. Phase shifters are employed to shift the $d$ and $q$ components of the rotor voltages by the angles $\Phi, \theta_{m}$ and $\theta_{s}$.

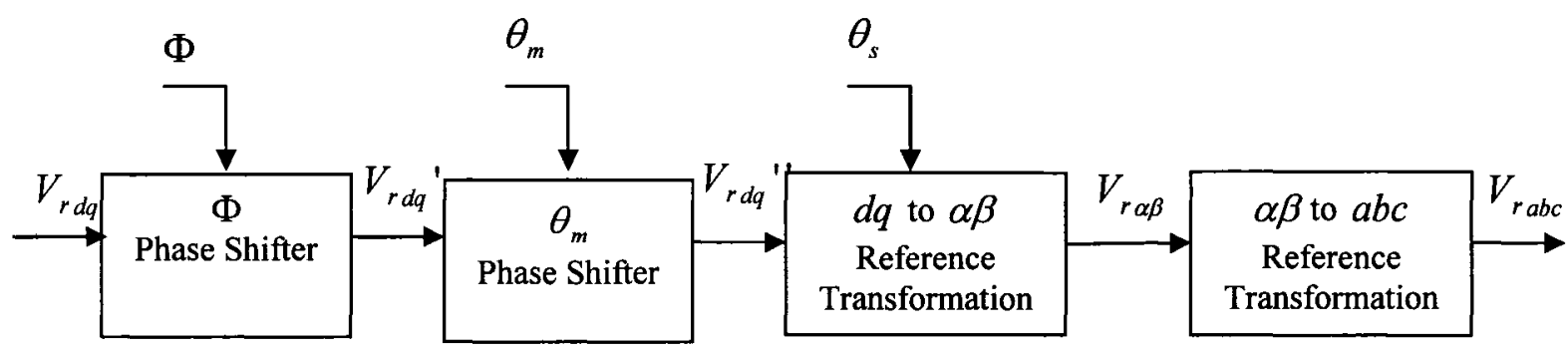

Figure 5.7: $D q$ reference frame transformation for rotor voltage - block diagram

The transformation from $d q$ to $\alpha \beta$ is shown below.

$$
\begin{aligned}
& {\left[\begin{array}{l}
V_{\beta} \\
V_{\alpha}
\end{array}\right]=K_{d q T O \alpha \beta} \times\left[\begin{array}{l}
V_{d} \\
V_{q}
\end{array}\right]} \\
& K_{d q T O \alpha \beta}=\left[\begin{array}{ll}
\cos \theta_{s}-\sin \theta_{s} \\
\sin \theta_{s} & \cos \theta_{s}
\end{array}\right]
\end{aligned}
$$

The transformation from $\alpha \beta$ to $a b c$ is shown below.

$$
\begin{aligned}
& {\left[\begin{array}{l}
V_{a} \\
V_{b} \\
V_{c}
\end{array}\right]=K_{\alpha \beta T O a b c} \times\left[\begin{array}{l}
V_{\alpha} \\
V_{\beta} \\
V_{0}
\end{array}\right]} \\
& K_{\alpha \beta T O a b c}=\left[\begin{array}{ccc}
1 & 0 & 1 \\
-0.5 & -\frac{\sqrt{3}}{2} & 1 \\
-0.5 & \frac{\sqrt{3}}{2} & 1
\end{array}\right]
\end{aligned}
$$

\subsubsection{Simulation Results of Machine-Side Converter}

In order to test the machine-side converter, the speed governor for reference power calculation is used. The circuit diagram of simulation setup of the machine-side 
converter is shown in Figure 5.8. A constant mechanical torque is inputted to the DFIG (1 p.u.), the machine-side converter is connected to the rotor and the stator is connected to the ac grid. Exact machine parameters are used in the algorithm. From the simulation results of Figure 5.9, we see the speed and reactive power are able to track their reference values and are independently controlled. In the case of sinusoidal reference changes above $1 \mathrm{~Hz}$, the speed and reactive power have more difficulty tracking their reference values (delay of less than $0.1 \mathrm{~s}$ and overshoots less than $1 \%$ ). The P-I controller is able to reduce the feedback noise but has a slower response for quicker reference changes (above $0.25 \mathrm{~Hz})$.

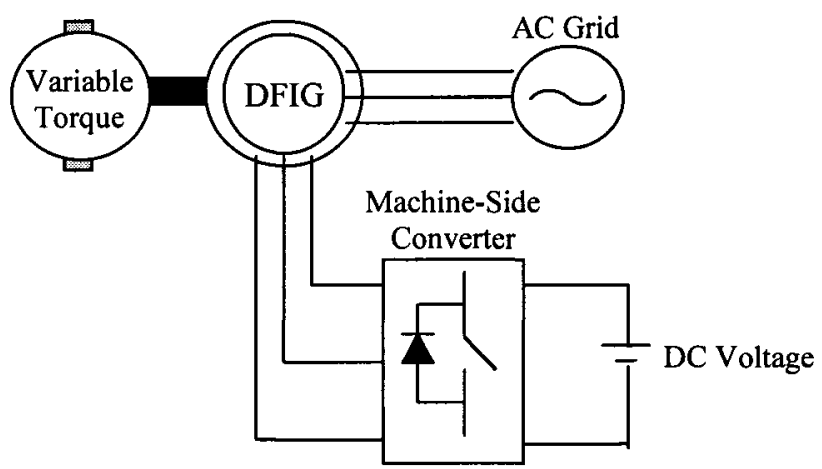

Figure 5.8: Machine-side converter - circuit diagram of simulation setup

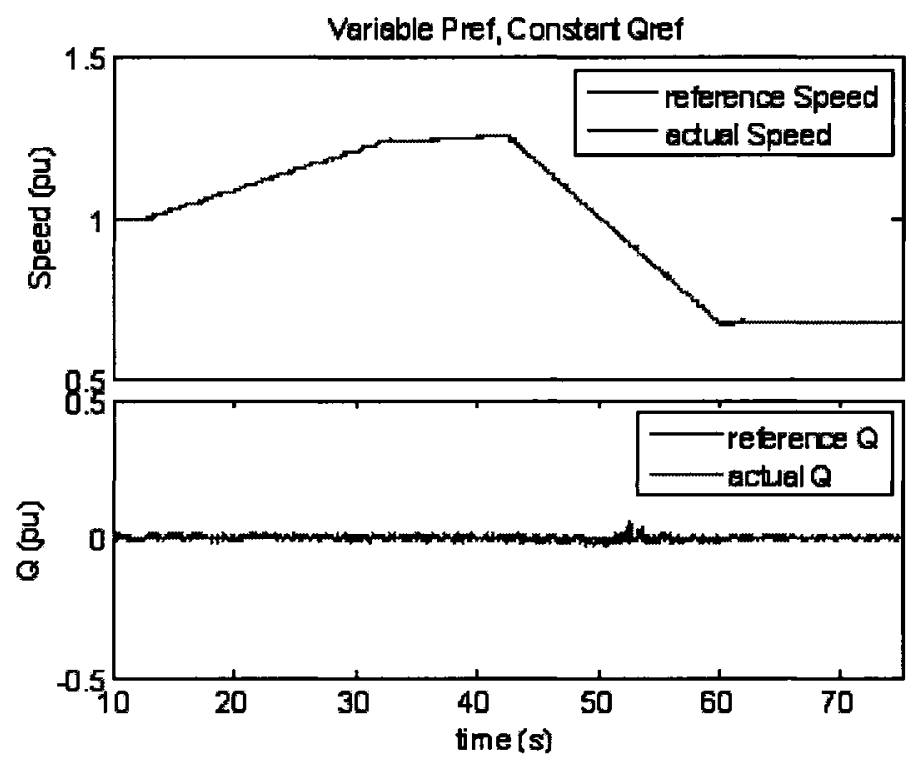

a) 


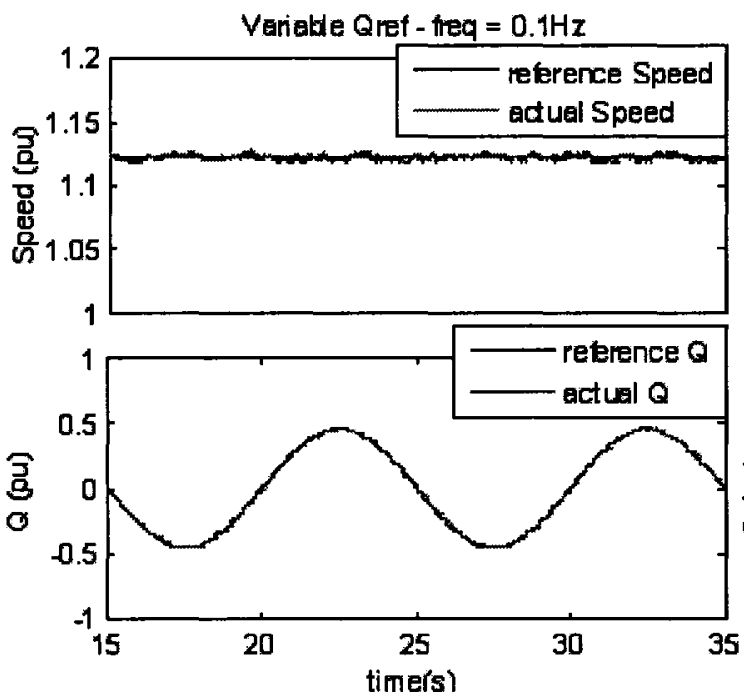

b)

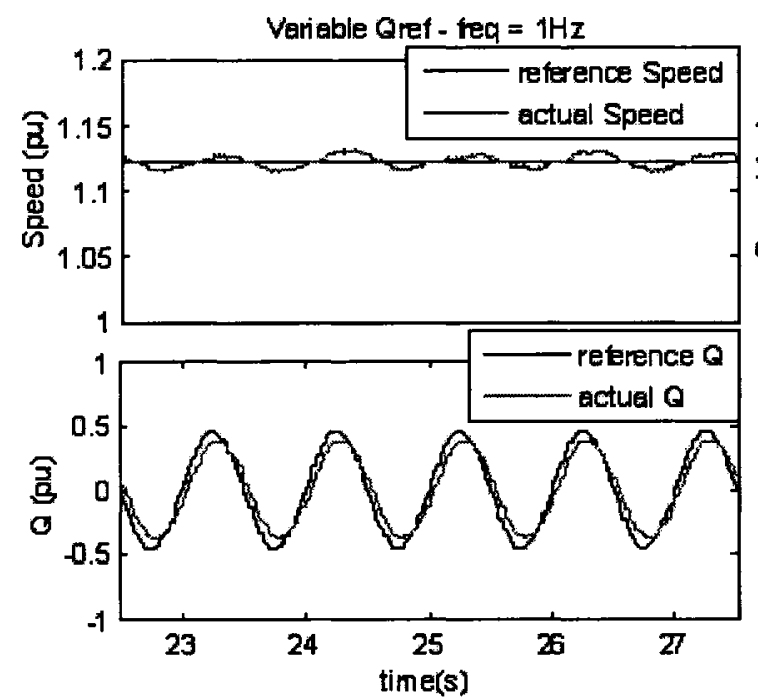

d)

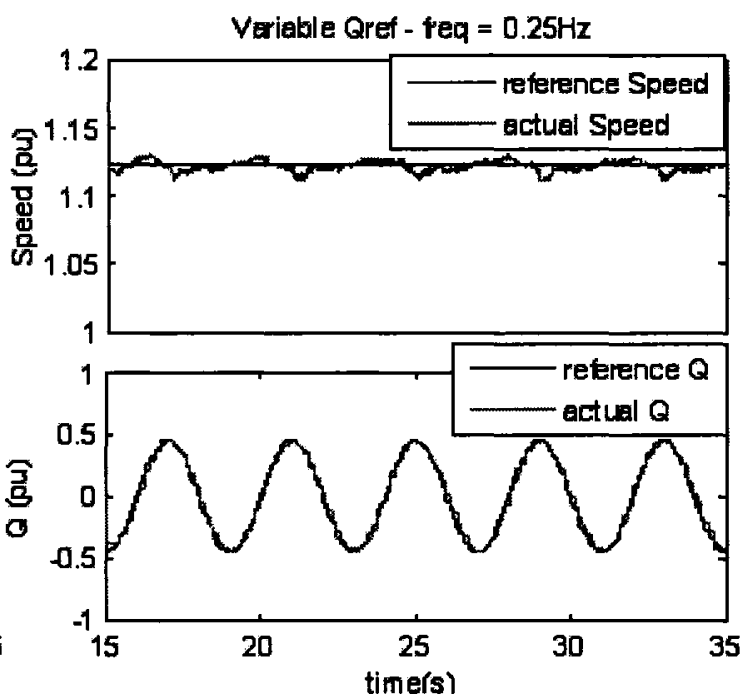

c)

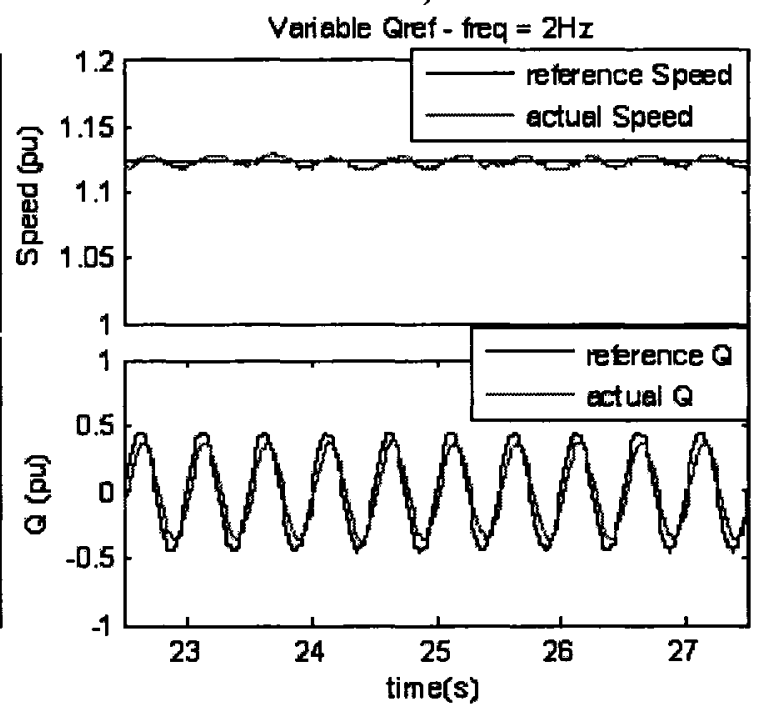

e)

Figure 5.9: Machine-side converter, speed and $Q$ control- constant generator torque input (1 p.u.), - exact machine parameters used in the sensorless algorithm - variables: actual and reference speed and Qs vs time Constant $Q s$ reference ( $Q s=0$ p.u.): a) variable speed reference (above and below $\omega_{\mathrm{m}}$ ),

Constant speed reference (1.125 p.u.), sinusoidal Qs reference: b) $0.1 \mathrm{~Hz} \mathrm{c)} 0.25 \mathrm{~Hz} \mathrm{d)} 1 \mathrm{~Hz}$ e) $2 \mathrm{~Hz}$

Then, the robustness of the speed control due to changes in machine parameters is evaluated. For different values of machine parameters, we get the results shown in Figure 5.10. We see from the results that the controller is designed in such a way to eliminate steady-state errors even with a difference of parameters. For instance, a controller that does not compensate for a steady-state error, we would get the results for $L_{s}=0.5^{*} L_{s}$ and 
$L_{m}=1.5^{*} L_{m}$ shown in Figure 5.11. In the case of $L_{m}$, we see that there is a significant steady-state error. Hence, for the proposed algorithm, it is essential to have an integrator in the controller to eliminate the steady-state error. Thus, the sensitivity of the sensorless position algorithm does not adversely affect the performance of the DFIG. In addition, since the estimation of the speed is independent of the values of machine parameters, the DFIG is able to track the reference speed without any steady-state error.

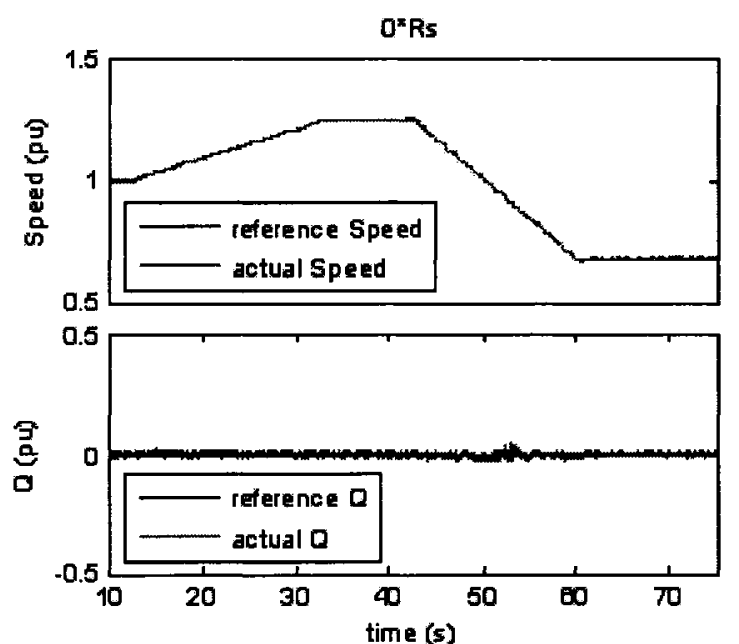

a)
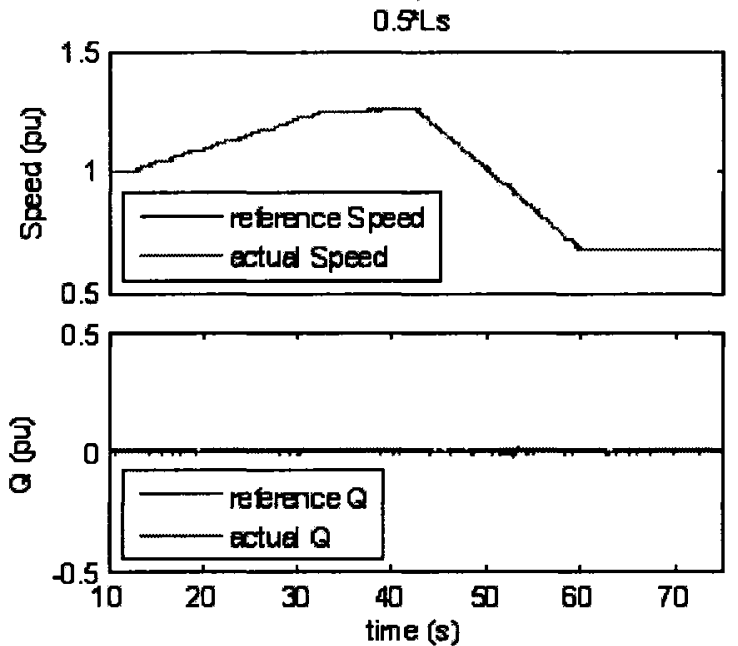

c)

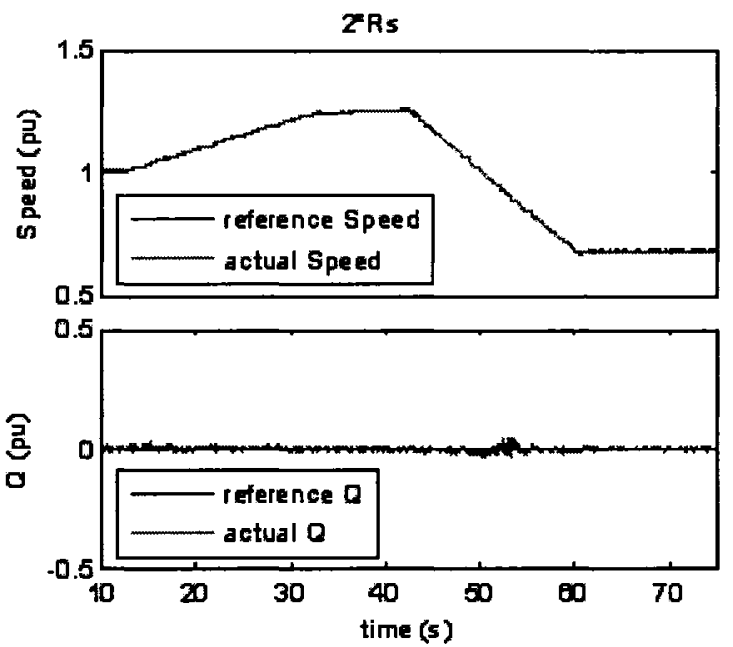

b)

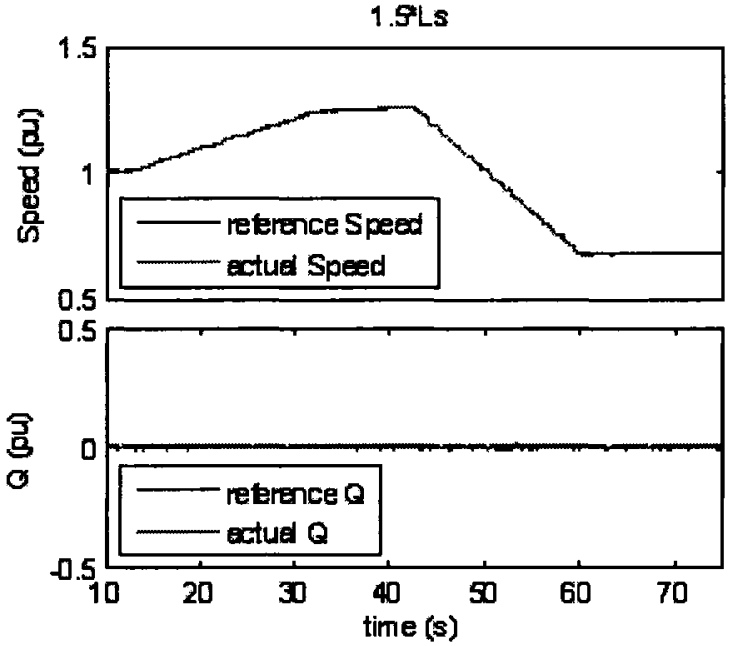

d) 

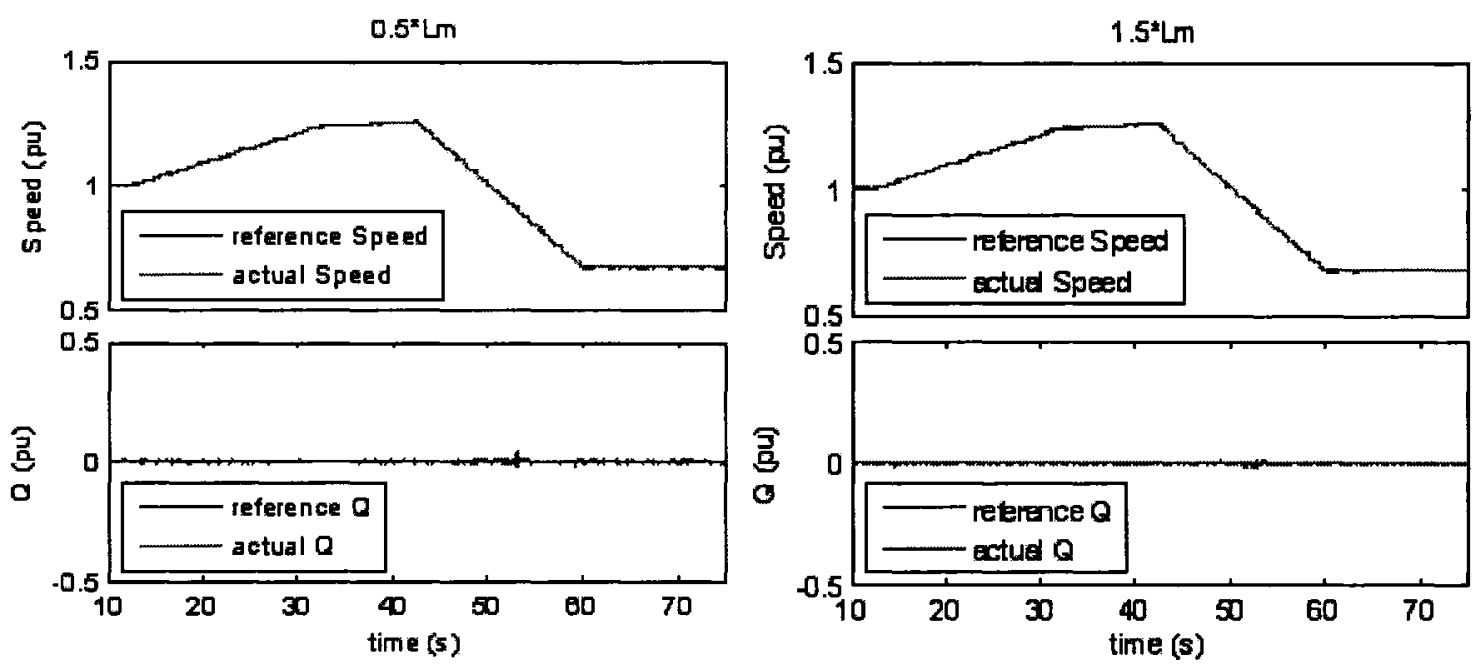

e)

f)

Figure 5.10: Machine-side converter, speed and Q control - constant generator torque (1 p.u.) - variable speed reference, constant $\mathrm{Qs}$ reference $(\mathrm{Q} s=0$ p.u. $)$ - modified machine parameters used in the sensorless algorithm - variables: actual and reference speeds and Qs

a) $R_{s}=0$ b) $R_{s}=2^{*} R_{s}$ c) $L_{s}=0.5^{*} L_{s}$ d) $L_{s}=1.5^{*} L_{s}$ e) $L_{m}=0.5^{*} L_{m}$ f) $L_{m}=1.5^{*} L_{m}$

D. ÍLs - No Integrator
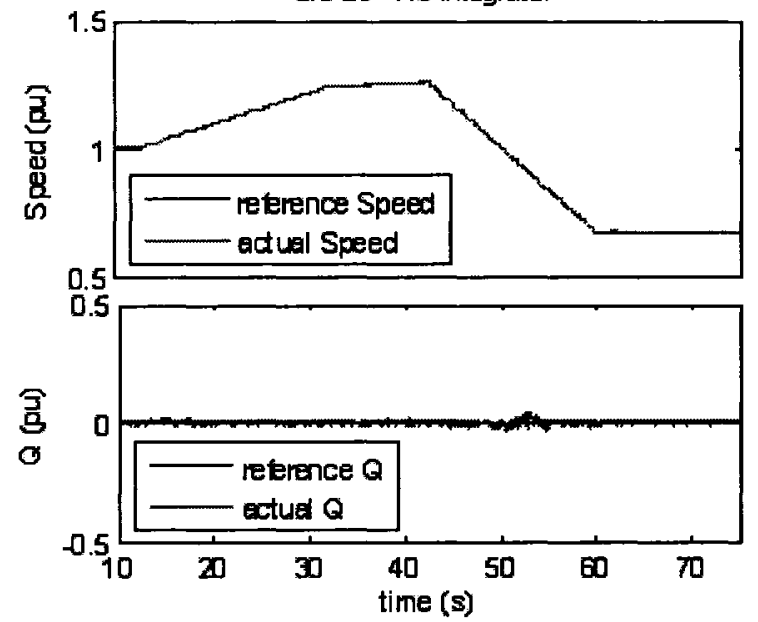

a)
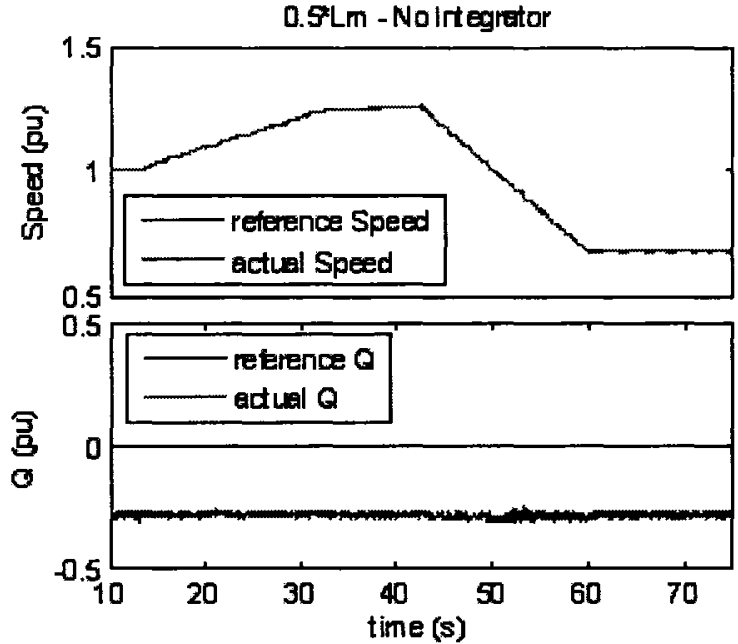

b)

Figure 5.11: Machine-side converter, speed and Q control - constant generator torque (1 p.u.) - variable speed reference, constant $\mathrm{Qs}$ reference $(\mathrm{Q} s=0$ p.u.) - modified machine parameters used in the sensorless algorithm - no integrator in P-I controller - variables: actual and reference speeds and Qs vs time a) $L_{s}=0.5^{*} L_{s}$, Qs error $=0.005$ p.u. b) $L_{m}=0.5^{*} L_{m}$; Qs error $=-0.2830$ p.u.

\subsection{Grid-Side Converter}

With the grid side converter, it is possible to control the active and reactive powers fed to the rotor and to achieve voltage regulation at the dc bus [20]. The entire system is shown in Figure 5.12. The control logic includes the hysteresis current 
controller and the reference current calculation which will be explained in the following subsections.

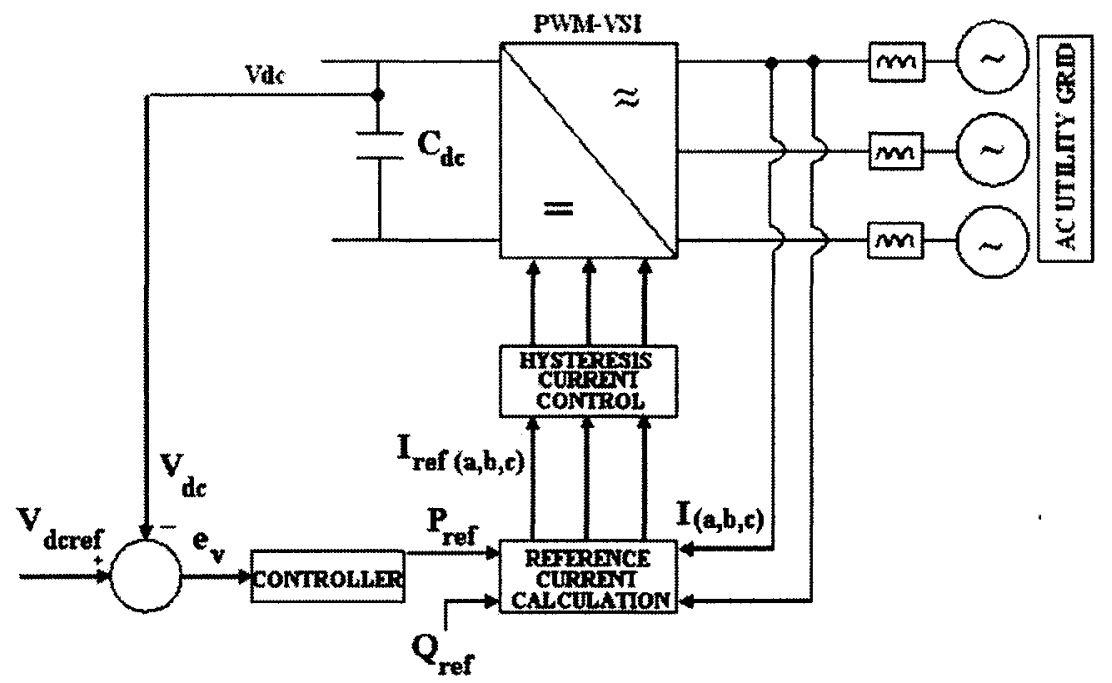

Figure 5.12: Grid-side converter - system configuration

\subsubsection{Reference Current Calculation}

The reference current calculation block receives as inputs the voltage at the dc bus $V_{d c}$ and three-phase voltages $v_{g a b c}$ and currents $i_{g a b c}$ measured at the ac side. Using this information, it calculates the three-phase reference currents provided to the hysteresis current controller which is essential to the switching of the PWM-VSI. The complete algorithm for reference current calculation is shown in Figure 5.13. The different blocks will be explained in the following subsections.

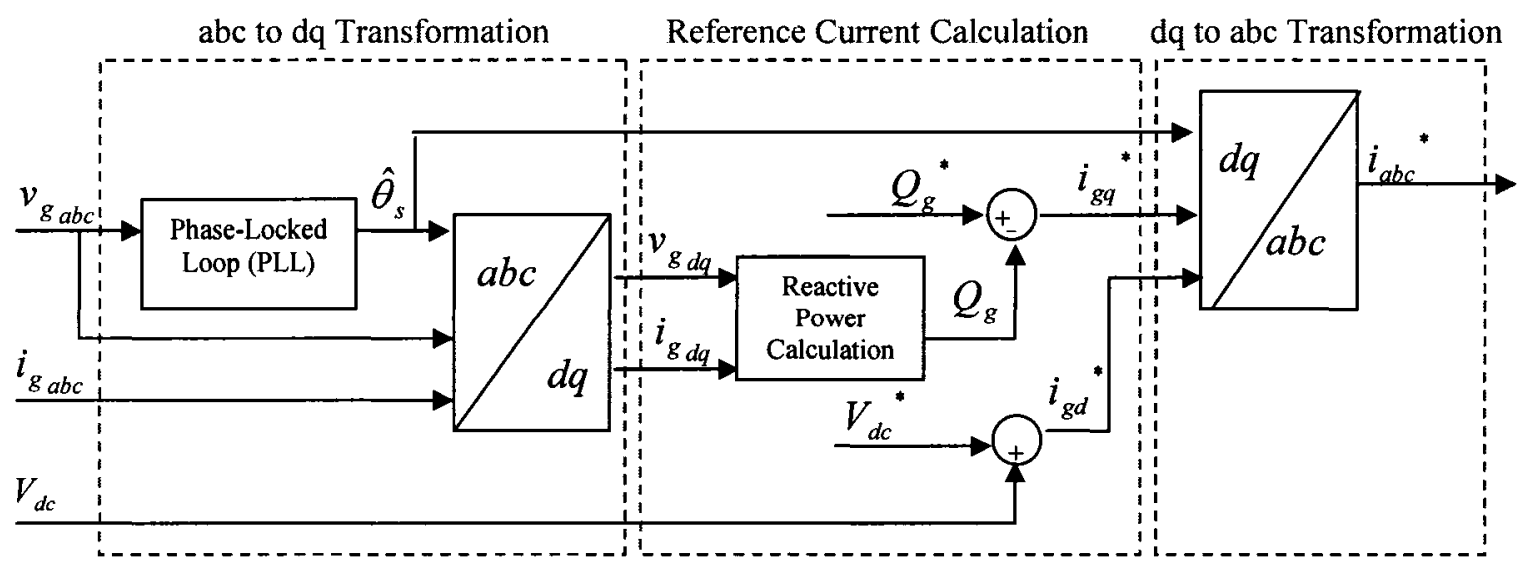

Figure 5.13: Reference current calculation of grid-side converter - block diagram 


\subsubsection{Voltage and Current dq Reference Transformation}

When dealing with instantaneous voltages and currents in three-phase circuits mathematically, it is preferable to express these three-phase $a b c$ quantities in the $d q$ reference frame. As shown in Figure 5.13, first, the angle of the grid voltage $\hat{\theta}_{s}$ is extracted using a phase-locked loop. Finally, the stator currents and voltages are converted from ac quantities to dc quantities in steady state using the $d q$ transformation.

\subsubsection{2 dq Reference Frame Current Calculation}

As mentioned in section 4, the real and reactive powers are decoupled and hence, they are defined as follows:

$$
\begin{aligned}
& P_{g}=\frac{3}{2} v_{g d} i_{g d} \\
& Q_{g}=-\frac{3}{2} v_{g d} i_{q d}
\end{aligned}
$$

Thus, in the closed-loop system, the difference between the reference and real dc bus voltage assigns the reference current value of $i_{g d}$ and the difference between the reference and real reactive power assigns the reference current value of $i_{g q}$. The P-I controllers were designed for fast response to reference changes without any large overshoots and minimal oscillations. The design of the controller is explained in the following section.

\subsubsection{Design of Reference DC Bus Voltage Controller}

The energy stored in the dc link capacitor $C_{d}$, is defined as:

$$
E_{c}=\int_{-\infty}^{t}\left(v_{d} \cdot i_{d}-p_{c}\right) d \lambda=\frac{1}{2} C_{d} v_{d}^{2}
$$

where $v_{d}$ is the instantaneous dc capacitor voltage (V)

$i_{d}$ is the instantaneous current from the bus feeding the grid-side controller (A) 
$p_{c}$ is the instantaneous real power at the PWM terminals which is fed to the rotor (W)

$\lambda$ is the integration variable

The energy stored in the dc capacitor is given by the integral of the instantaneous difference $P_{c d}=\left(v_{d} i_{d}-P_{c}\right)$. Then considering a small signal model, working $P_{c d}=$ $P_{c d}+\Delta P_{c d}$ and $V_{d}=V_{d c}+\Delta V_{d}$ and applying the Laplace transformation, we obtain:

$$
\frac{\Delta V_{d}(s)}{\Delta P_{c d}(s)}=\frac{1}{s C_{d} V_{d c}}
$$

where $V_{d c}$ is the dc link average voltage (V)

$\Delta V_{d}(S)$ is the Laplace transformation for small variation of the dc voltage (V)

$\Delta P_{c d}(s)$ is the Laplace transformation for small variation of the real power flowing from the capacitor $(\mathrm{W})$

The small-signal system diagram of the grid-side converter is shown on Figure 5.14. The output signals is the dc bus voltage $\Delta V_{d c}$ which is compared to the reference voltage $\Delta V_{d c r e f}$. The error is fed to a controller which produces the reference real power signal. The transfer function of the system is:

$$
H(s)=\frac{K(s) \frac{1}{s C V_{d}}}{1+K(s) \frac{1}{s C V_{d c}}}=\frac{K(s)}{s C V_{d c}+K(s)}
$$

where $K(s)$ is the controller.

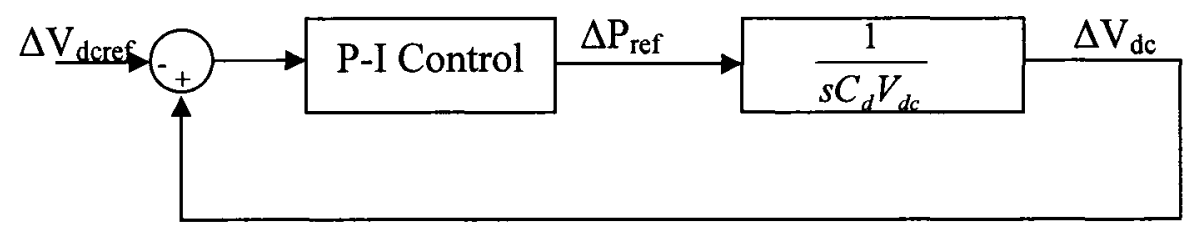

Figure 5.14: Grid-side converter - small signal system diagram

For the controller $K(s)$, a P-I controller was used. Hence, the transfer function becomes:

$$
H(s)=\frac{s K_{p}+K_{I}}{s^{2} C V_{d}+s K_{p}+K_{I}}
$$


For the system used in the experimental setup, using $C_{d}=1500 \mu F$, for a voltage variation $\Delta V_{d c}$ between 50 and $150 \mathrm{~V}$ and $K_{P}=0, K_{I}=0.75$, we get the step responses shown in Figure 5.15. We see that there is no overshoot and that the response is quick (less than 1.5s).

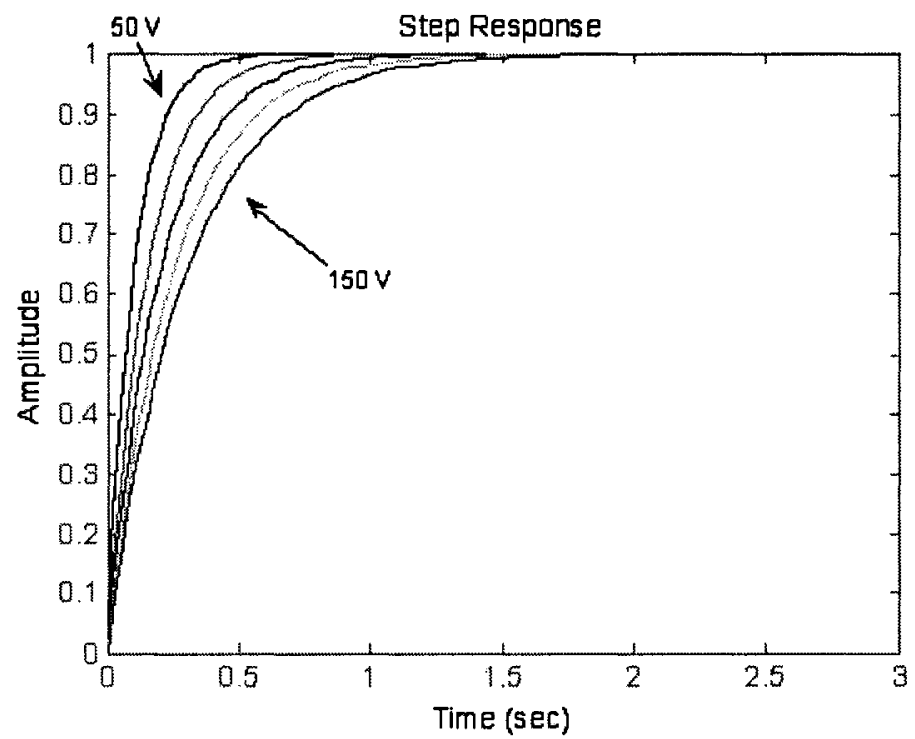

Figure 5.15: Dc bus voltage controller design - step response $\Delta \mathrm{V}_{\mathrm{d}}(50$ to $150 \mathrm{~V})$

\subsubsection{Reference Current abc Reference Frame Transformation}

Once the $d q$ reference currents are obtained, the next step involves the conversion from $d q$ to $a b c$. The block diagram for this conversion is shown in Figure 5.16, which uses the equations (5.4) and (5.6).

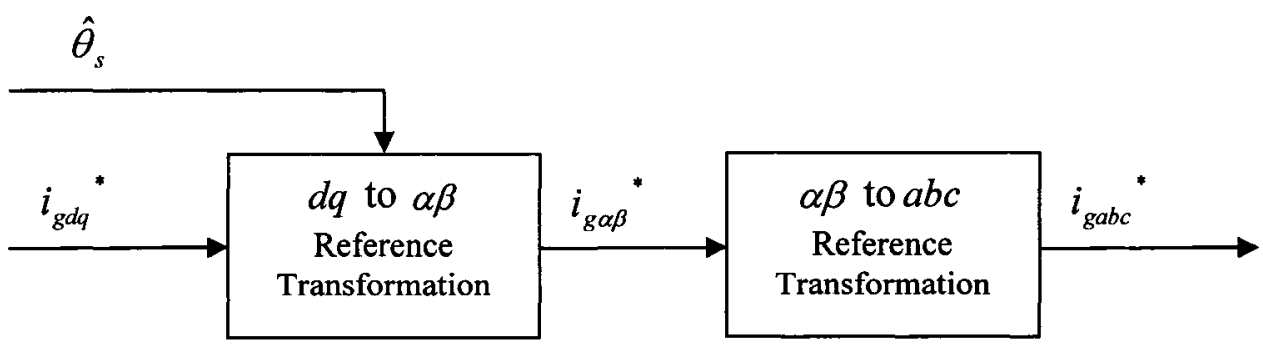

Figure 5.16: $D q$ reference frame transformation for reference current - block diagram 


\subsubsection{Simulation Results of Grid-Side Converter}

The circuit diagram, of the simulation setup is shown in Figure 5.17. A resistor and a dc current source are placed in parallel to the dc bus in order to emulate the power flow either from ac to dc or dc to ac. The dynamic response due to changes of voltage reference, power flow and reactive power reference are studied in the following subsections.

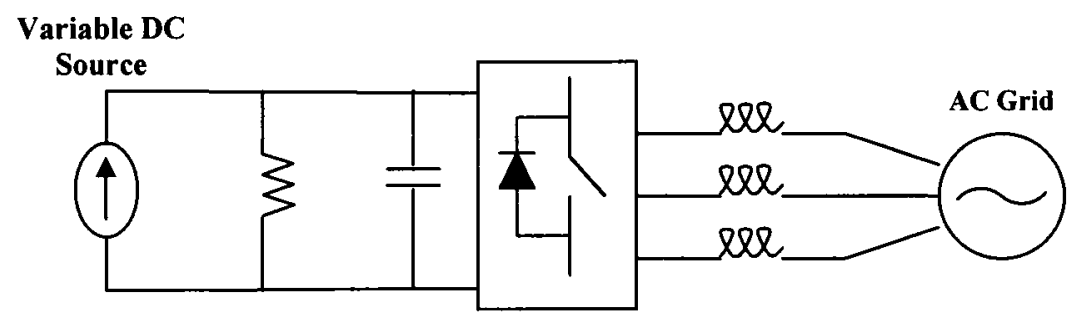

Figure 5.17: Grid-side converter - circuit diagram of simulation setup

\subsubsection{Performance of DC Bus Voltage Controller}

The first test involves changing the value of the dc bus reference. As shown in Figure 5.18, the response is quick (less than $0.1 \mathrm{~s}$ for a step change of $0.25 \mathrm{p}$.u.) and there is no steady-state error.

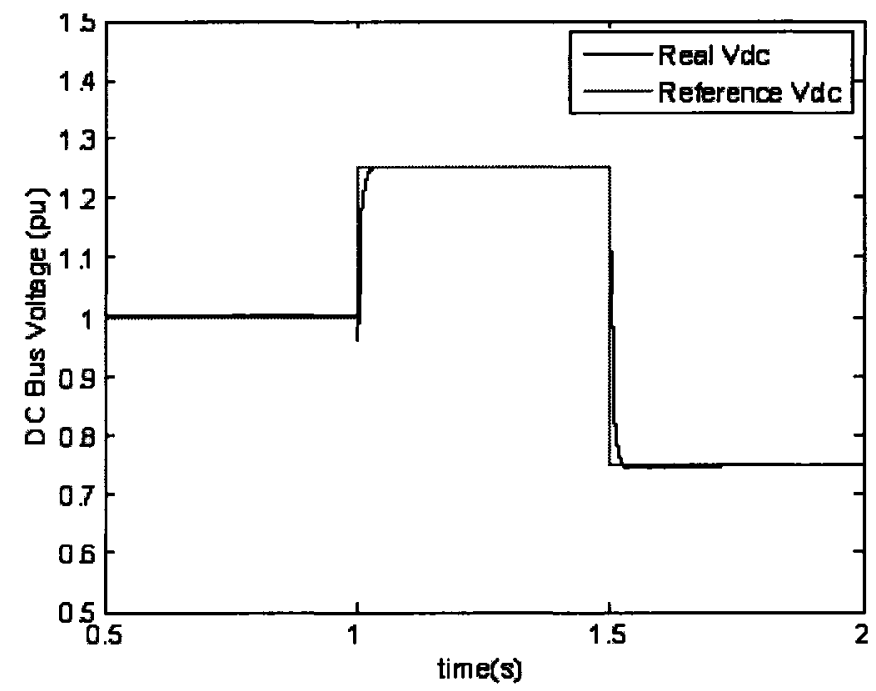

Figure 5.18: Grid-side converter, dc bus voltage controller - constant $\mathrm{Qg}$ reference ( $\mathrm{Qg}=0$ p.u.), step changes of $\mathrm{dc}$ bus voltage reference - variables: reference and actual Vdc vs time 


\subsubsection{Performance of Power Controller}

The next test involves changing the dc current. We are able to control the value of the power flow from the ac grid to the dc bus (both the magnitude and the direction). As shown in Figures 5.19, we see that a change in power causes small changes (less than $2 \%$ ) in the magnitude of the dc bus voltage, but it settles back to the steady state value in less than 0.5 seconds. Figure 5.20 shows that even in dynamic changes, the converter is still able to maintain a power factor of one.
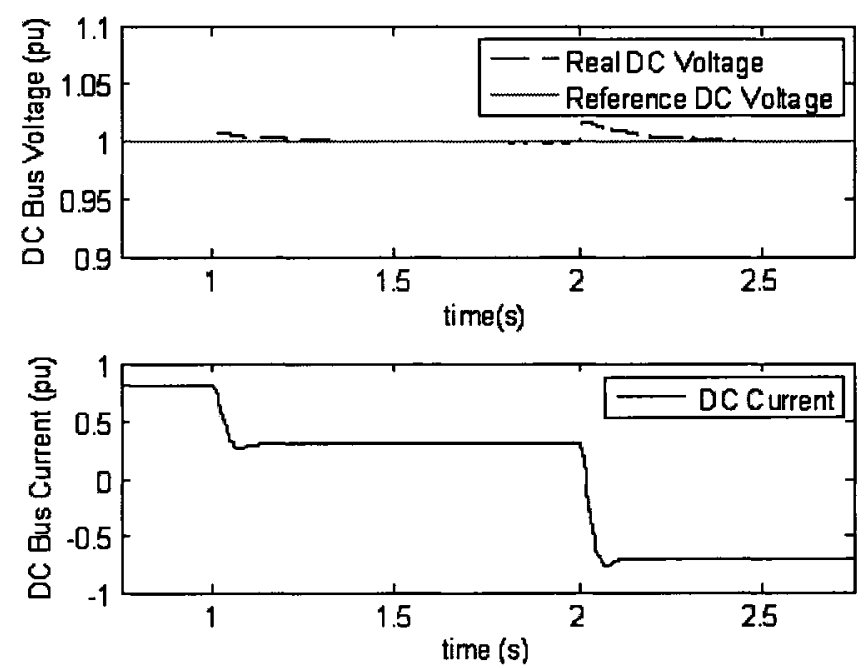

Figure 5.19: Grid-side converter, performance power controller - step changes in power flow (variable dc current) - constant dc voltage reference ( $V d c=1$ p.u. $)$, constant $Q g$ reference $(Q g=0$ p.u. $)$ - variables: $d c$ bus voltage Vdc and current vs time
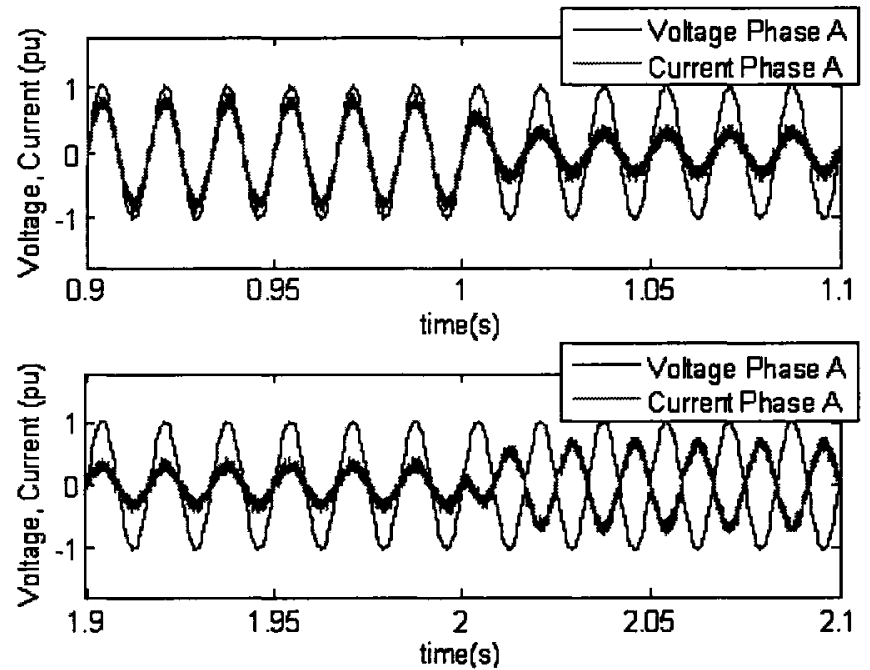

Figure 5.20: Grid-side converter, performance power controller - step changes in power flow - constant dc voltage reference $(V d c=1$ p.u. $)$, constant $Q g$ reference $(Q g=0$ p.u. $)$ - variables: grid converter voltage Vg and current Ig vs time 


\subsubsection{Performance of Reactive Power Controller}

The final test involves changing the reactive power reference. We see from the results in Figure 5.21 and 5.22, that the dc voltage maintains its reference value and that the reactive power controller has a quick response (less $0.1 \mathrm{~s}$ for step change of $1 \mathrm{p} . \mathrm{u}$. .) with no steady-state error.
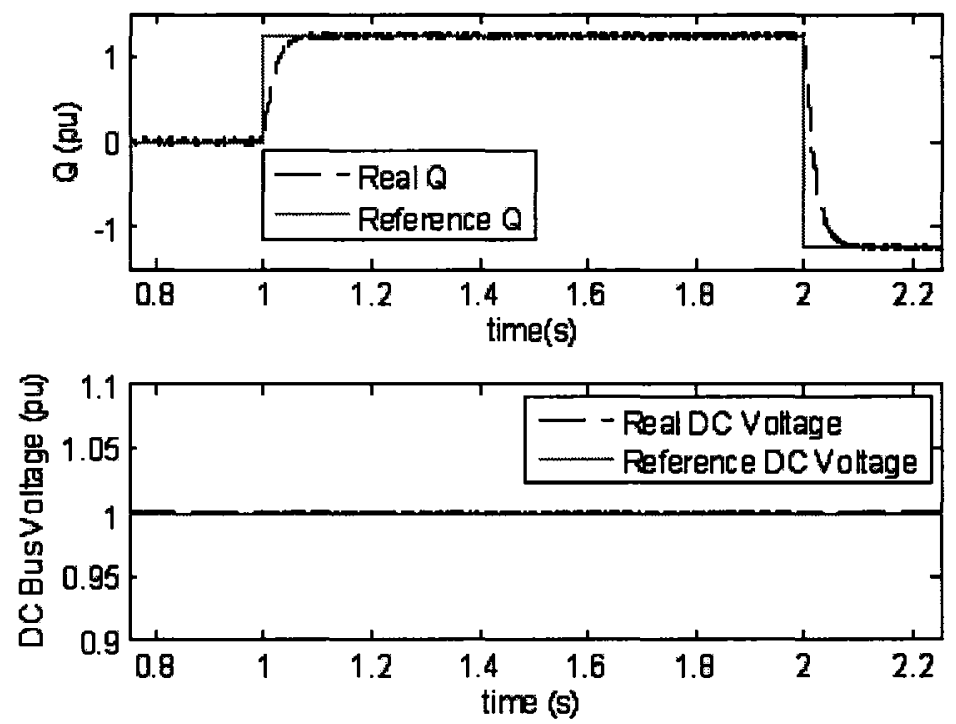

Figure 5.21: Grid-side converter, performance reactive power controller - step changes in reactive power constant dc voltage reference ( $\mathrm{Vdc}=1$ p.u.), constant dc bus load - variables: reference and actual Vdc and Qg vs time

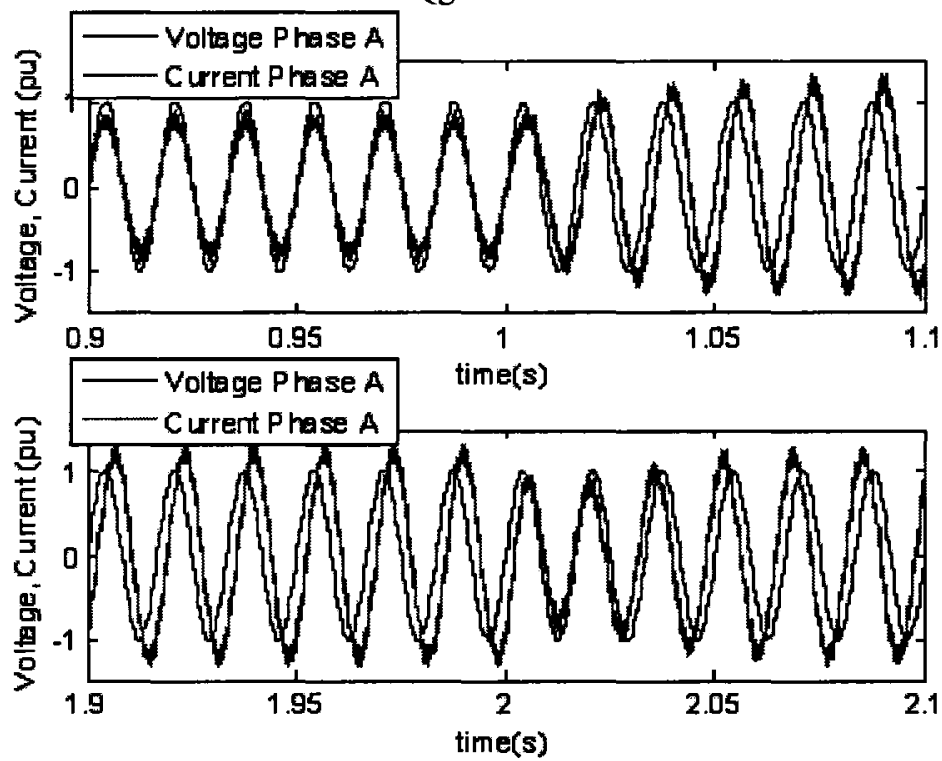

Figure 5.22: Grid-side converter, performance reactive power controller - step changes in reactive power constant $\mathrm{dc}$ voltage reference ( $\mathrm{Vdc}=1$ p.u.), constant dc bus load - variables: grid converter voltage $\mathrm{Vg}$ and current Ig vs time 


\subsection{Complete DFIG System}

The entire system was simulated, using both the current reference calculation for the grid-side converter, and the voltage reference calculation for the machine-side converter. The power factor of the grid-side converter is set at unity; the reactive power fed to the grid is controlled exclusively by the machine-side converter. Instead of the speed governor, the reference power is set directly. Figure 5.23 shows the result for a constant input torque (1 p.u.), a varying reference power and constant reference reactive power. Figure 5.24 shows the results for constant reference power and variable reference reactive power. We find that there are no steady-state errors for the real and reactive powers compared to their reference values and the control of the real and reactive powers are independent (decoupled control).
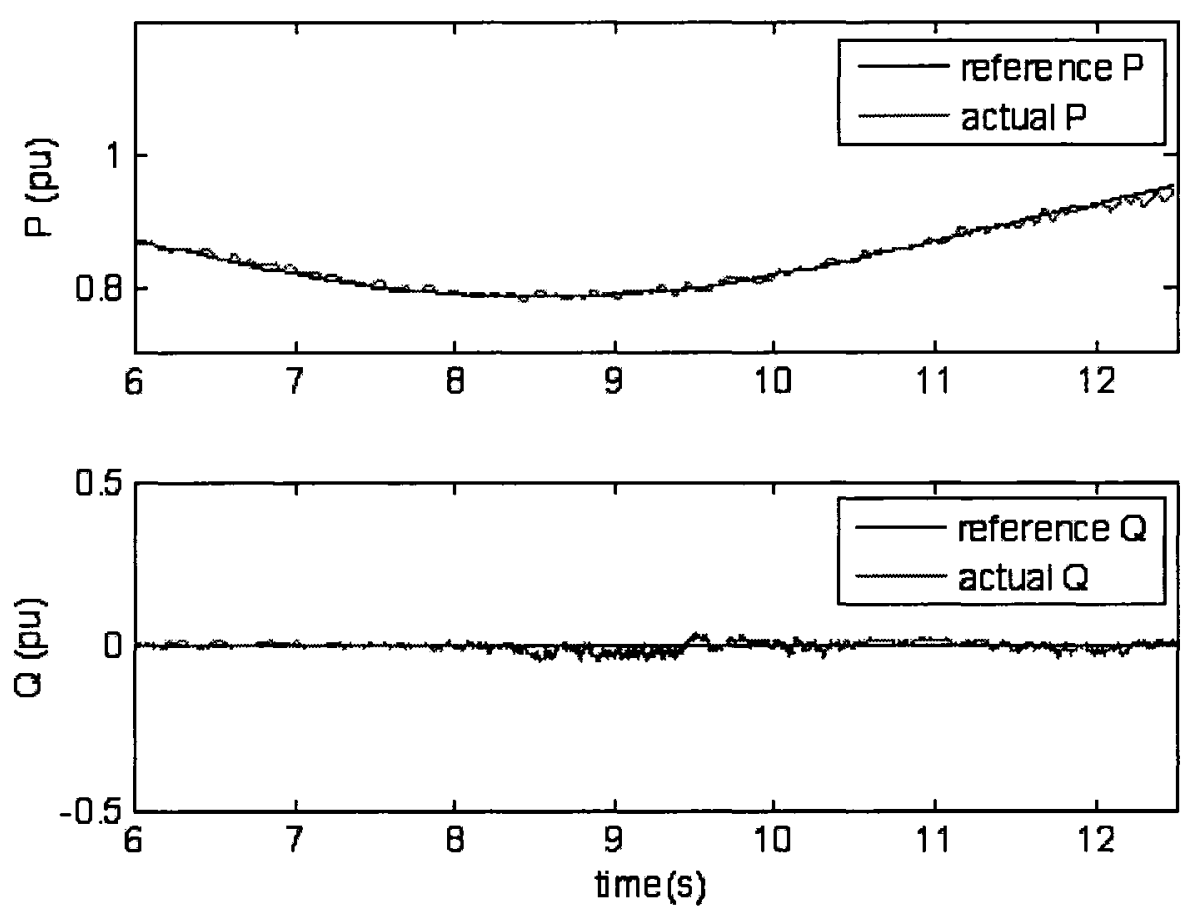

Figure 5.23: Complete DFIG system performance, P-Q control - constant generator torque (1 p.u.) variable $P$ s reference, constant $Q$ s reference $(Q s=0$ p.u. $)$ - variables: reference and actual $P s$ and $Q s ~ v s$ time 

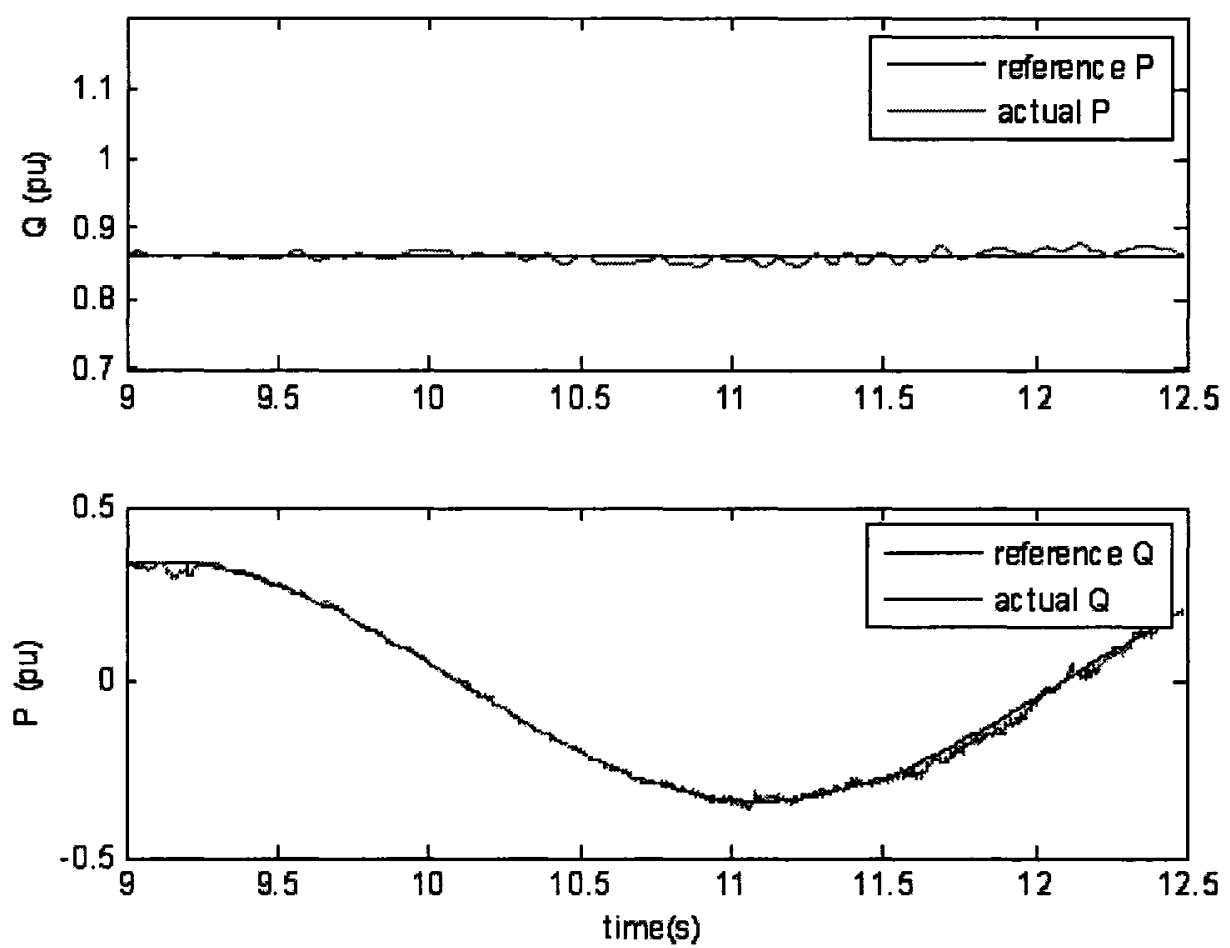

Figure 5.24: Complete DFIG system performance, P-Q control - constant generator torque (1 p.u.) variable $Q s$ reference, constant Ps reference $(P s=-0.875$ p.u.) - variables: reference and actual $P s$ and $Q s$ vs time

In the next test shown Figure 5.25, the input torque (wind speed) is varied, while the reference real and reactive powers are kept constant. From the results we see whereas the reactive power is maintained constant, the real power has a small oscillation (less than $3 \%$ ). In order to make a comparison, for an exact torque input, results for a wind energy conversion system with an induction generator (IG) without any control are shown in Figure 5.26. Hence, we see that there is significant reactive power in the output (around 1 p.u., instead of 0 p.u. with control), and a much larger oscillation in the output power without any control. 

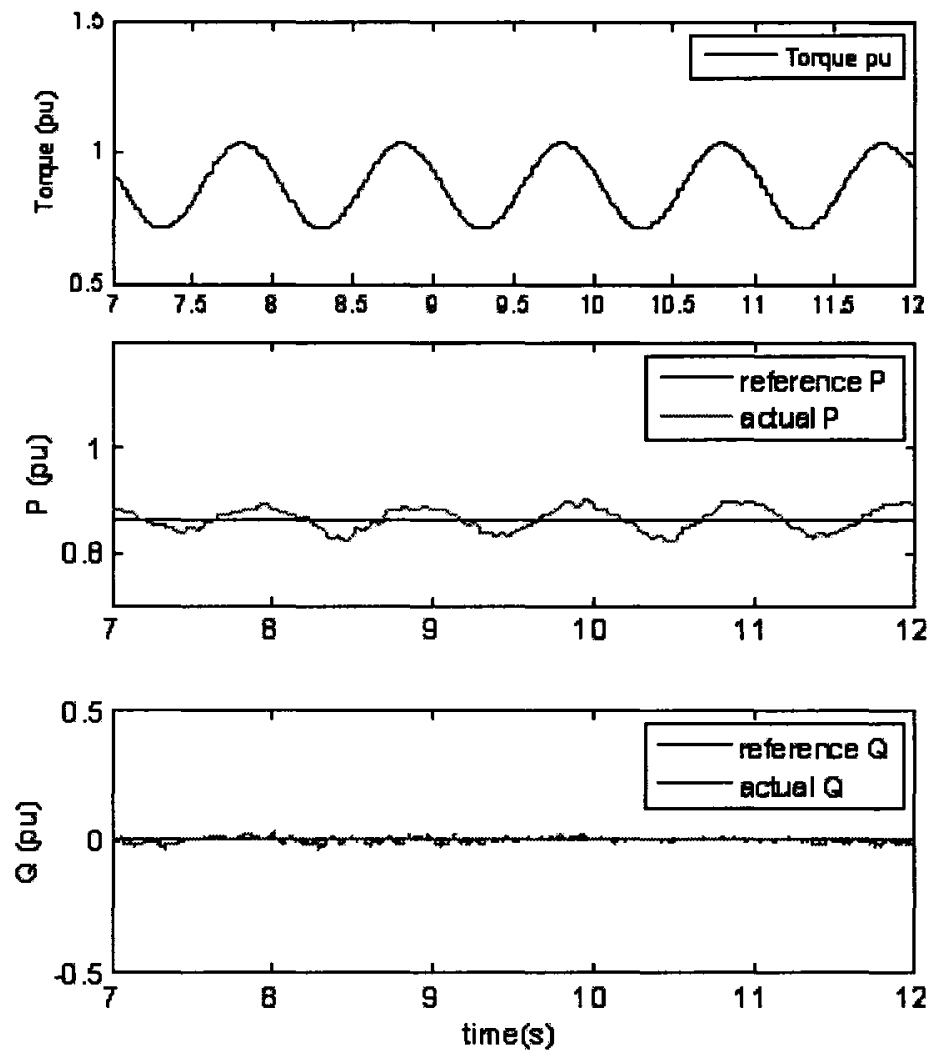

Figure 5.25: Complete DFIG system performance, P-Q control - variable generator torque- constant Qs reference, constant Ps reference ( $P s=-0.825$ p.u.) - variables: torque, reference and actual $P s$ and $Q s$ vs time
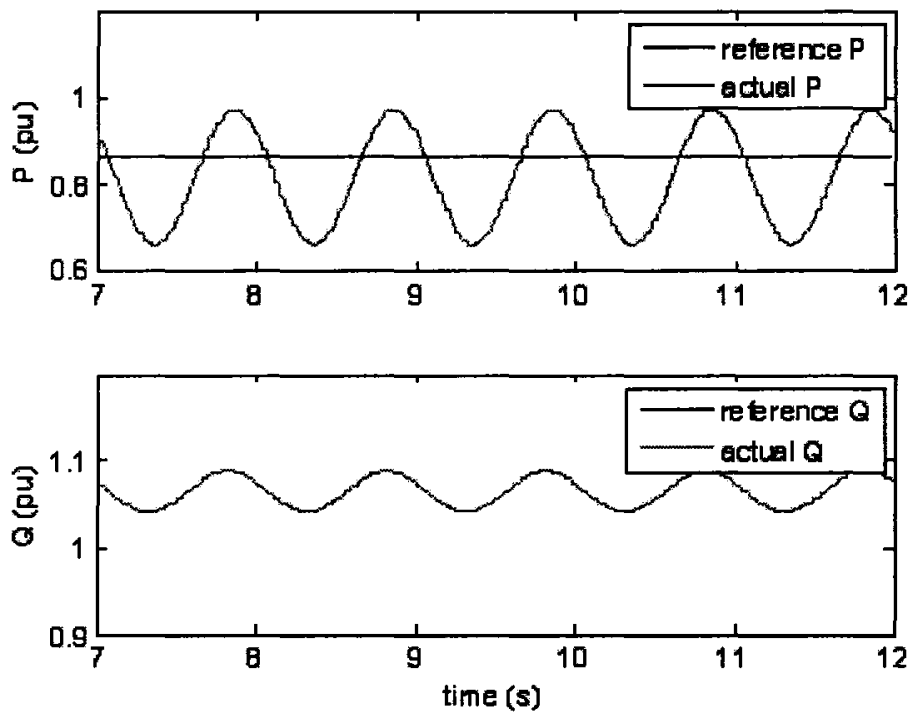

Figure 5-26: Induction generator connected to the ac grid, no P-Q controller - variable generator torque variables: reference and actual Ps and Qs vs time

The final test involves adjusting the input torque for a variable wind speed and adjusting the reference power accordingly for maximum power output of the wind 
turbine, while maintaining the reference reactive power constant. As seen in Figure 5.27, for a change of input torque, the DFIG tracks the reactive and real stator power references. Figure 5.28 shows the actual and estimated speed, which goes both above and below synchronous speeds. The estimated speed is able to track the real speed, even close to synchronous speed. Also shown are the rotor currents to illustrate that from a change from below to above synchronous speeds, the current goes from positive sequence to negative sequence. Also shown is the dc bus voltage, which remains constant with little variation despite a change in power flow at the dc bus. Figure 5.29 shows the stator current, which is $180 \mathrm{deg}$. out of phase from the voltage and the grid converter current which is in phase with the grid converter voltage.

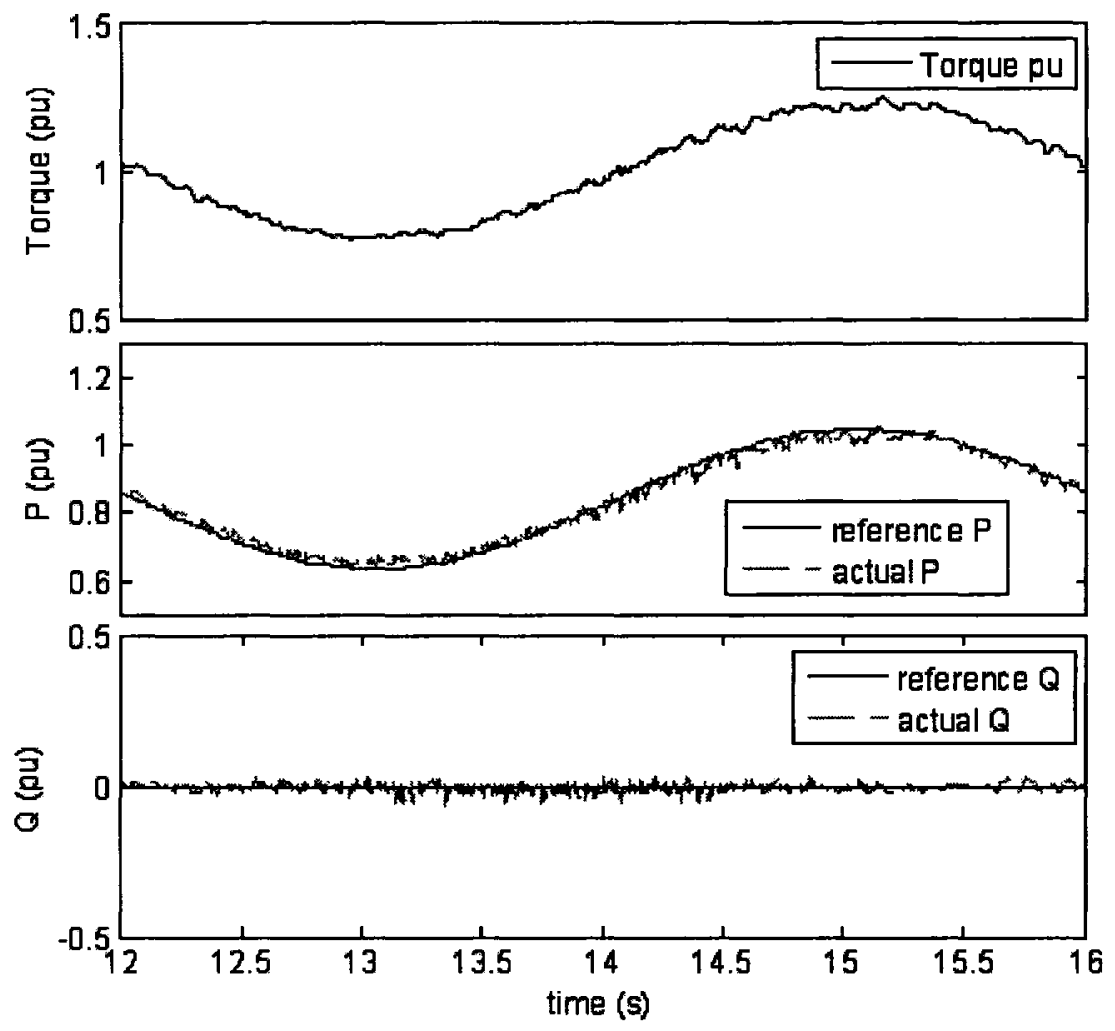

Figure 5.27: Complete DFIG system performance, P-Q control -variable generator torque- variable Ps reference, constant $Q$ s reference $(Q s=0$ p.u.) - variables: torque, reference and actual $P s$ and $Q s$ vs time 

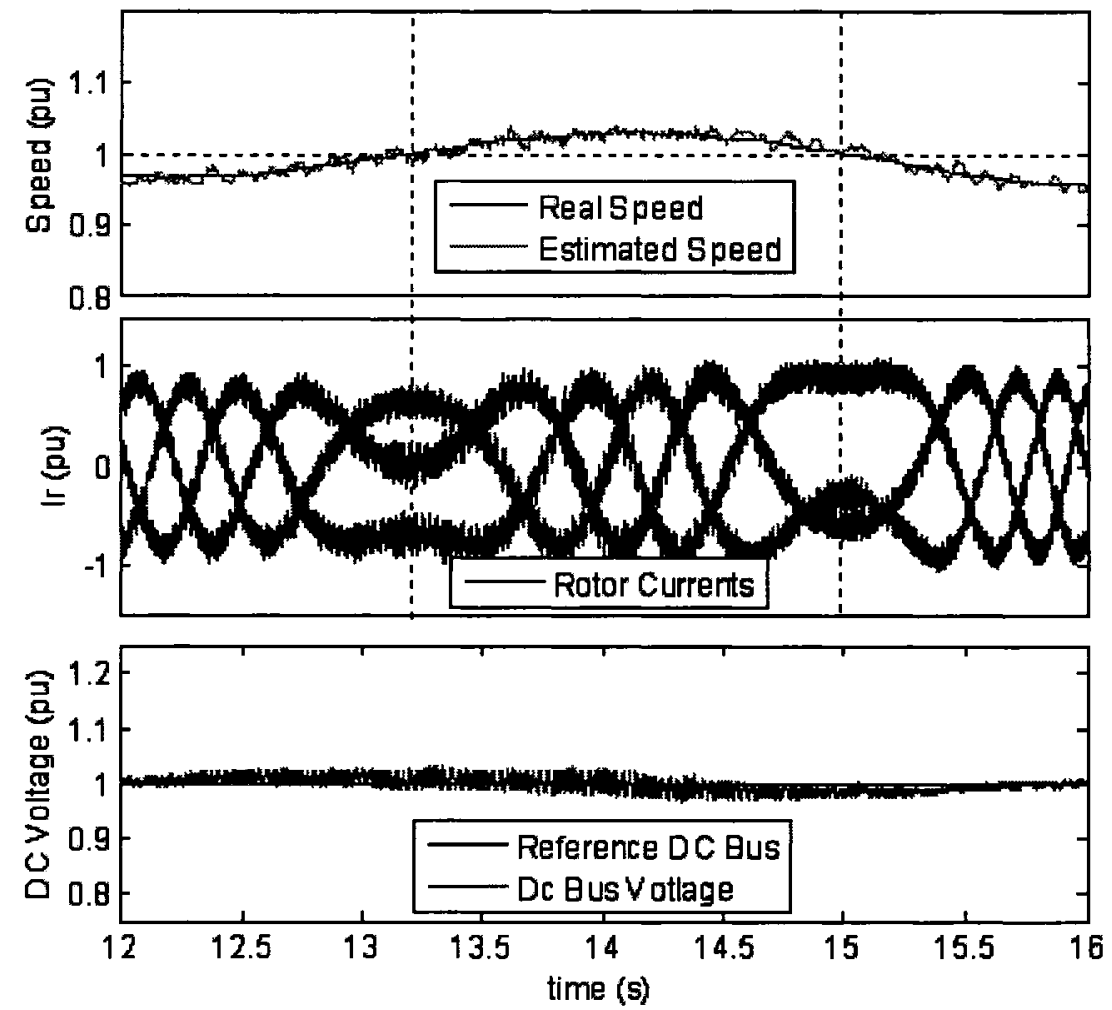

Figure 5.28: Complete DFIG system performance, $\mathrm{P}-\mathrm{Q}$ control -variable generator torque- variable Ps reference, constant $\mathrm{Qs}$ reference $(\mathrm{Q} s=0$ p.u. $)$ - variables: speed, rotor currents and dc bus voltage vs time

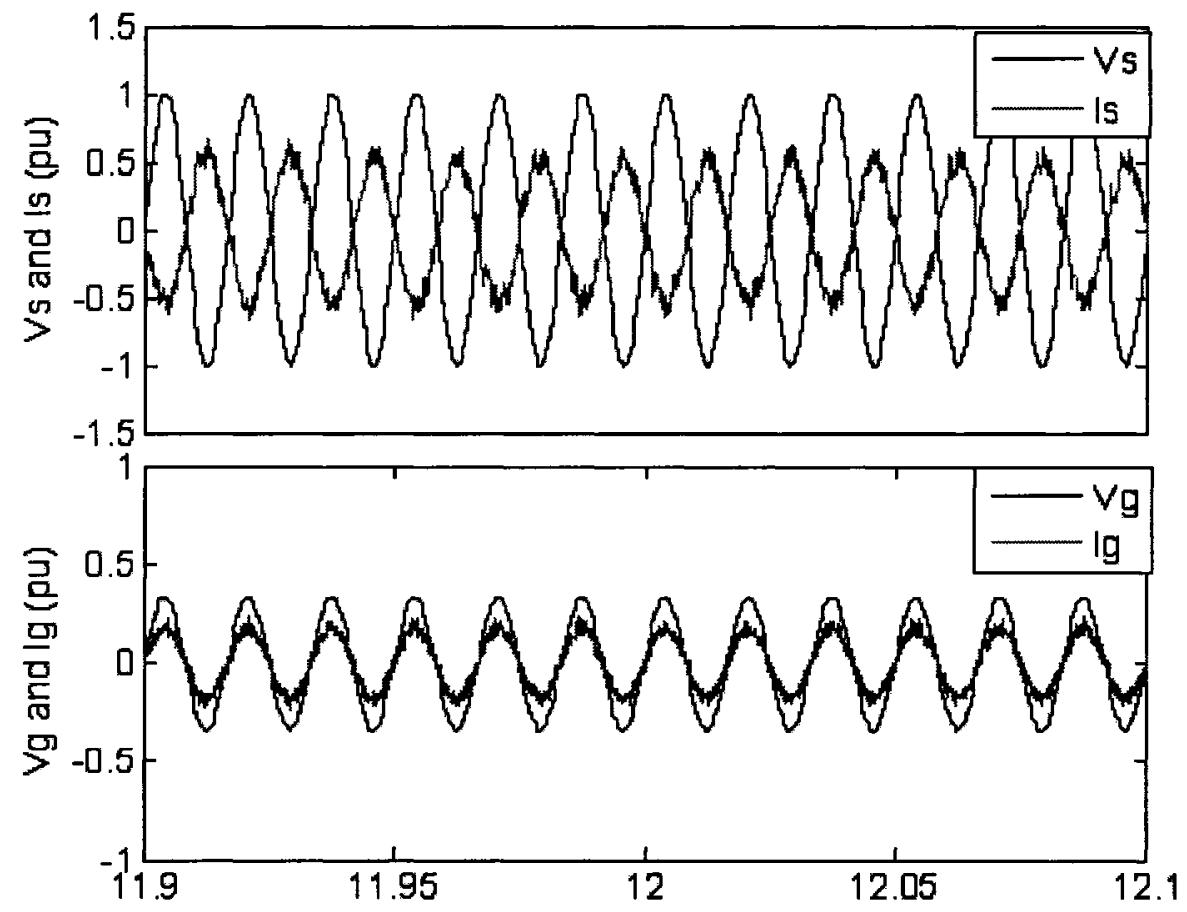

Figure 5.29: Complete DFIG system performance, P-Q control -variable generator torque- variable Ps reference, constant $Q s$ reference $(Q s=0$ p.u.) - variables: grid converter voltage Vg and current Ig vs time 


\section{Chapter 6: Experimental Validation}

\subsection{Introduction}

The experimental equipment used is described in more detail in Appendix A. OPAL-RT facilitates the development, testing and optimization of control algorithms. Once the algorithm was implemented in Matlab/Simulink, it was translated into a RealTime Interface using a powerful digital controller based on INTEL Core 2 Duo processors. The digital controller allows real-time testing of the algorithm, by taking as inputs the voltages and currents measured by the sensors and outputting the gating signals which are used as inputs to Semikron power electronic devices. The power electronic devices allow for control of the dc bus voltage, line power (P-Q) and machine speed. As mentioned in Chapter 2, identification tests were done to obtain the machine parameters of the induction machine, which is used as a generator. A variable torque drive is used to emulate the wind energy. Appendix B shows the complete experimental setup. First the accuracy of the sensorless speed algorithm is evaluated. Then, the grid-side and machineside converters are tested separately. Finally, the performance of the entire DFIG decoupled control algorithm is evaluated.

\subsection{Sensorless Speed Measurement}

The experimental setup of the sensorless speed measurement algorithm is shown in Figure 6.1. The wound-rotor induction machine has its rotor windings shorted and is driven speeds above and below the synchronous speed by an external prime mover (in our case a dc machine). The induction machine operates both as a generator and a motor. 


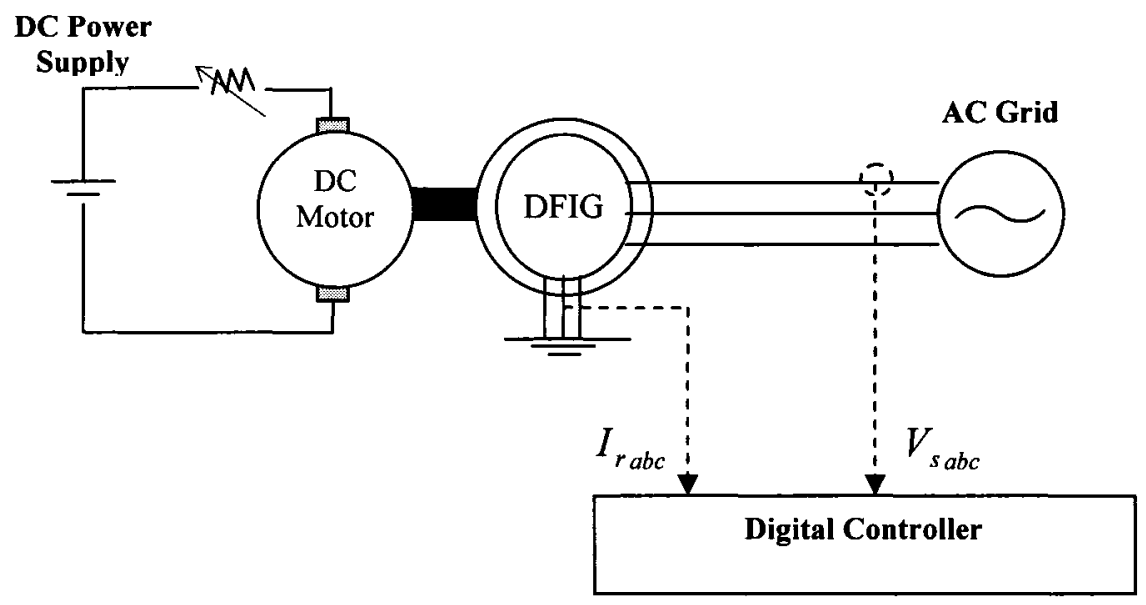

Figure 6.1: Speed sensorless measurement - experimental setup

Experimental results showing the induction machine running both below and above synchronous speeds are shown in Figure 6.2. The discontinuities occur due to the fact at synchronous speed, the rotor currents are nearly zero, and hence, the current sensors are unable to read their values. However, when the rotor is fed a voltage there is no discontinuity around the synchronous speed. Note that during motor operation, the rotor currents are in the $a b c$ sequence, whereas, in the generator operation, the currents are in the $a c b$ sequence. Figure 6.3 shows the plot for different speed measurements made with an analog speed sensor and the estimated speed. We see that the algorithm is able to estimate the speed within very small range of error. Since the estimation of the speed is independent of the values of machine parameters, the DFIG is able to track the reference speed without any steady-state error. 


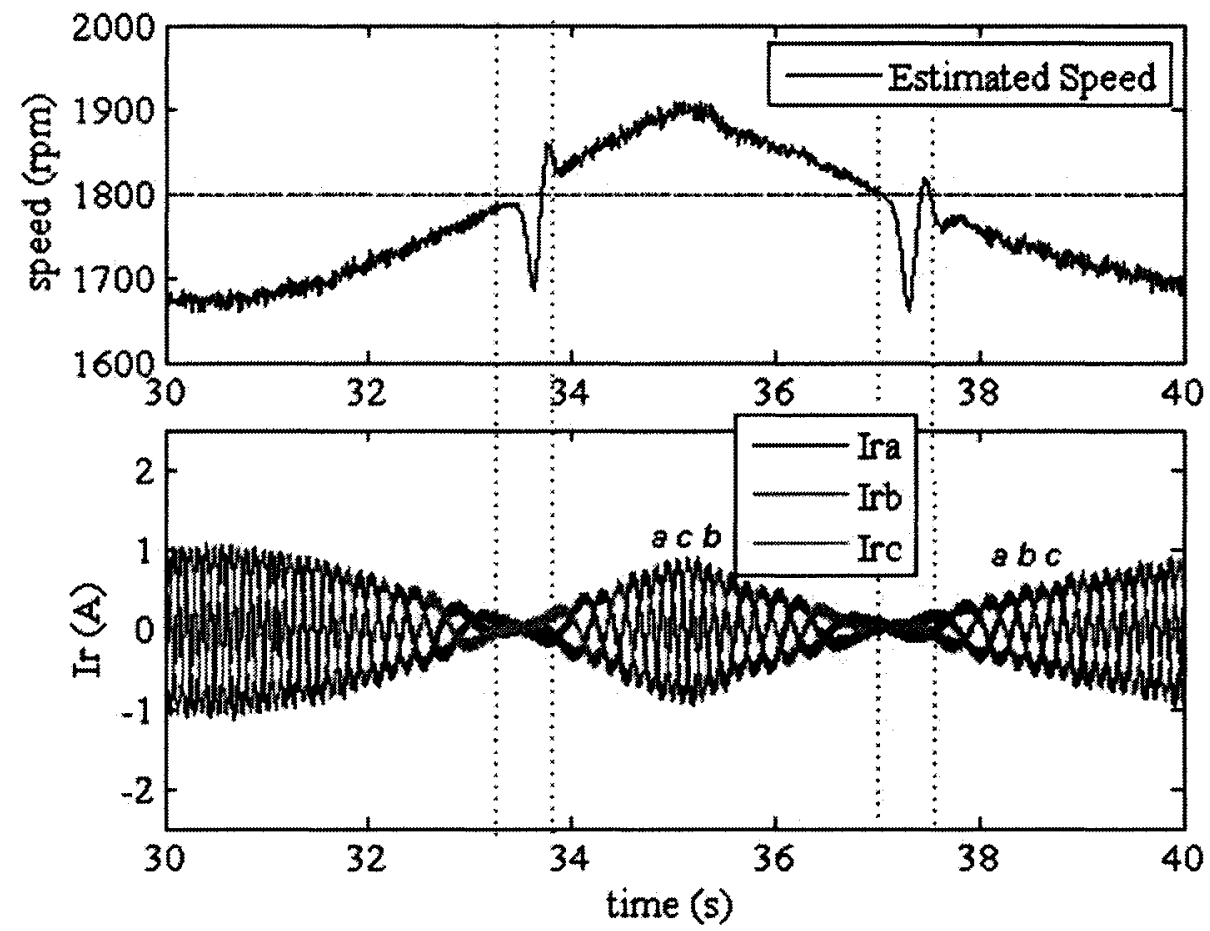

Figure 6.2: Sensorless speed measurement - variable input torque, shorted rotor - above and below synchronous speed (generator and motor operation) - variables: estimated speed and rotor currents vs time

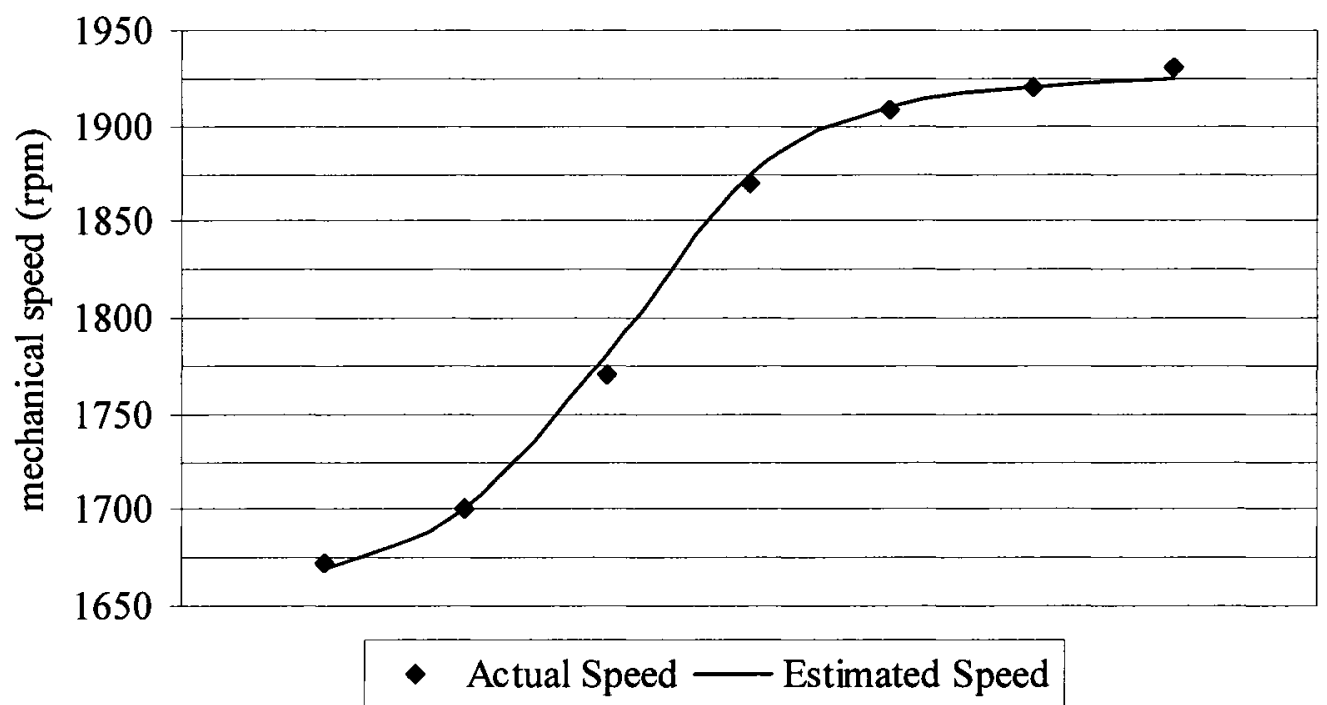

Figure 6.3: Sensorless speed measurement - variable input torque, shorted rotor - above and below synchronous speed (generator and motor operation) - variables: estimated and actual speeds in stead-state

\subsection{Machine-Side Converter Operation}

The machine-side converter feeds the DFIG rotor with the active and reactive power necessary to optimize the wind power acquisition and control the stator side power 
factor. It uses the sensorless speed and position algorithms as part of its implementation. The experimental setup is shown in Figure 6.4. The digital controller receives as input the three-phase ac voltages and currents and outputs the gating signals. The machine-side converter is connected to the rotor of the induction machine. The diode rectifier converts the ac voltage to a constant dc voltage at the dc bus. A resistor is placed in parallel to the dc bus in order to absorb the power fed from the rotor to the dc bus

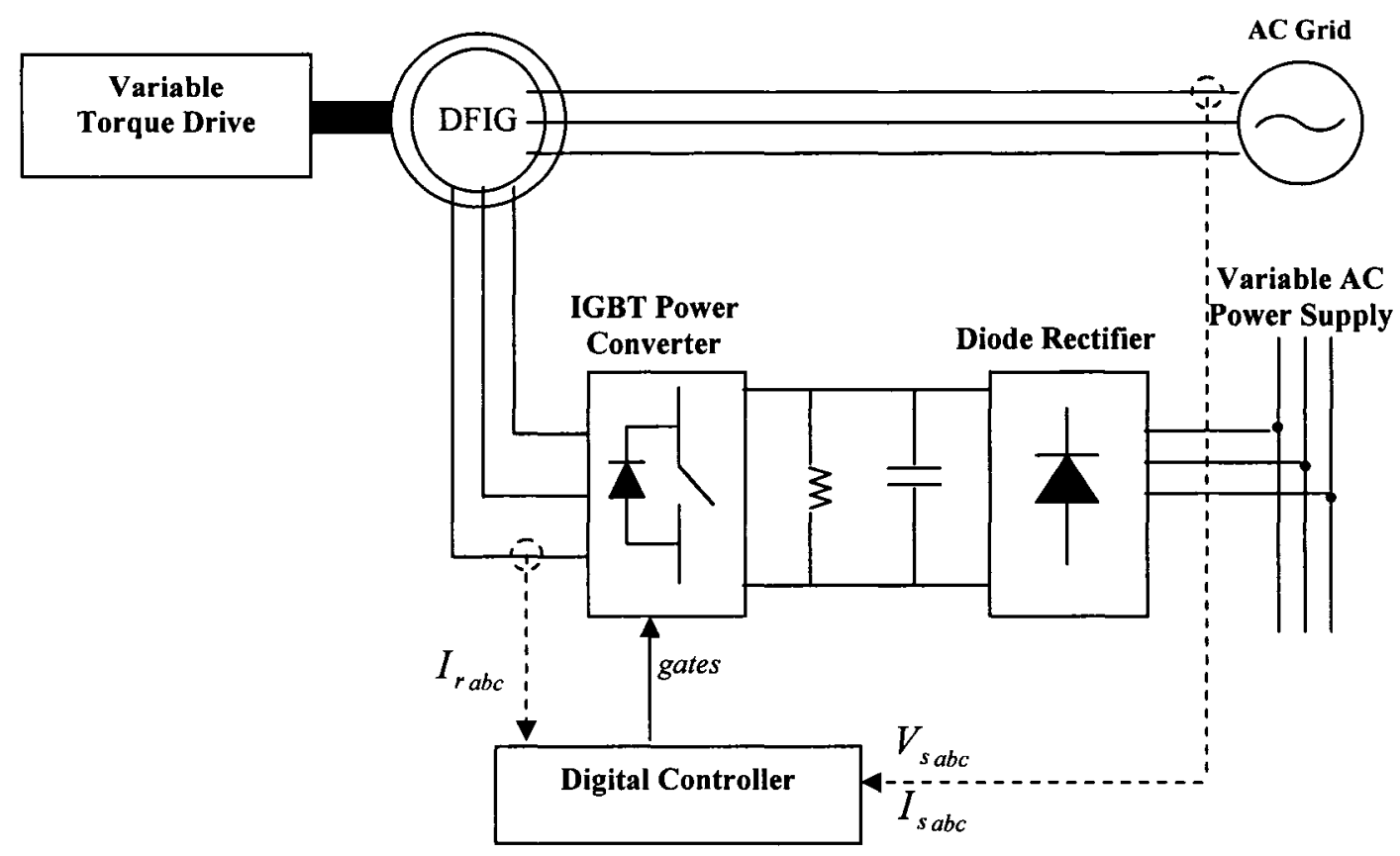

Figure 6.4: Machine-side converter - experimental setup

The controller in first tested for changes of reference speed and constant reactive power. From the experimental results shown in Figure 6.5, we find that there are no steady-state errors for the speed and reactive power compared to their reference values. The plots of the stator currents and voltages are also shown in Figure 6.6. They are 180 deg. out of phase as expected (since the induction machine is in generator operation). 

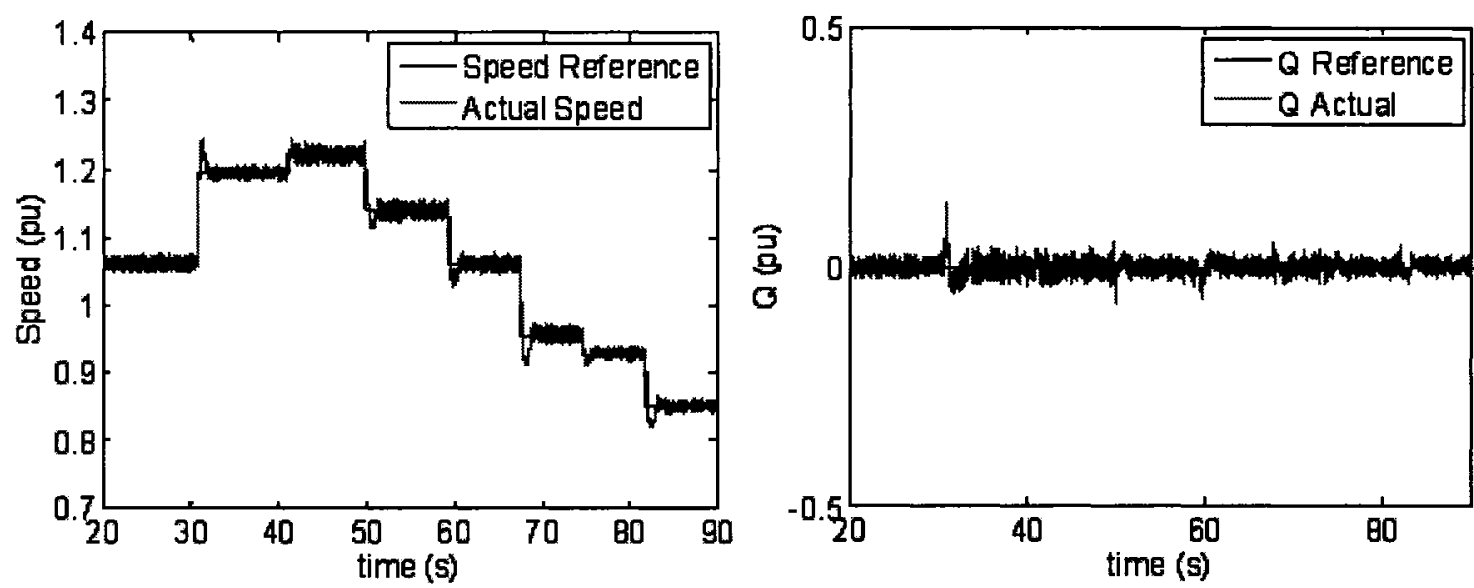

a)

b)

Figure 6.5: Machine-side converter, speed and $Q$ control - unregulated generator torque ${ }^{1}$ - variable speed reference, constant $Q s$ reference $(Q s=0$ p.u.) - above and below synchronous speed (generator operation) a) actual and reference speed vs time b) real and reference $Q s$ vs time

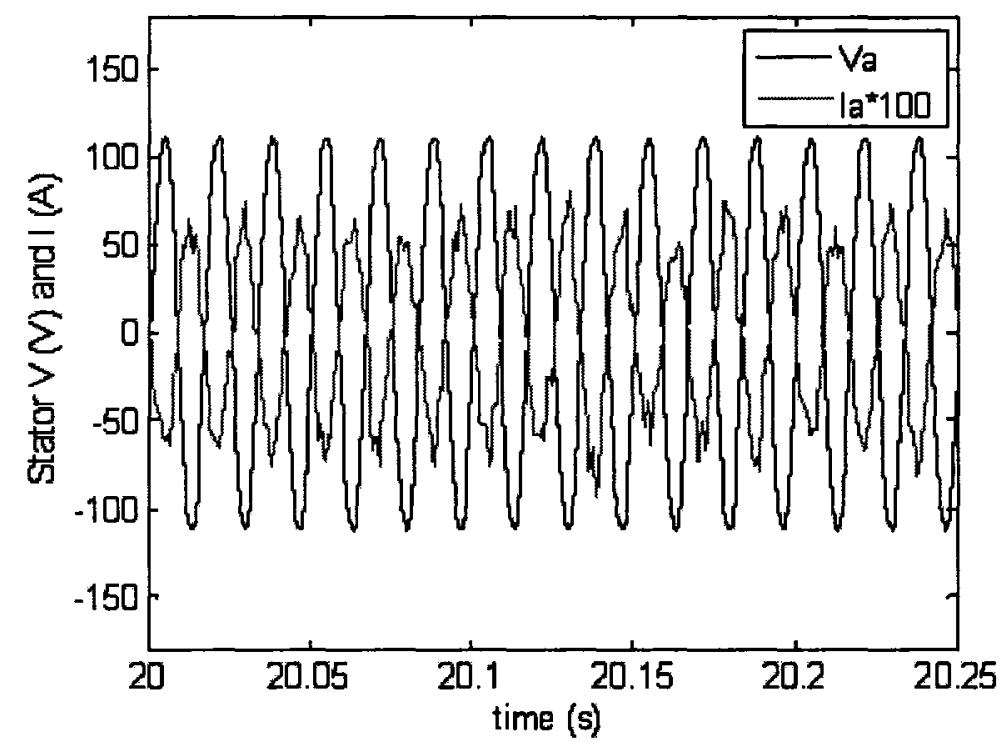

Figure 6.6: Machine-side converter, speed and $\mathrm{Q}$ control -unregulated generator torque - operating speed: $1.07 \mathrm{rated}$ speed, $200 \mathrm{rad} / \mathrm{s}$, constant $\mathrm{Qs}$ reference $(\mathrm{Qs}=0 \mathrm{p} . \mathrm{u}$. $)$ - variables: stator voltage $\mathrm{Va}$ and current Ia vs time

Figure 6.7 shows the experimental results for a variable reference reactive power and a constant reference speed. Again, we find that there are no steady-state errors for the speed and reactive power compared to their reference values. Also, we see a quick dynamic response of the reactive power tracking the reference value (less than $1 \mathrm{~s}$ for a

\footnotetext{
' Field current of $\mathrm{dc}$ machine is maintained constant, whereas torque is not explicitly controlled
} 
reference change of 0.25 p.u.). Figure 6.8 shows the stator voltages and currents for different values of reactive power reference.
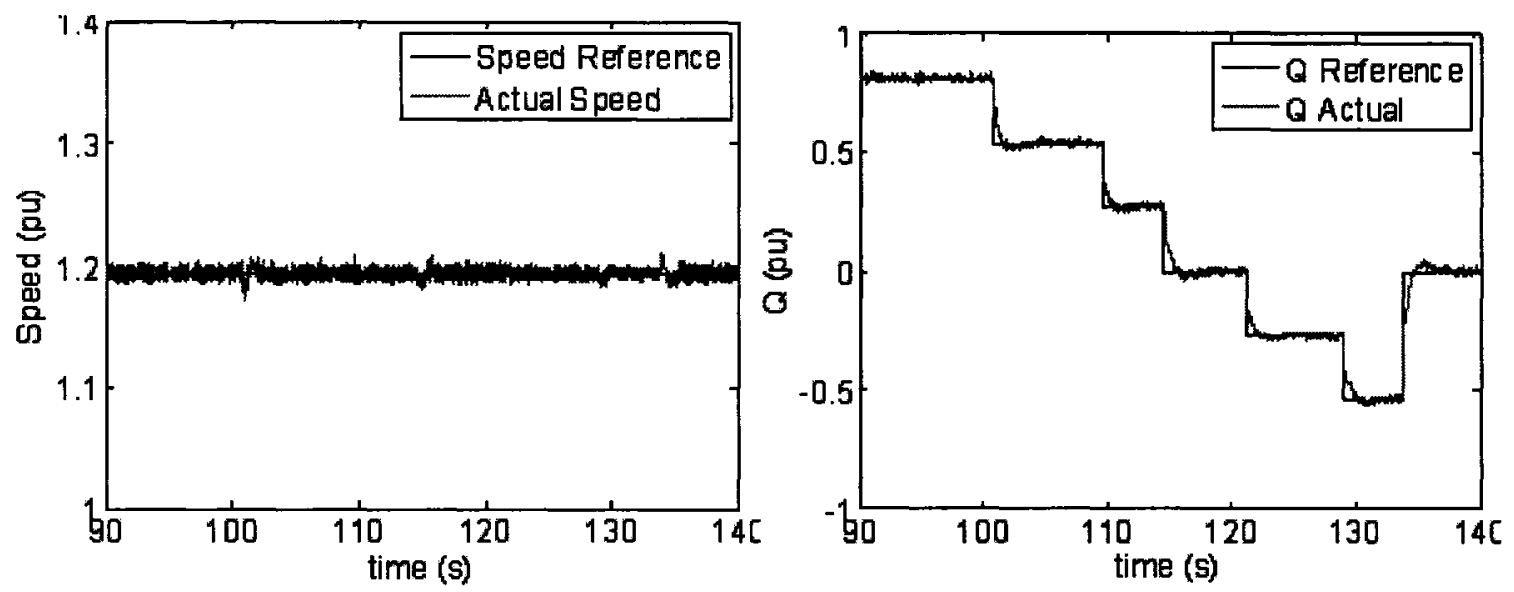

Figure 6.7: Machine-side converter, speed and Q control - unregulated generator torque - variable Qs reference, constant speed reference (speed $=1.2$ p.u.)

a) actual and reference speed vs time b) real and reference $Q s$ vs time
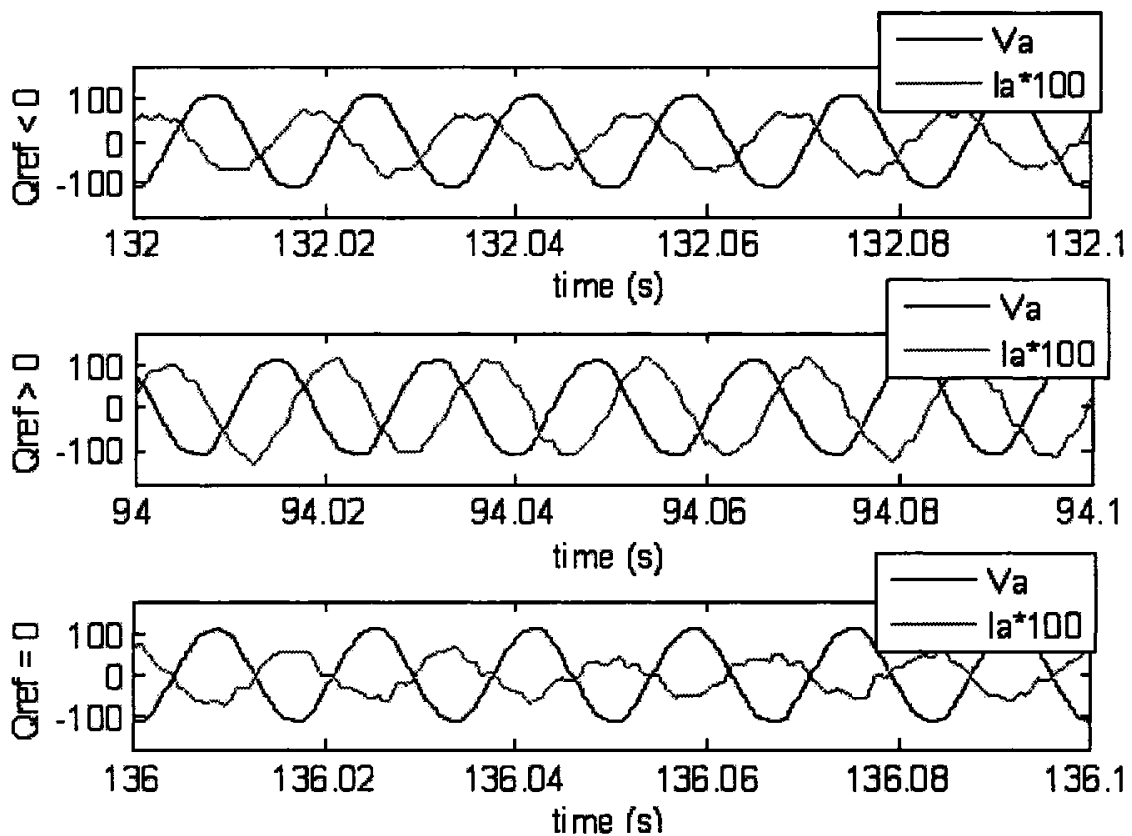

Figure 6.8: Machine-side converter, speed and $Q$ control -unregulated generator torque - variable Qs reference, constant speed reference (speed $=1.2$ p.u.) - variables: stator voltage $\mathrm{Va}$ and current Ia $(\mathrm{Q} s=-0.5$ p.u.; $\mathrm{Qs}=0.8$ p.u.; $\mathrm{Qs}=0$ p.u. $)$

\subsection{Grid-Side Converter Operation}

The main objective of the grid-side converter is to maintain control of the voltage level on the dc bus capacitor by exchanging active power with the grid. The experimental 
setup for the grid-side converter is shown in Figure 6.9. This setup is composed of the digital controller, the current and voltage sensors and the IGBT power converter. A rheostat (set to $300 \mathrm{ohms}$ ) is placed in parallel to the dc bus capacitor. The digital controller receives as input the three-phase ac voltages and currents and outputs the gating signals.

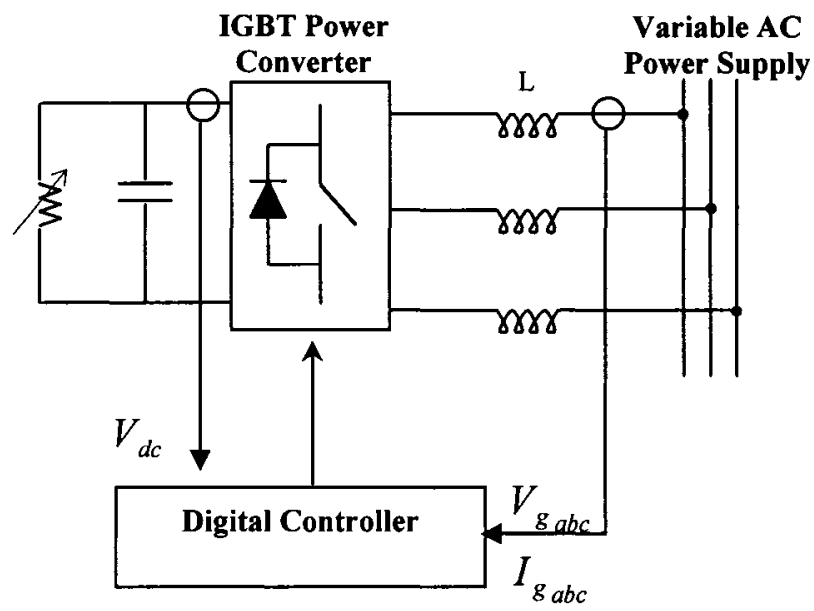

Figure 6.9: Grid-side converter - experimental setup

The first experimental test involves varying the value of the reference dc voltage. The results are shown in Figure 6.10. As we can see, the response is nearly instantaneous, with no overshoot; hence, the dc bus voltage controller is well designed.

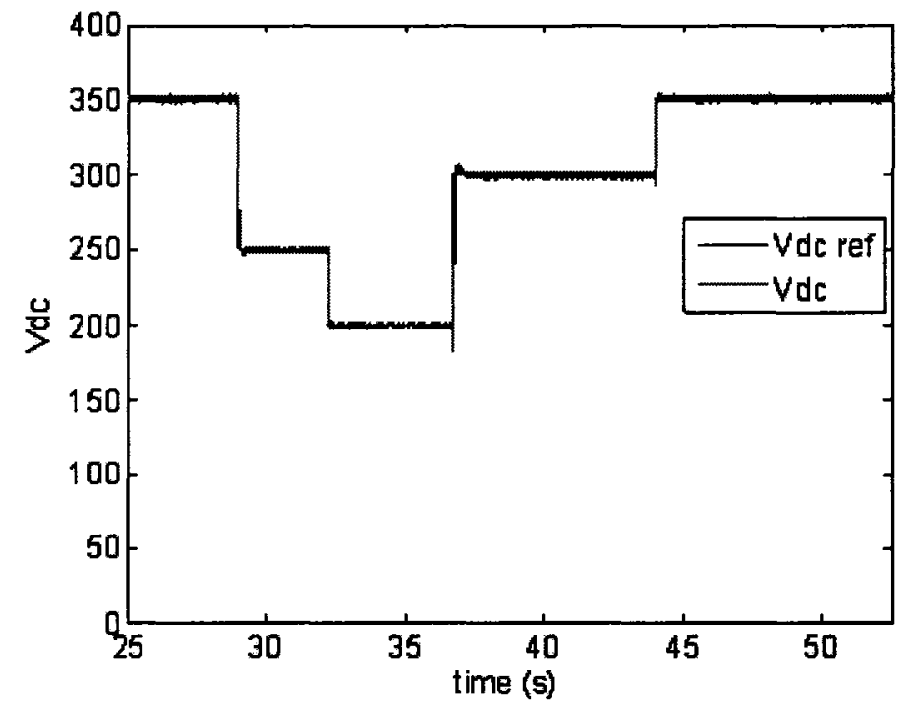

Figure 6.10: Grid-side converter, dc bus voltage controller - constant $Q g$ reference $(Q g=0$ p.u. $)$, step changes of dc bus voltage reference - variables: reference and actual Vdc vs time 
For the next test, the reference reactive power is varied for a constant dc voltage reference. The reference and real current are shown system in Figure 6.11. Also shown are the current and voltage for different reactive power references in Figure 6.12. There is a $5^{\text {th }}$ harmonic present, which is caused by the autotransformer's magnetizing current of the variable ac source. This phenomena is inherent in small transformers due to lower saturation levels (magnetizing curve).

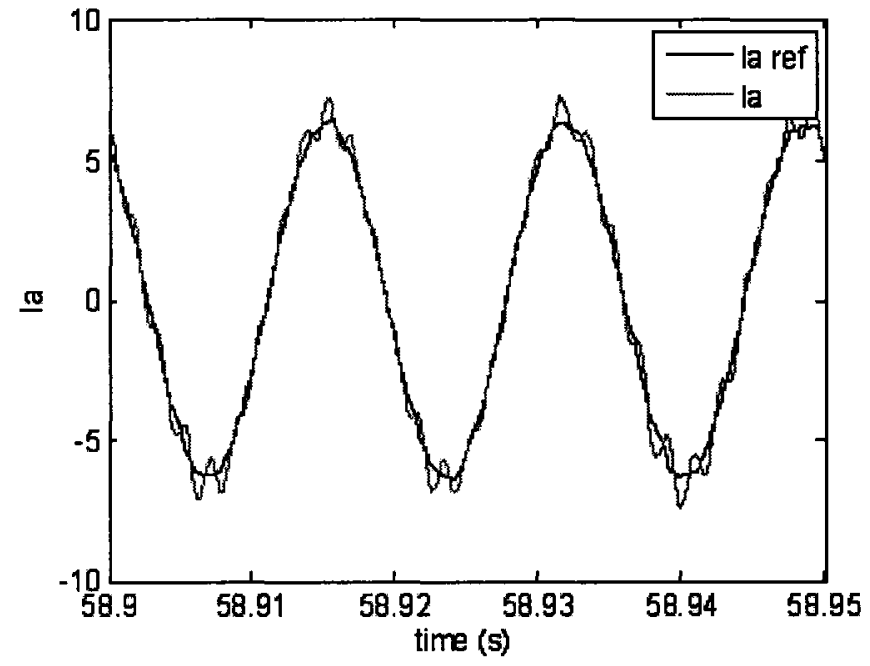

Figure 6.11: Grid-side converter, performance reactive power controller - step changes in reactive power - constant $\mathrm{dc}$ voltage reference $(\mathrm{Vdc}=350 \mathrm{~V})$, constant $\mathrm{dc}$ bus resistive load - variables: reference and actual grid converter current Ig vs time
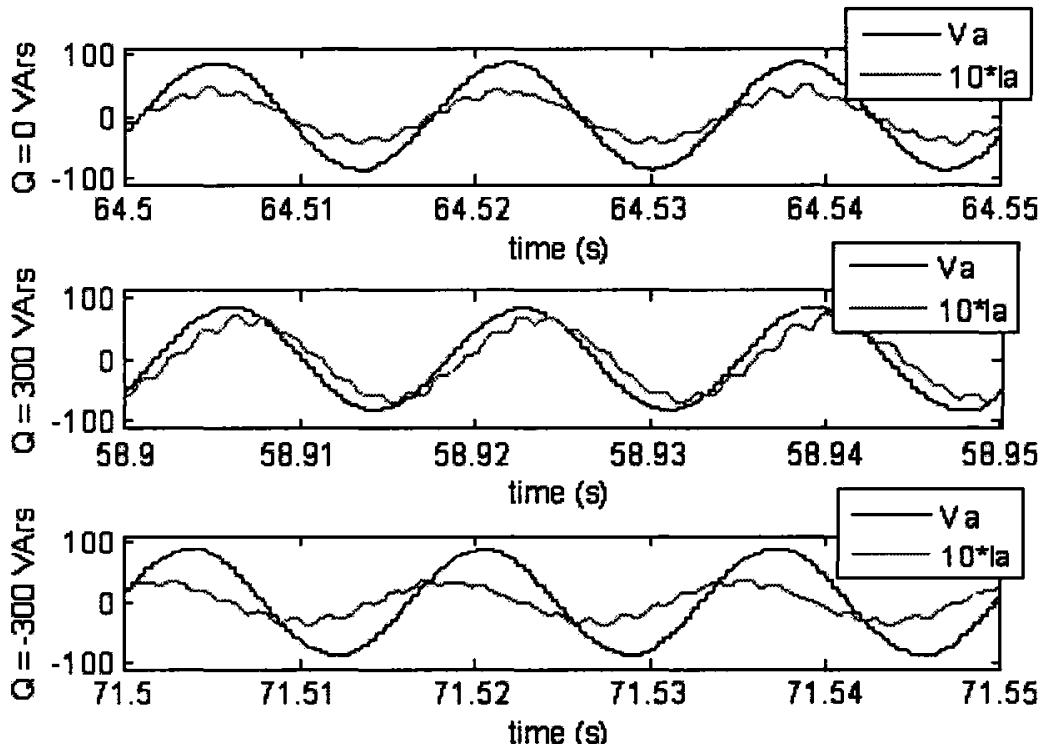

Figure 6.12: Grid-side converter, performance reactive power controller - step changes in reactive power constant dc voltage reference $(\mathrm{Vdc}=350 \mathrm{~V})$, constant $\mathrm{dc}$ bus resistive load - variables: grid converter voltage $\mathrm{Vg}$ and current Ig vs time $(\mathrm{Qs}=0 \mathrm{VArs} ; \mathrm{Qs}=300 \mathrm{VArs} ; \mathrm{Qs}=-300 \mathrm{VArs})$ 
The next test involved keeping the reference voltage constant and varying the power consumed by the dc load bus. To conduct this test, three rheostats connected in series are used. Two are rated at $100 \Omega$ and the other is variable, between 0 and $100 \Omega$, which is varied in order to model variations in power (due to the relationship $P=V^{2} / R$ ). From Figure 6.13 , it is seen that the dc bus voltage remains constant even with a change of the value of power at the dc bus.
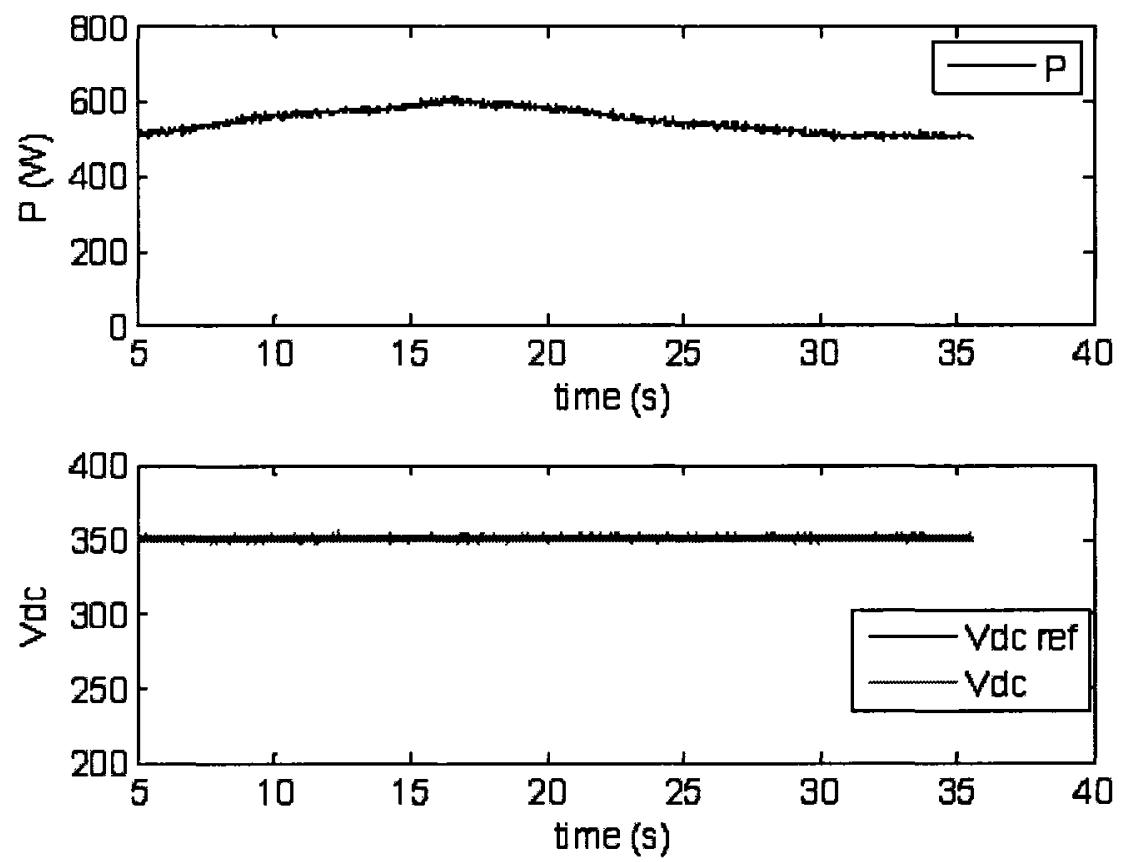

Figure 6.13: Grid-side converter, performance power controller - variable resistive load - constant dc voltage reference $(\mathrm{Vdc}=350 \mathrm{~V}$, constant $\mathrm{Qg}$ reference $(\mathrm{Qg}=0$ p.u. $)$ - variables: grid converter voltage $\mathrm{Vg}$ and current Ig vs time

\subsection{Complete DFIG System Performance}

The experimental setup of the overall system is shown in Figure 6.14. A variable torque drive is used to emulate the wind turbine. A wound-rotor induction machine is also used, for which identification tests were to determine its machine parameter values. Two power converters are used, one for the grid-side converter and the other for the 
machine-side converter. The converters allow for control of the dc bus voltage, line power (P-Q) and machine speed. The power factor of the grid-side converter is set at unity; the reactive power fed to the grid is controlled exclusively by the machine-side converter. The controller interface takes as inputs the voltage and current values of the DFIG stator and rotor windings and outputs the gating signals of the converters.

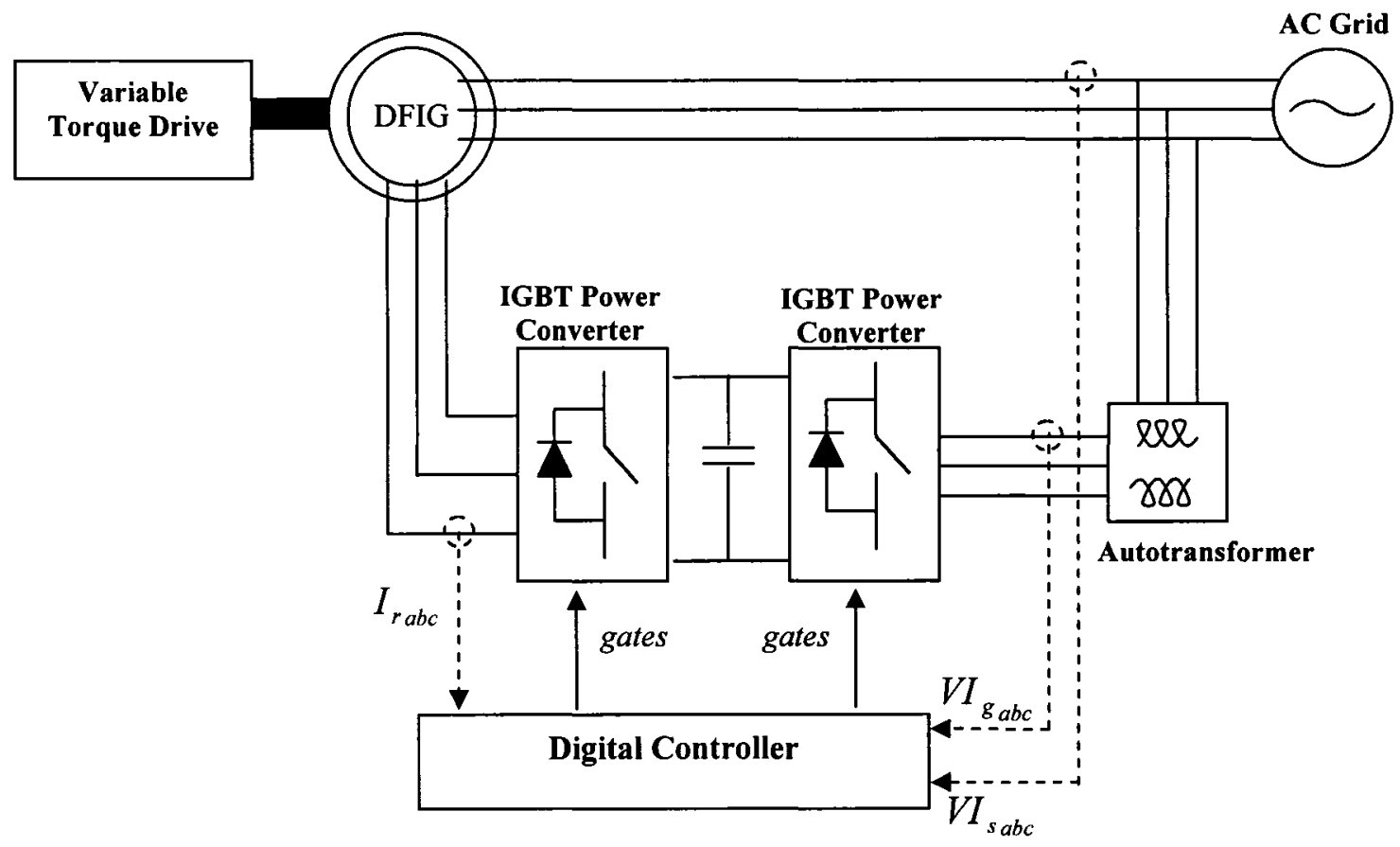

Figure 6.14: Complete DFIG system - experimental setup

Figure 6.15 shows the result for a varying reference power and constant reference reactive power. Figure 6.16 shows the results for constant reference power and variable reference reactive power. We find that there are no steady-state errors for the real and reactive powers compared to their reference values and the control of the real and reactive powers are independent (decoupled control). Figure 6.17 shows the stator voltage and currents for different values of reactive power reference. 

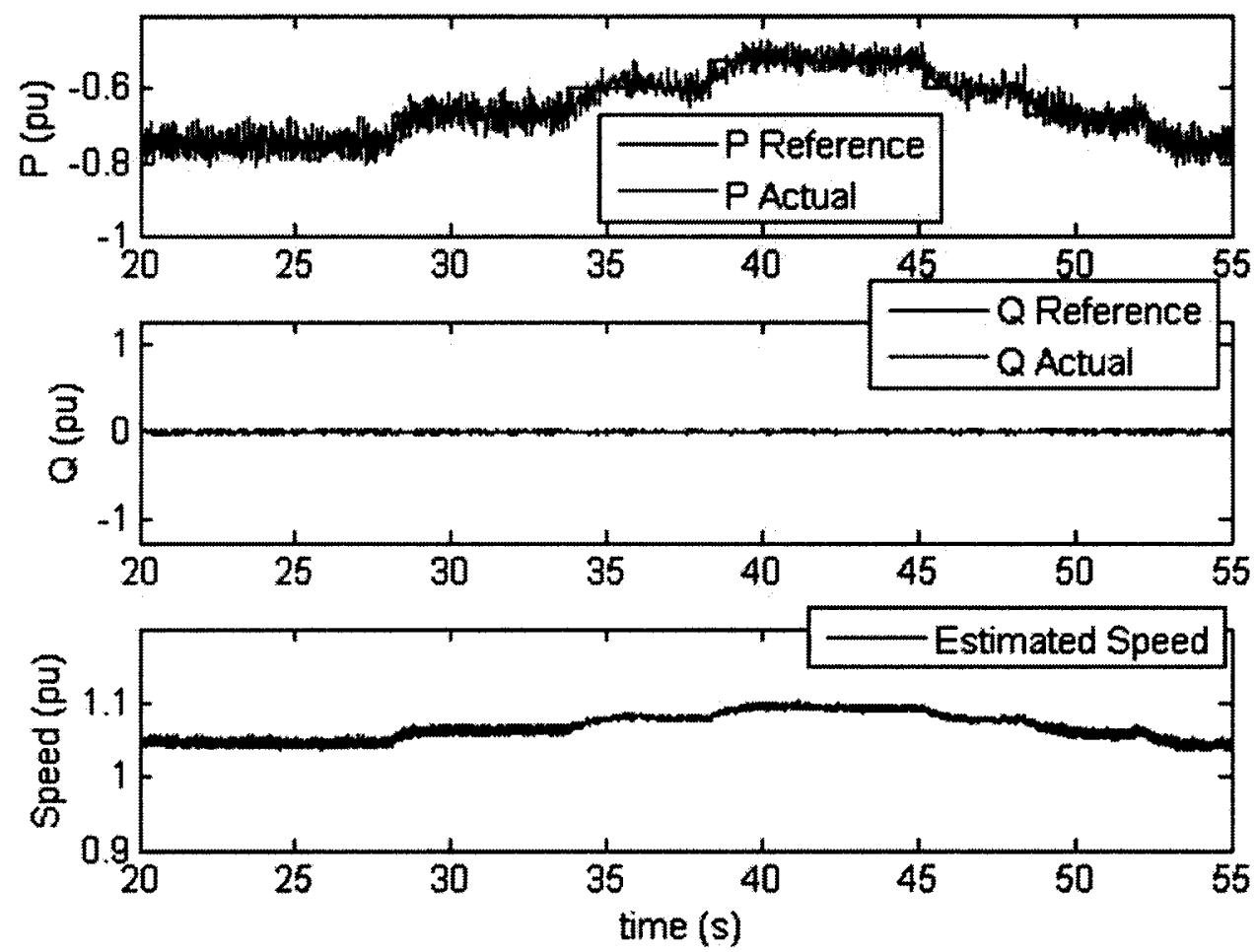

Figure 6.15: Complete DFIG system performance, P-Q control - unregulated generator torque - variable Ps reference, constant Ps reference $(Q s=0$ p.u.) - variables: reference and actual Ps and Qs and speed vs time
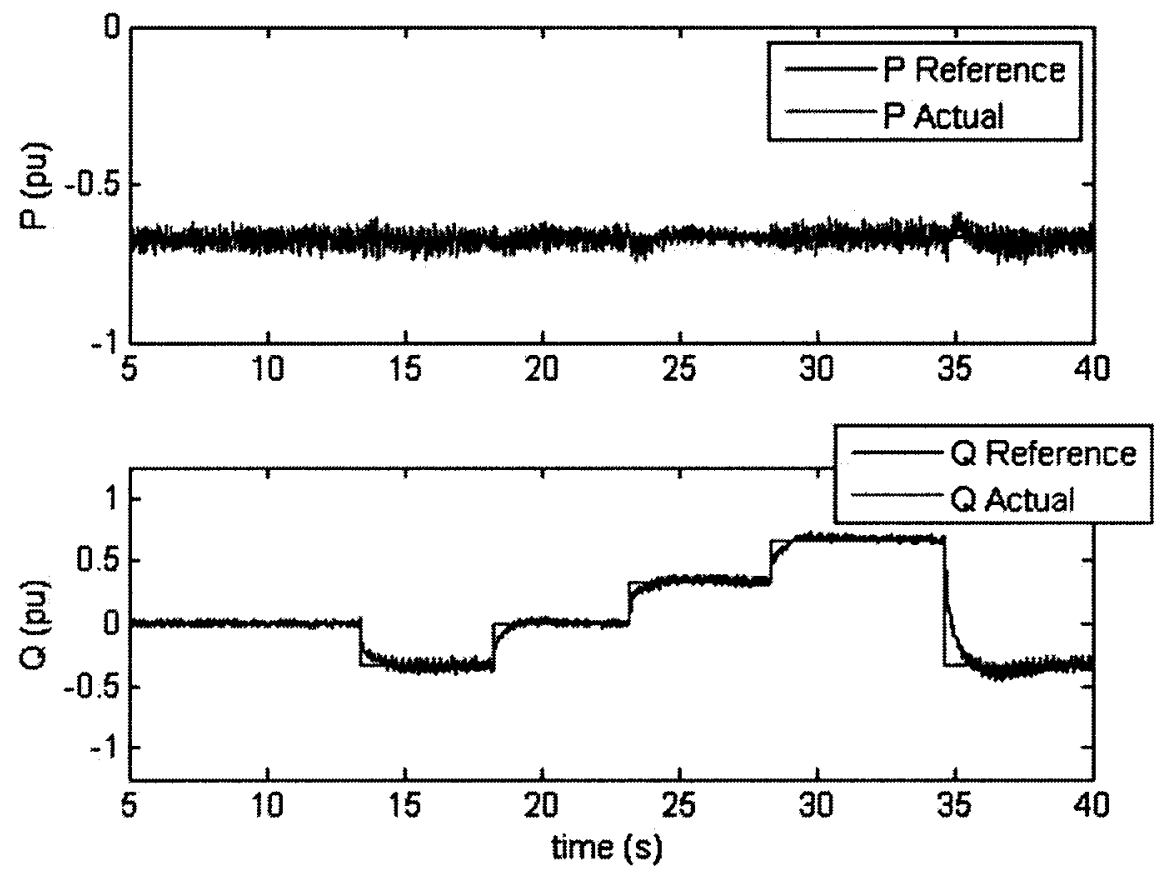

Figure 6.16: Complete DFIG system performance, $\mathrm{P}-\mathrm{Q}$ control - unregulated generator torque - variable Qs reference, constant Ps reference (Ps = -0.7 p.u.) - variables: reference and actual Ps and Qs vs time 

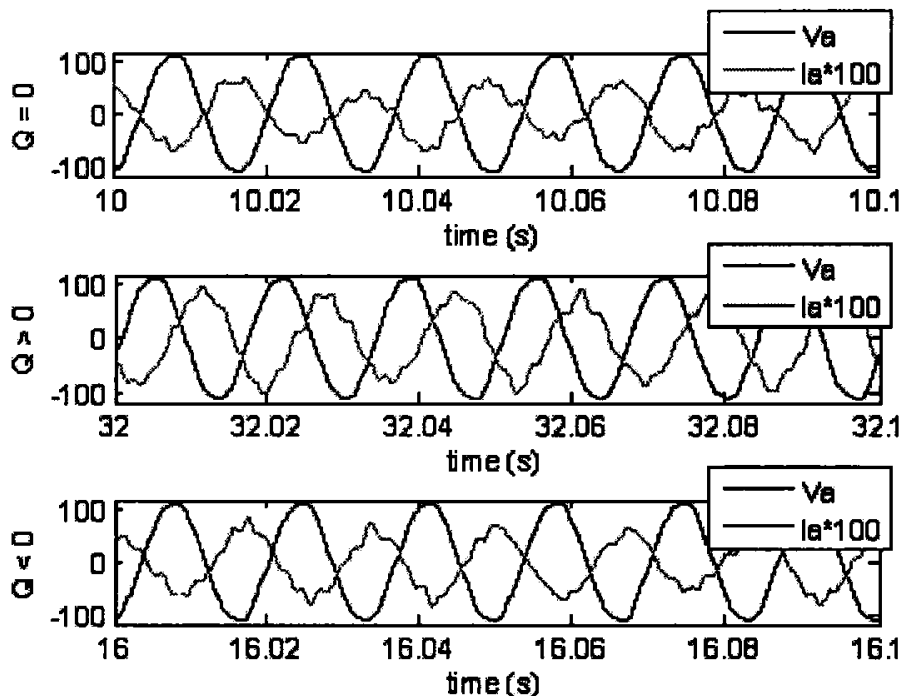

Figure 6.17: Complete DFIG system performance, $\mathrm{P}-\mathrm{Q}$ control - unregulated generator torque - variable Qs reference, constant $P$ s reference $(P s=-0.7$ p.u. $)$ - variables: stator voltage $\mathrm{Va}$ and current la vs time $(\mathrm{Q}=0$ p.u.; $\mathrm{Q}=0.6$ p.u.; $\mathrm{Q}=-0.3$ p.u. $)$

Figure 6.18 shows results for a varying input generator torque and constant reference real and reactive power. It is seen that both real and reactive powers are maintained to their reference values. The speed changes to compensate for a change of generator torque.
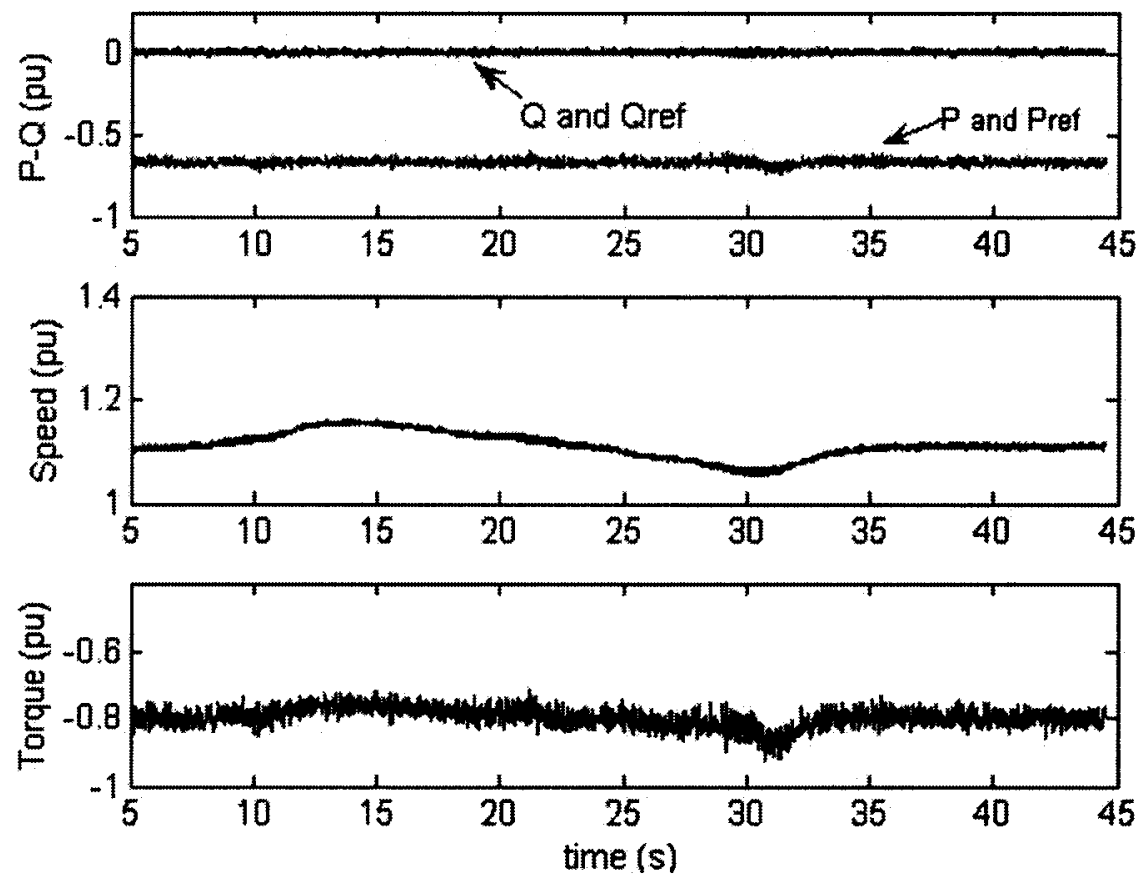

Figure 6.18: Complete DFIG system performance, $\mathrm{P}-\mathrm{Q}$ control - variable generator torque- constant Qs and $\mathrm{Ps}$ reference $(\mathrm{Q} s=0$ p.u., $\mathrm{Ps}=-0.7$ p.u. $)$ - variables: reference and actual $\mathrm{Ps}$ and $\mathrm{Qs}$, speed and torque vs time 
Similar to the previous test, the torque is varied while the reference real and reactive powers remain constant. The speed goes both below and above synchronous speeds as shown in Figure 6.19. From Figure 6.19, we see the rotor currents, as expected, go from negative sequence to positive sequence. In Figure 6.20, we also see that the dc bus voltage remains constant, even with a change of power at the grid converter. Similarly, the grid converter current is in phase with the grid voltage.

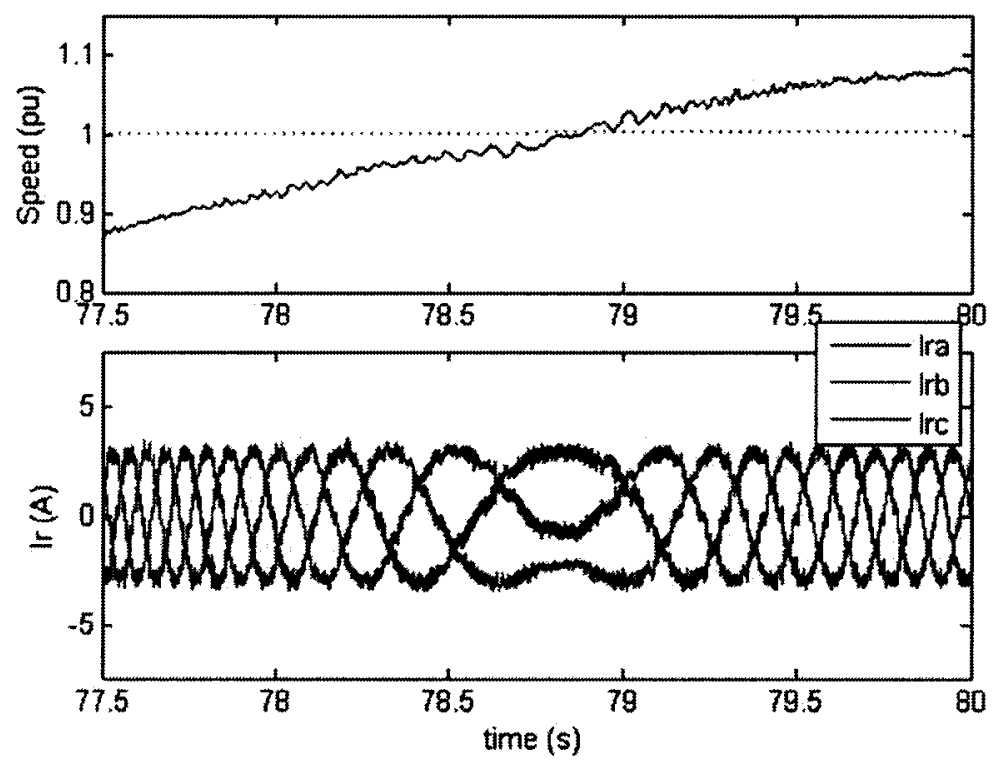

Figure 6.19: Complete DFIG system performance, $\mathrm{P}-\mathrm{Q}$ control - variable generator torque, above and below synchronous speed - constant $Q$ s reference $(Q s=0$ p.u.), constant $P s$ reference $(P s=-0.6$ p.u. $)-$
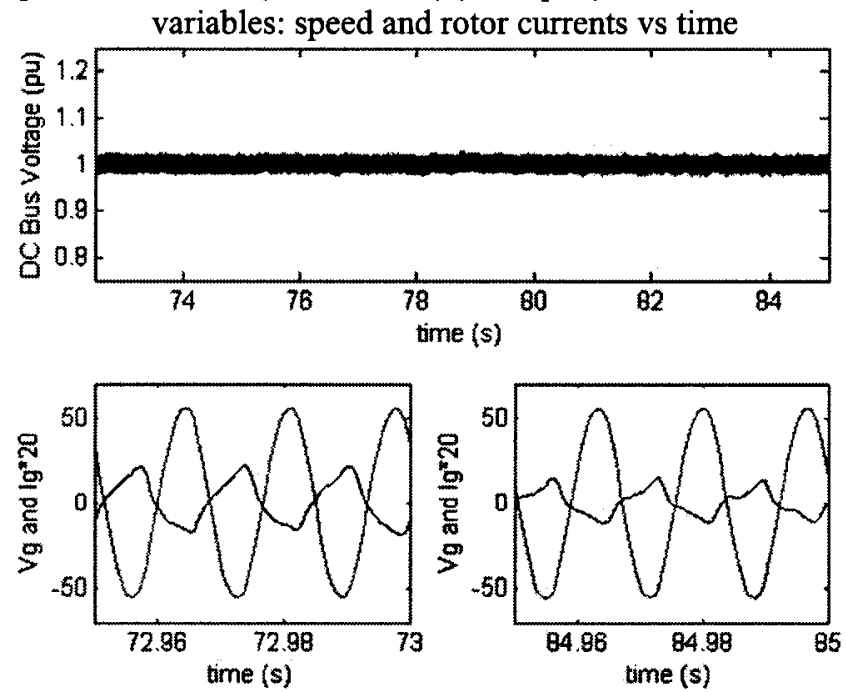

Figure 6.20: Complete DFIG system performance, P-Q control - variable generator torque - constant Qs reference $(\mathrm{Qs}=0$ p.u.), constant Ps reference $(\mathrm{Ps}=-0.7$ p.u. $)$ - variables: dc bus voltage and grid converter voltage $\mathrm{Vg}$ and current Ig vs time 


\section{Chapter 7: Conclusions}

\subsection{Summary}

The ability to vary operating speed is important in wind generation because it allows for an optimization of the transfer of power from the wind to the turbine shaft. As was investigated in this thesis, DFIGs are an interesting solution for variable-speed systems with limited variable speed range, that is $\pm 30 \%$ of the synchronous speed. Power electronic converters only need to handle a fraction of the total real power (around $30 \%$ ). In addition to the cost of the converter becoming lower, there is also less losses compared to a system where the converter has to handle the total power. The back-toback converter consists of a machine-side and grid-side converters. With the machineside converter, it is possible to control the torque or speed of the DFIG and also the power factor at the stator terminals. With the grid-side converter, we are able to maintain the dc voltage and to control the reactive power fed from the grid to the rotor.

There is a significant interest in sensorless drives due to lower cost and increased reliability. The objectives of this thesis are to implement a decoupled P-Q control of a DFIG that does not rely on mechanical sensors and to design a speed and position sensorless algorithm that is robust to variations of the values of the machine parameters. Speed and position sensorless algorithms are implemented using a modified PLL and a dq-axes aligner respectively. The PLL-based algorithm is then compared to the machineequation based algorithm typically found in literature. A sensorless P-Q decoupled 
control DFIG is also implemented. Theoretical and simulation results are validated on an experimental setup.

\subsection{Conclusions}

\subsubsection{Sensorless Measurement of Speed and Position}

The sensorless speed and position algorithms developed in this thesis are based on a modified phased-lock loop with an improved positioning algorithm. With the measured stator voltages, stator and rotor currents, the speed and position of the DFIG are estimated. The speed is estimated independent of machine parameters, which results in a significant improvement in speed control robustness to parameter variations. In addition, the algorithm avoids using differentiation, which significantly improves its immunity to noise and does not require the measurement of the rotor voltages. From both the simulation and experimental results, it is shown that the sensorless speed algorithm is able to track the actual speed both below and above synchronous speeds. However, the drawback of the PLL based algorithm is that it has more difficulty handling fast instantaneous changes in speed. Under transient conditions, that is for step changes of the speed, the DFIG is capable of tracking the actual value with a response time of less than $0.1 \mathrm{~s}$. This however is not an issue as wind variations (input torque) and variation of the power sent to the grid (load) are typically much slower than those typically found in other motor drive application, and thus variations in speed are much slower. Also, it was shown that the positioning algorithm has an improved operation in generator mode. The steadystate error with exact machine parameters is eliminated with the new dq-axes aligner.

Comparison with the machine-equation based sensorless algorithm showed the advantages of the slip PLL speed estimation, which are better immunity to noise and 
robustness to variations of machine parameters. In the case of the estimation of the position, similar results are obtained for both algorithms. Changes of machine parameters, especially the magnetizing inductance $L_{m}$, lead to a significant steady-state error in the position. This issue is addressed in the design of the decoupled P-Q control of the DFIG.

\subsubsection{Sensorless P-Q Control of DFIG}

Since the estimation of the speed is independent of the values of machine parameters in the proposed system, the DFIG is able to track the reference speed without any steady-state error. Other sensorless algorithms found in literature would incur a steady-state error in the speed control due to the sensitivity of the speed algorithm to machine parameters.

The proposed sensorless $\mathrm{P}-\mathrm{Q}$ control does effectively control the $\mathrm{P}$ and $\mathrm{Q}$ components of the power delivered by the DFIG. As shown both in the simulation and experimental results, there is no steady-state errors for the real and reactive powers compared to their reference values and the control of the real and reactive power are independent (decoupled control). The control remains effective for changes in machine parameters.

Under transient conditions, and for step changes of the real and the reactive power references, the DFIG is capable of tracking the references with a response time of less than $1 \mathrm{~s}$. This is fast enough for changes made by the power system operator, and for tracking wind speed variations. Thus, the sensorless measurement of the position is effective in controlling $\mathrm{P}$ and $\mathrm{Q}$. 


\section{References}

[1] M. Abolhassani, P. Niazi, H.A. Toliyat and P. Enjeti, "A sensorless integrated doubly-fed electric alternator/active filter (IDEA) for variable speed wind energy system", Conference Record - IAS Annual Meeting (IEEE Industry Applications Society), v 1, 2003, p 507-514

[2] R. Cardenas, R. Pena, J. Proboste, G. Asher and J. Clare, "MRAS observer for sensorless control of standalone doubly fed induction generators", IEEE Transactions on Energy Conversion, v 20, n 4, December, 2005, p 710-718

[3] R. Cardenas and R. Pena, "Sensorless vector control of induction machines for variable-speed wind energy applications", IEEE Transactions on Energy Conversion, Vol. 19, No. 1, March 2004

[4] R. Datta and V.T. Ranganathan, "A simple position-sensorless algorithm for rotorside field-oriented control of wound-rotor induction machine", IEEE Trans. Ind. Electron., vol.48, no.4, Aug. 2001, p 786-793

[5] B. Hopfensperger, D.J. Atkinson and R.A. Lakin, "Stator-flux-oriented control of a doubly-fed induction machine with and without position encoder", IEEE Proc. Electr. Power Appl., vol. 147, July 2000, p 241-250

[6] H. Huang, Y. Fan, R.C. Qiu and X.D. Jiang, "Quasi-steady-state rotor EMForiented vector control of doubly fed winding induction generators for wind-energy generation", Electric Power Components and Systems, v 34, n 11, Nov 1, 2006, p $1201-1211$

[7] E.H. Kim, S. B. Oh, Y.H. Kim and C.H. Kim, "Power control of a doubly fed induction machine without rotational transducers", Proc. Of 3 rd International Conference on Power Electronics and Motion Control, vol. 2, Beijing, China, Aug. 15-18 2000, p 951-955

[8] O.A. Mohammed, Z. Liu and S. Liu, , "A novel sensorless control strategy of doubly-fed induction machines", 2005 IEEE International Conference on Electric Machines and Drives, 2005, $\mathrm{p} 315-319$

[9] L. Morel, H. Godfroid, A.Miraian, and J.M. Kauffmann, "Doubly-fed induction machine: converter optimization and field oriented control without position sensor", Proc. Inst. Elect. Eng., Pt.B. vol 145, no.4, July 1998, p 360-368

[10] R.C. Qiu, Y.M. Yan and X.D. Jiang, "Research on a quasi-stable state rotor EMForiented doubly fed winding induction machine in wind-energy generation", 
Proceedings of the Chinese Society of Electrical Engineering, v 23, n 11, November, 2003, p 133-138+168

[11] B. Shen and B.T. "Ooi, "Novel sensorless decoupled P-Q control of doubly-fed induction gnerator (DFIG) based on phase locking to g-d frame", Power Electronic Specialists Conference, June 2005, Recife, Brazil

[12] B. Shen, V. Low, B.T. Ooi, "Slip frequency phase lock loop (PPL) for decoupled PQ control of doubly fed induction generator (DFIG)", The 30th Annual Conference of the IEEE Industrial Electronics Society, Nov. 2004

[13] H. Akagi and H. Sato, "Control and performance of a doubly-fed induction machine intended for a flywheel energy storage system", IEEE Transactions on Power Electronics, v 17, n 1, January, 2002, p 109-116

[14] V. Akhmatov, "Variable-speed wind turbines with doubly-fed induction generators; Part I: Modelling in dynamic simulation tools", Wind Engineering Volume 26, no. 2,2002 , pp. 85-108

[15] F. Blaschke, "The principle of field orientation applied to the new TRANSVEKTOR closed-loop control system for rotating-field machines", Siemens Review, vol. 34, no. 1, pp217-223, May 1972

[16] Jian Hu, "Deadbeat controlled PWM converter", Thesis of Department of Electrical Engineering, McGill University, Montreal, 1999, Canada

[17] M. Islam, A. Fartaj and D.Ting, "Current utilization and future prospects of emerging renewable energy applications in Canada", Renewable and Sustainable Energy Reviews, 8 (2004), p 493-519

[18] R.J. Koessler, S. Pillutla, L.H. Trinh and D.L. Dickmander, "Integration of large wind farms into utility grids (Part 1 - Modeling of DFIG)", Power Engineering Society General Meeting, 2003, IEEE, Volume 3, 13-17 July 2003

[19] Y. Lei, A.Mullane, G.Lightbody and R. Yacamini, "Modeling of the wind turbine with a doubly fed induction generator for grid integration studies", IEEE Transactions on Energy Conversion, v 21, n 1, March, 2006, p 257-264

[20] W. Lu, B.T. Ooi, "Multiterminal LVDC system for optimal acquisition of power in wind-farm using induction generators", IEEE Transactions on Power Electronics, Vol. 17, No. 4, July 2002, p 558-563

[21] E. Muljadi and C. Butterfield, "Pitch-controlled variable-speed wind turbine generation," IEEE Trans. Ind. Applicat., vol. 37, Jan./Feb. 2001, p 240-246 
[22] R. Ottersten, "On control of back-to-back converters and sensorless induction machine drives", Department of Electrical Power Engineering, Chalmers University of Technology, Goterborg, Sweden, 2003

[23] R. Pena, R. Cardena, G.M. Asher, J.C. Clare, J. Rodriguez, P. Cortes, "Vector control of a diesel-driven doubly fed induction machine for a stand-alone variable speed energy system “, IECON Proceedings (Industrial Electronics Conference), $\mathrm{v}$ 2,2002, p $985-990$

[24] R. Pena, J.C. Clare and G.M. Asher, "Doubly fed induction generator using backto-back PWM converters and its application to variable-speed wind-energy generation", Proc. Inst. Elect. Eng., Pt.B. vol. 143 no. 3, pp. 231-241, May 1996

[25] A. Petersson, "Analysis, modeling and control of doubly-fed induction generators for wind turbines", Department of Electrical Power Engineering, Chalmers University of Technology, Goterborg, Sweden, 2005

[26] F. Rasmussen and P.H. Madsen, "Current direction of Danish wind energy research -The researchers point of view", Journal of Solar Energy Engineering, Vol. 126 pp. 1105-1109, November 2004

[27] J.G. Slootweg, H. Polinder, W.L. Kling, "Dynamic modeling of a wind turbine with doubly-fed induction generator", Proceedings of the IEEE Power Engineering Society Transmission and Distribution Conference, v 1, n SUMMER, 2001, p 644649

[28] T. Thiringer, L.J. Chalmes, Comparison of reduced-order dynamic models of induction machines, IEEE Transactions on Power Systems, v 16, n 1, February, 2001, p 119-126

[29] R .W. Thresher and D.M. Dodge, Trends in the evolution of wind turbine generator configurations and systems. Wind Energy, S1 (1998), pp. 70-85

[30] P. Tiitinen, P. Pohjalainen and J. Lalu, "The next generation motor control method: Direct torque control (DTC)", EPE Journal, vol. 5, no. 1, pp. 14-18, Mar. 1995

[31] Vestas, OptiSpeedTM, Vestas Converter System, General Edition, Item. no. 947543.R0 - Class 1, 3rd January 2001

[32] Doughert, Kevin. "Toronto firm a partner in \$3-billion wind farm: 1,100 windmills in Quebec" National Post, April 5, 2006

[33] L. Brazeau, "2006 A Record Breaking Year for the Global Wind Energy Industry with Canada now Ranking 12th in the World for Total Installed Wind Energy Capacity", Canadian Wind Energy Association (CanWEA), Press Release 2006, http://www.canwea.ca/news releases.cfm? $\mathrm{ID}=41$ 
[34] D. Darling, "Wind Energy Conversion System", The Encyclopedia of Alternative Energy and Sustainable Living, http://www.daviddarling.info/encyclopedia/W/AE wind energy conversion syste $\underline{\text { m.html }}$

[35] Hydro-Québec, "Wind Power Facilities", www.hydroquebec.com/generation/eolien/index.html

[36] The NFO Control Website, http://www.nfo.se

[37] Wind Energy Manual, Iowa Energy Center, 2006, http://www.energy.iastate.edu/renewable/wind/wem/wem-01_print.html

[38] V. Voldgade, "Guided Tour on Wind Energy", Danish Wind Energy Association, http://www.windpower.org/en/tour.htm

[39] IEEE Std 112-1991, "IEEE standard test procedure for polyphase induction motors and generators", Electrical Machinery committee of the IEEE Power Engineering Society, 10 Mar 1991

[40] IEEE Std 118-1978, "IEEE standard test code for resistance measurement", Power Engineering Society of the Institute of Electrical and Electronics Engineers, 29 May 1978

[41] National Electrical Manufacturers Association, "Motors and Generators", Publication No. MG1-1993, Washington D.C., NEMA, 1993 


\section{Appendix A: Experimental Equipment}

\section{A.1 Digital Controller}

All the model were translated into a Real-Time Interface using OPAL-RT. The OPAL-RT controller takes as inputs the voltage and current values of the DFIG stator and rotor windings and outputs the gating signals of the converter.

The Opal-RT LAB MX Station is a compact, portable and powerful mechatronics and power electronics control prototyping and hardware in the loop (HIL) system based on the new INTEL Core 2 Duo processors, OP5000 XILINX FPGA reconfigurable I/O boards and RT-LAB XSG FPGA development systems. Simulink models can be executed on INTEL and XILINX processors. The MX Station can be equipped with up to 5 FPGA boards and 128 fast IO channels with integrated signal conditioning. It has the following I/O interface :

- 16-ch. A/D modules,16-bit 2-us total sampling time

- 16-ch. D/A modules, 16-bit, lus update time.

The OP5110 I/O interface from Opal-RT Technologies allows the incorporation of FPGA technologies, for high-speed, high-density digital I/O in real-time models, in RT-LAB simulation clusters. Based on an ultra-high-density reconfigurable module using Xilinx Virtex-II Pro Platform FPGAs, the OP5110 allows the inclusion of up to 128 channels of Digital LO, operating at up to $100 \mathrm{MHz}$ cycle frequencies, with a pulse resolution down to $10 \mathrm{~ns}$. 


\section{A.2 Power Electronic Converter}

The power electronics used are the Semikron Miniskiip 8 Three-Phase Inverter. The inverter contains an $800 \mathrm{~V}$ dc Link, $1500 \mu \mathrm{F}$ of dc link capacitance, a three-phase IGBT bridge, all necessary driver circuitry, heat sink and fans. It also contains an integrated temperature sensor, integrated closed loop current sensors, dc Link monitor as well as fault monitoring and latching circuitry.

\section{A.3 Current-Voltage Sensors}

The high-current and high-voltage input conditioning module allows the conversion of 4 current and 4 voltage signals to $\pm 10 \mathrm{~V}$ voltage level. The current inputs are factory configurable for up to $50 \mathrm{~A}$ continuous. The measured voltage range is configurable for up to 600 volts.

\section{A.4 Machines}

The wound-rotor induction machine used is a $0.2 \mathrm{~kW}(0.25 \mathrm{hp})$ machine rated at $1500 \mathrm{rpm}, 208 \mathrm{~V}, 1.3 \mathrm{~A}$ and $60 \mathrm{~Hz}$. The direct current machine used is a $0.2 \mathrm{~kW}(0.25$ $\mathrm{hp)} \mathrm{rated} \mathrm{at} 1800 \mathrm{rpm}$ and $120 \mathrm{~V}$. 


\section{Appendix B: Experimental Setup}

Figures B.1 shows a picture of the experimental setup.

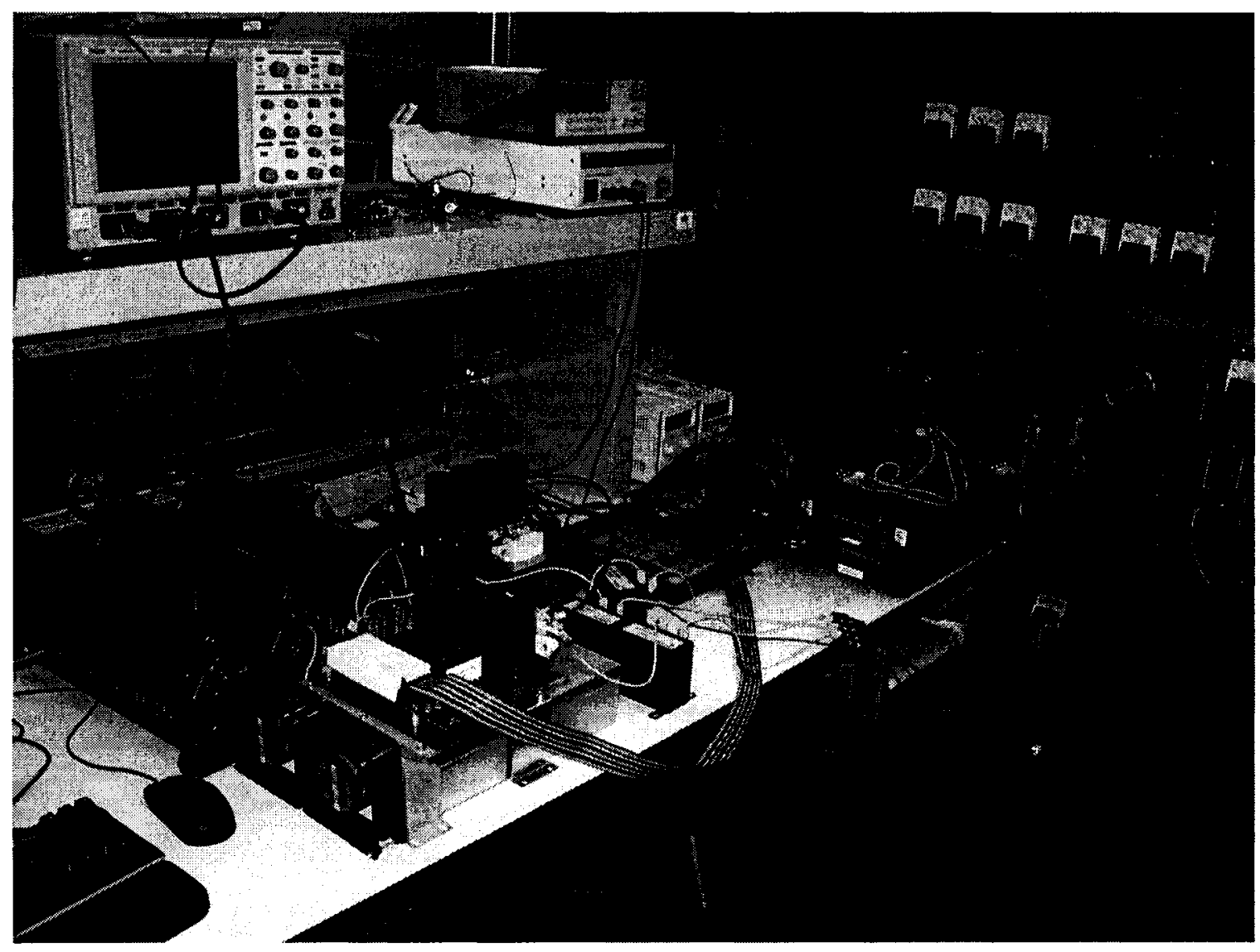

Figure B.1: Experimental Setup 